\title{
PATIENT SAFETY OF OLDER ADULTS WITH COGNITIVE IMPAIRMENT: EVALUATION OF A SERVICE IMPROVEMENT INITIATIVE
}

By

Radhika Patel

\author{
A thesis submitted to \\ Victoria University of Wellington in partial fulfilment \\ of the requirements for the degree of \\ Master of Nursing Science
}

Victoria University of Wellington

2020 


\section{Abstract}

\section{Background}

The safety of older adults with cognitive impairment is linked to falls and to aggressive incidents, therefore patient safety is an important aspect of care for this group of older adults. Environmental changes to create a more 'dementia-friendly' setting can create a safer space for patient care. The Kings Fund Healing the Healthy Environmental tool was used to make small changes to a ward environment. The changes included; large face clocks, identification of bed spaces, lavender oil diffusor, and viewing gardens, to improve patient safety.

\section{$\underline{\text { Research Objectives }}$}

-To assess the impact of environmental changes on patient reportable events (falls and aggression) in older persons' wards, through a comparative analysis of incidents in the wards - one (Ward A) with environmental changes and the other (Ward B) with usual environment. -To obtain staff perspectives of the changes implemented in the service initiative.

\section{$\underline{\text { Method }}$}

A practice-based impact evaluation using mixed methods was undertaken to evaluate the service initiative. The methods included an analysis of data from an established database that captured reported falls and aggressive behaviour (quantitative data), and a survey of healthcare staff about the effectiveness of environmental changes (qualitative data).

\section{$\underline{\text { Results }}$}

The results show that the environmental changes implemented through the service initiative reduced the number of reported falls and aggressive incidents in Ward A in the high visible room. Following the environmental change, the rate of falls per 100 nights in Ward A high visible room was 2.43 compared with a rate of 3.23 times in Ward B. The number of aggressive incidents was 10 in Ward A and 9 in Ward B. The survey findings indicated staff valued the environmental changes particularly the large face clocks.

\section{Conclusion}

While the quantitative data results are not statistically significant the results indicate that the environmental changes implemented (large face clocks, identification of bed spaces, lavender oil diffusor, and viewing gardens) led to a lower number of reportable events for falls in 
Ward A. Any reduction in the numbers of falls and aggressive behaviour is clinically significant given the impact of such events on patient health and length of stay. The dementia-friendly environmental changes implemented were shown to be an effective service initiative.

\section{$\underline{\text { Clinical and research implications }}$}

Wards that cater for older people with cognitive impairment should consider implementing low-cost environmental changes such as introducing large face clocks, clear identification of bed spaces, lavender oil diffusors, and viewing gardens. Further research using a larger patient population (a longer time frame or several wards) is required to obtain an adequately powered study.

$\underline{\text { Keywords }}$

Ward environment, dementia-friendly, falls, aggression, patient safety, evaluation. 


\section{Acknowledgements}

This research is a culmination of work completed over 24 months. This study is my work. I have been supervised and supported during this period by numerous brilliant individuals.

I would like to acknowledge my supervisors, Kim Van Wissen and Kathy Nelson, who have been a huge source of expertise and support throughout the planning and writing of this research. Thanks also to Lisa Woods for her time in helping to develop the initial study methodology and for assistance with analysing the quantitative data through $\mathrm{R}$ studio. Also, the numerous meetings, and conversations I had with Rosemary Patterson about searching for literature and Endnote were invaluable. I have always felt like the team at Victoria University Student Learning Centre was there to support me and their mentorship has been invaluable. I cannot thank you enough.

I would also like to acknowledge Richard Paul and Colin Milligan who in their respective roles in the District Health Board where this research was conducted assisted me in obtaining the initial collection of data. In addition, I would like to acknowledge the support of healthcare staff in the Health of the Older Person (HOP) wards who have supported me through my thesis journey and taken an interest in the thesis process despite the high acuity in the wards. I hope I have respected their contribution both in the time and support they have given me throughout this study.

Many people inspired and supported me during the writing of this research - I would like to extend my thanks to all of you. Special mention must go to my friend and colleague, Mikaela Shannon. Thank you also to Lisa MacDonald, my Charge Nurse Manager (CNM) who has supported me through flexibility with the challenging nursing roster to allow for study days. I value the support and advice you have given me, to make my journey an easier one, and your lessons about the importance of leading with kindness to myself and others.

I would like to thank CCDHB for supporting me through their contribution of university course fees and reimbursement of environmental changes implemented in the ward. Without this type of support, conducting Masters-level studies would be beyond my reach.

I would like to acknowledge the contribution of my family (Bhaskar, Bharati, Jiten, Asha, Darshan, Shivam) who has allowed me to study, be supported, and stay grounded, in particular the matriarch of my family, my grandmother (Ma). 


\section{Table of contents}

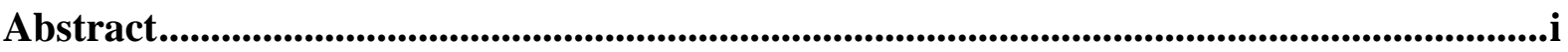

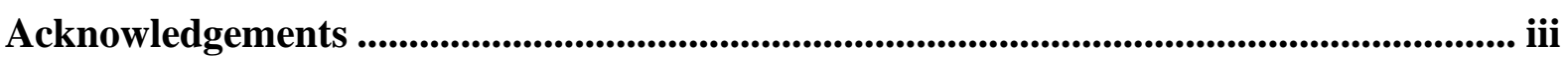

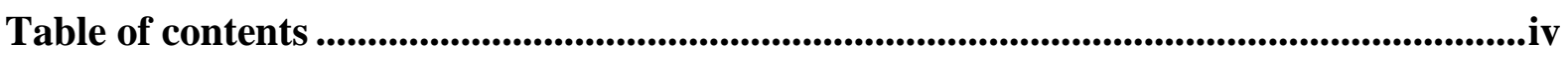

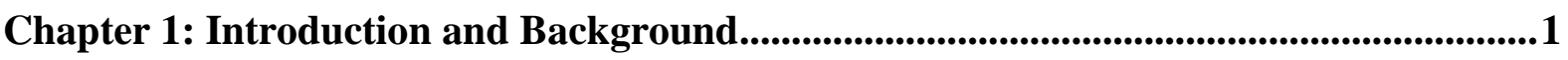

1.1 Introduction...............................................................................................................1

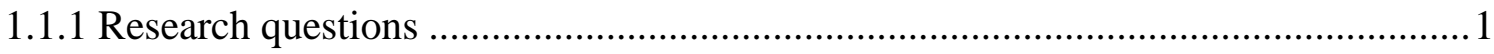

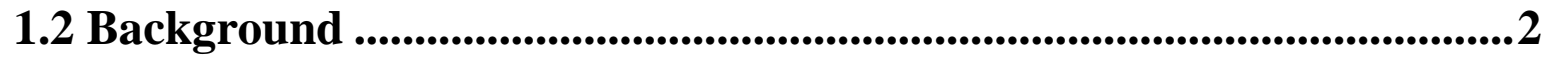

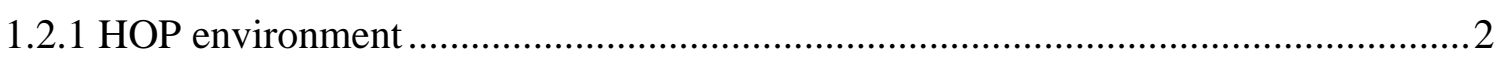

1.2.2 Nurse researcher introduction..................................................................... 3

1.2.3 The current practices used for HOP patients challenging behaviour ........................4

1.3 Definitions of concepts pertinent to this research.....................................5

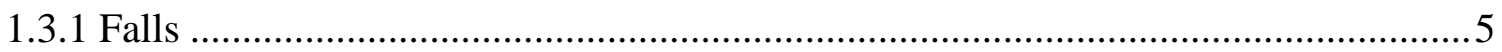

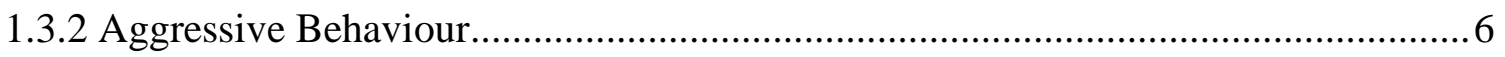

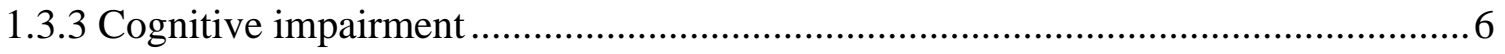

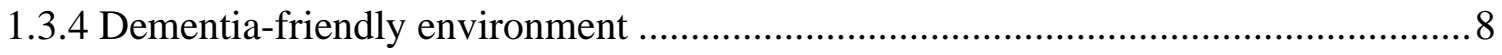

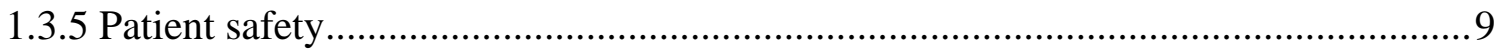

1.3.6 The Enhancing the Healing Environment tool ..................................................... 10

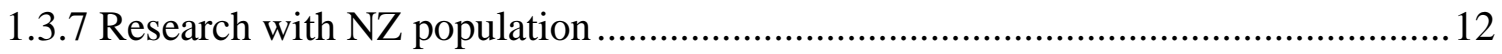

1.4 Thesis overview ........................................................................................12

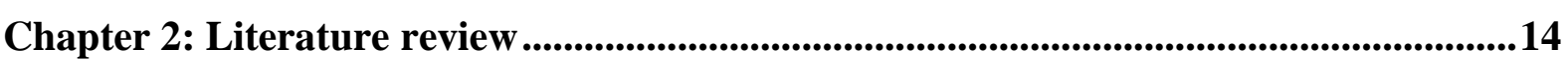

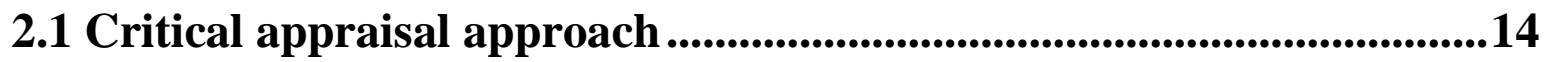

2.2 Environmental interventions implemented.........................................15

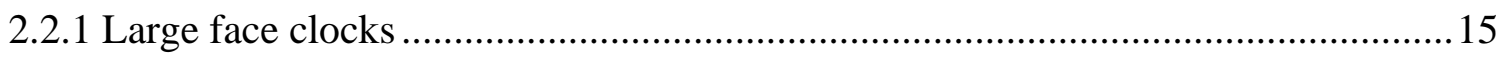

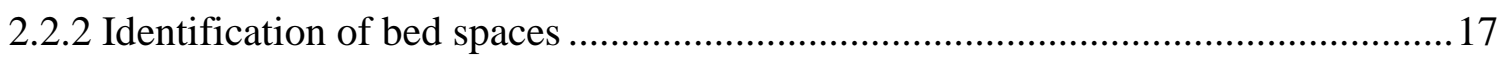

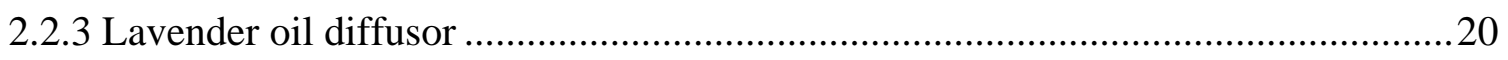

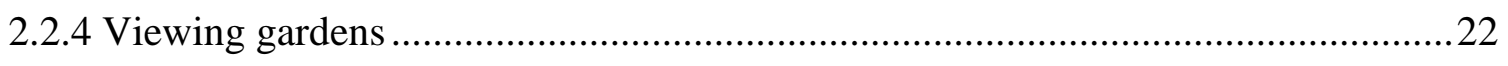

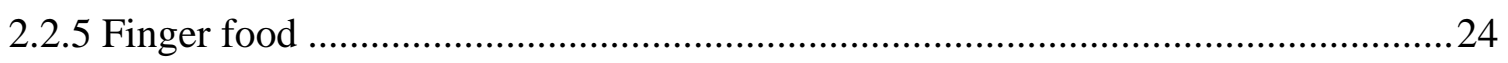

2.3 Research gaps in the literature

2.4 Summary.........................................................................................................................22

Chapter 3: Methodology and Methods ...........................................................................28

3.1 Methodology ...........................................................................................................28

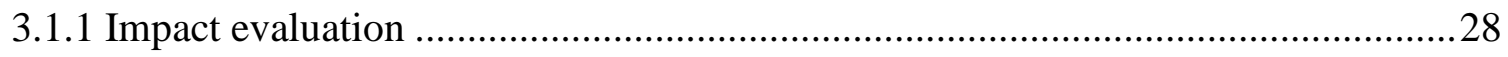


3.1.2 Mixed Methods Research

3.1.3 Mixed methods research in impact evaluation ................................................... 32

3.2 Methods...........................................................................................33

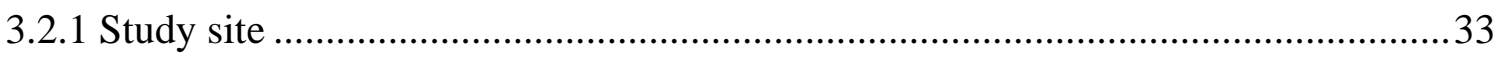

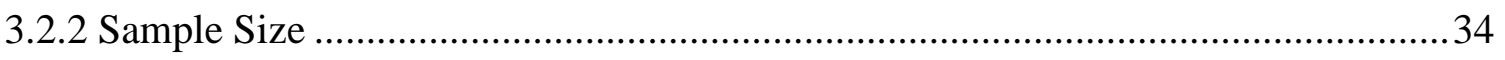

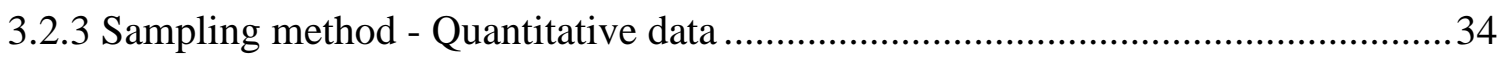

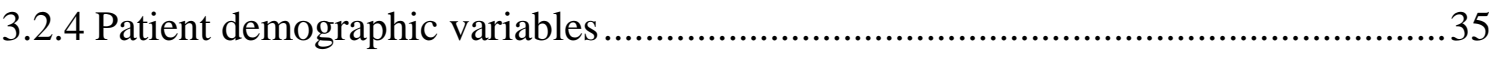

3.3 Data Analysis ......................................................................36

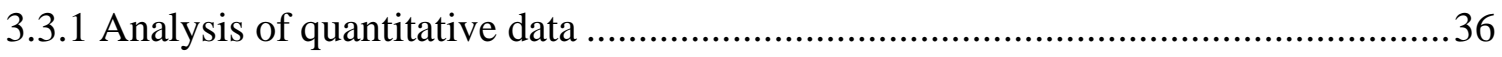

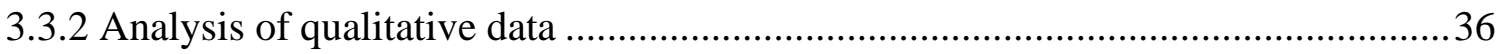

3.4 Issues with the data collection ..............................................................38

3.5 Ethical approval ..................................................................................40

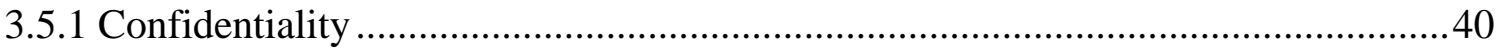

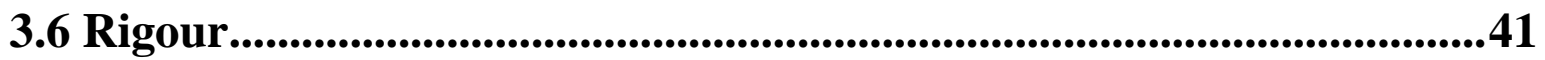

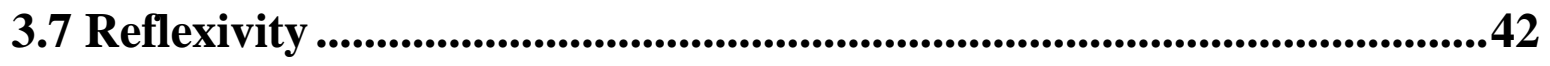

Chapter 4: Findings ...........................................................................................................................43

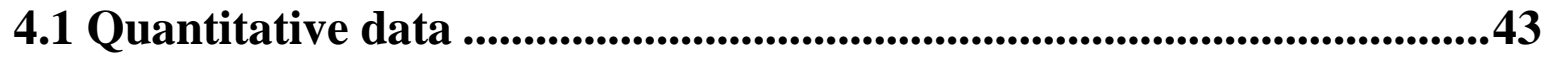

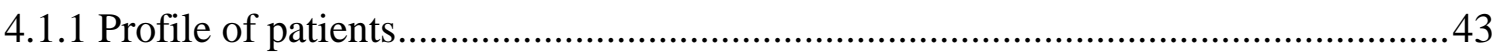

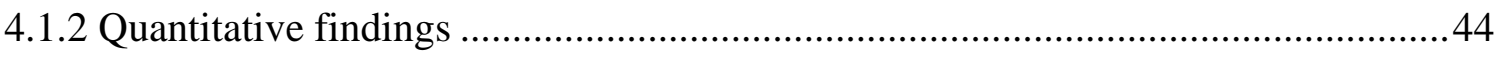

4.2 Qualitative findings...........................................................................49

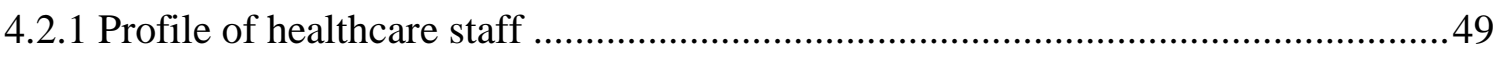

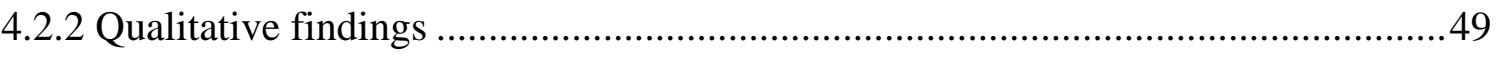

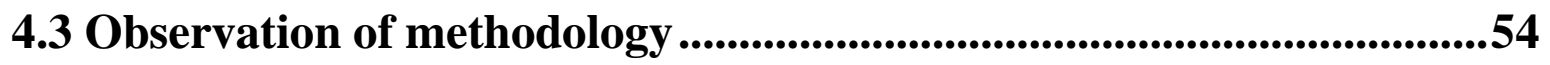

4.4 Summary

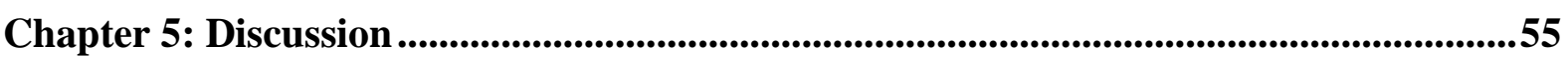

5.1 Further Interpretation .......................................................................55

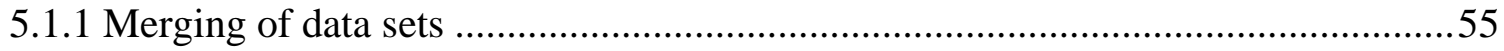

5.1.2 Lack of data to support aggressive behaviour .....................................................56

5.1.3 Effect of environment for older adults with cognitive impairment .........................56

5.1.4 The impact of cognitive impairment for falls ........................................................57

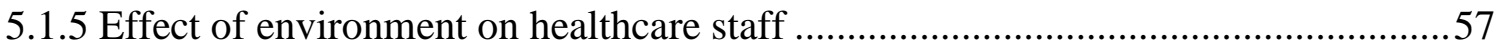

5.1.6 The specific environmental changes implemented.............................................58

5.1.7 Dementia-friendly environment for older adults' safety .......................................59 
5.2 Implications for hospital settings .............................................................60

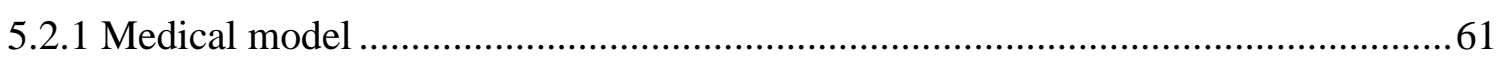

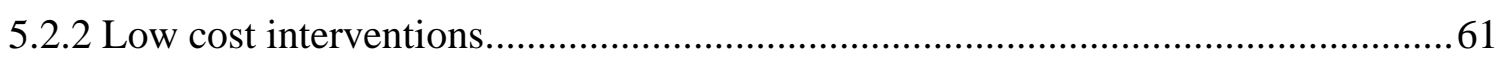

5.2.3 Reflection post completion of the thesis............................................................62

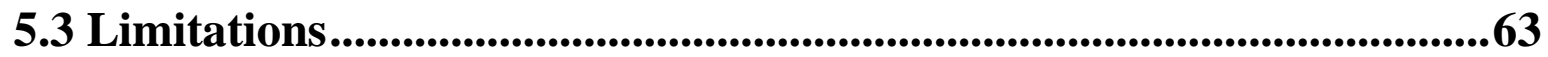

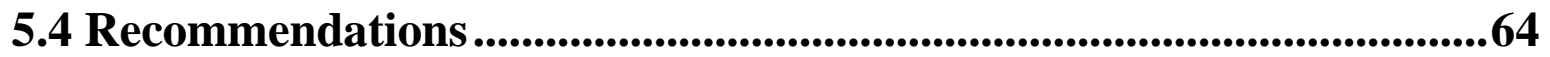

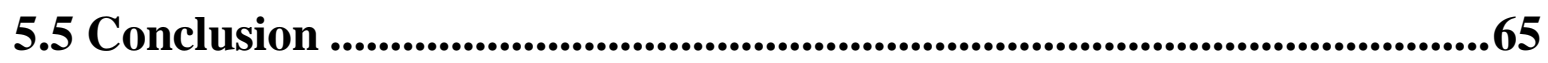

References.....................................................................................................................67

Appendices...................................................................................................................76

Appendix A .....................................................................................................................76

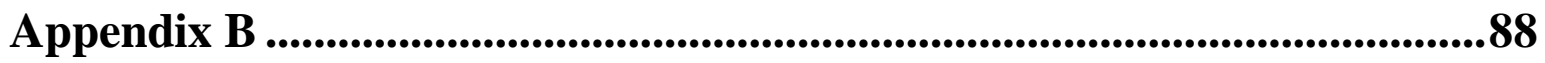




\section{Chapter 1: Introduction and Background}

\subsection{Introduction}

Patient safety is a challenge faced by all hospitals around the world when managing the care of older adults. The challenge is further complicated when vulnerable older adults have cognitive impairment. New Zealand (NZ) is in line with global trends which shows that ageing creates an increased risk of developing cognitive impairment (Alzhemiers New Zealand, 2017). The need to create a hospital environment that is safe for older adult patients with cognitive impairment is important, as these patients are vulnerable and more susceptible to negative outcomes in hospital such as falls and incidents of aggression. The consequence of these negative outcomes is that these vulnerable patients are required to have constant observers and/or be placed into highly visible areas in hospital wards. Yet, there is a lack of clear evidence about the effectiveness of these costly interventions. Therefore, the introduction of different approaches such as environmental changes to create a more dementia-friendly ward is necessary. The focus of this evaluation is to report on a study that investigated the impact of environmental changes in a hospital ward for older adults with cognitive impairment.

An introduction to the research and background is detailed in this chapter. This introduction includes research questions for this evaluation. The background includes literature regarding the clinical environment, introduces the nurse researcher and outlines the practices currently used to manage challenging behaviour of older adults with cognitive impairment. In addition, the chapter includes the definitions pertinent to the evaluation and provides an overview of the thesis.

\subsubsection{Research questions}

This research was designed to evaluate the impact of a service initiative involving environmental changes in a Health of the Older Person (HOP) service. It addressed two research questions:

1) What are the outcomes (incidents of falls and aggression) from the service initiative for older adult patient safety in the context of cognitive impairment?

2) What are the staff's perspectives of the service initiative implemented? 


\subsection{Background}

\subsubsection{HOP environment}

The HOP service primarily consists of two identical busy, dynamic wards that have similar patient flow. Figure 1 is photos of the Ward A high visible room before environmental changes subject to this evaluation were implemented. The wards are in a tertiary hospital in NZ consisting of four inpatient wards (A, B, C, D) and share medical and allied health teams. A Charge Nurse Manager (CNM) oversees the four wards, and each ward has its own Associate Charge Nurse Manager (ACNM) and nursing team. The nursing teams consist of registered nurses, enrolled nurses, and healthcare assistants. A nurse educator, clinical nurse specialist and discharge coordinator are also shared across the service.

The changes decided for the service initiative in Ward A were based on the results of a ward assessment using the Enhancing the Healing Environmental Assessment tool used by nurses in the United Kingdom (UK) (Appendix A). This King's Fund Enhancing the Healing Environment Assessment tool was designed to identify ways to create a more dementiafriendly environment while also ensuring patient safety (Waller, Masterson, \& Evans, 2017). This current evaluation was undertaken as it is important to obtain evidence of the impact of initiatives to decide whether other wards should implement similar changes. 


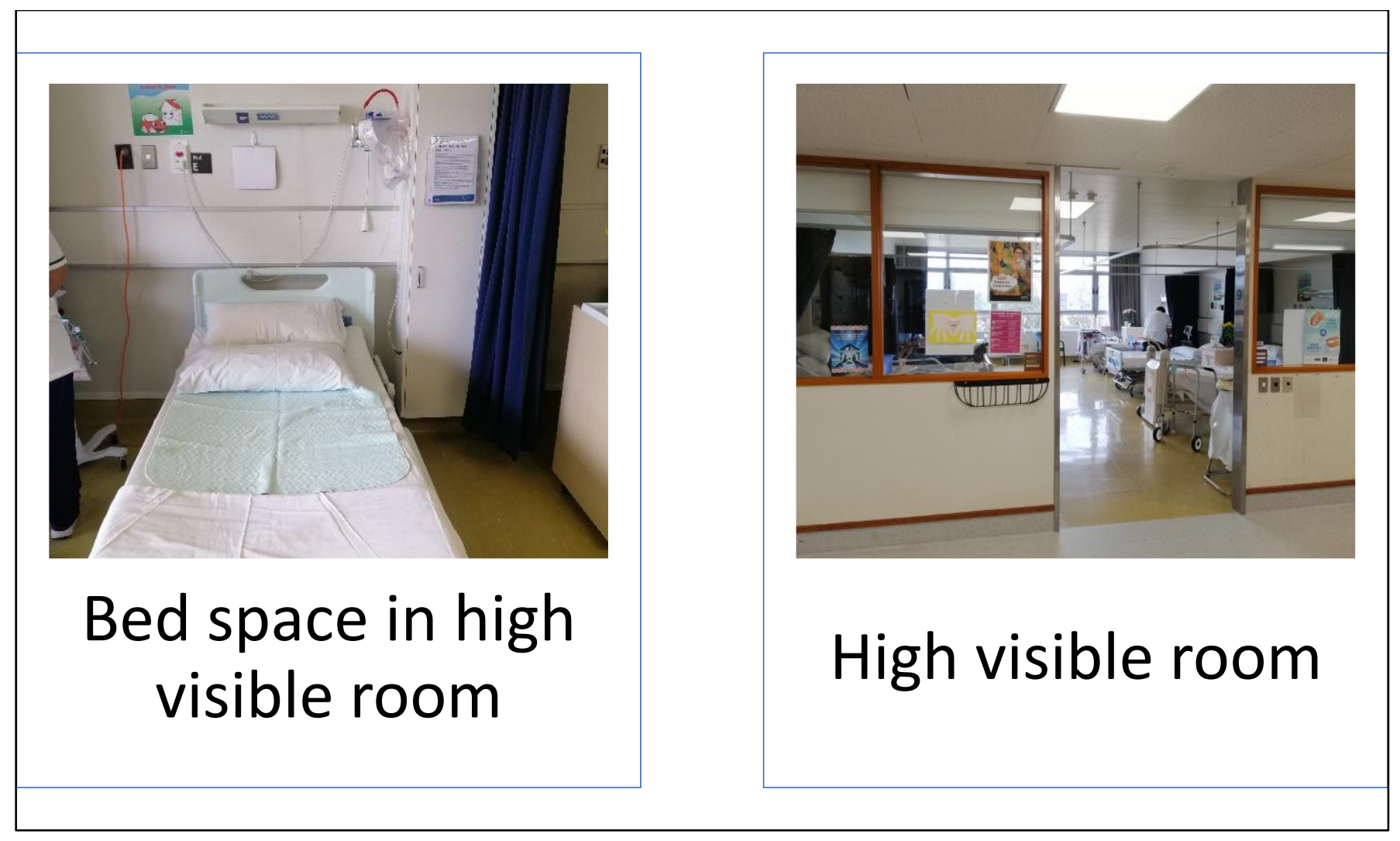

Figure 1: Photos showing Ward A high visible room before environmental changes were implemented

\subsubsection{Nurse researcher introduction}

I have an interest in working with older adult patients with cognitive impairment as I was involved in the care of my grandmother. My grandmother was a stroke patient who had several falls which resulted in her being admitted to the HOP service several times during my nursing studies and at the start of my nursing career. I observed care given to her by healthcare staff and it made me think of alternatives ways my grandmother's care could have been more safely managed in the hospital and home environment to prevent falls. I now work in the HOP service.

The need for the service initiative was conceived through observation of the environment in my role as an ACNM in Ward A. The ACNM role oversees the ward to ensure patient and staff safety. This involves identifying ways to reduce patient risks such as falls and aggression, while also taking into consideration the availability of resources. The HOP service is restricted to patients over the age of 65 years. Cognitive impairment is a common admission diagnosis for older adult patients. Patients admitted to HOP are placed in the high 
visible room if they have cognitive impairment and are at high risk of falls and/or aggression. The high visible room is close to the nurses' station and highly visible to the healthcare staff working in the ward. The management plan over the winter period includes planning for increased bed numbers by having HOP patients admitted into Ward C and Ward D.

Incidents of falls and aggression are distressing for the patient, staff, and the patient's family/whānau. Staff are required to complete incident reports (reportable events) when any fall happens. My role as ACNM includes reviewing these reportable events to determine what occurred and how reoccurrence can be prevented by liaising with other staff in the DHB, the patient, and their family/whānau. Therefore, any intervention that may reduce falls and aggressive incidents in the ward are beneficial to HOP patients, healthcare staff and patient's family/whānau.

\subsubsection{The current practices used for HOP patients challenging behaviour}

Older adults in the HOP service with cognitive impairment often display challenging behaviour while in hospital, which increases their risk of falls and/or aggression (Soto, 2012). Challenging behaviour is generally managed by staff through requesting a constant observer which has a high cost to the DHB but is required for patient safety. Alternatively, challenging behaviour is managed by the medical team prescribing antipsychotic medication. There are conflicting reports on the merits and disadvantages of the use of constant observers and antipsychotic medications in these instances as explained next.

Constant observation provides enhanced safety for patients with cognitive impairment when they are at risk of harm to themselves and/or others. The care of patients with cognitive impairment should involve therapeutic engagement to reduce the risk of harm. The use of family/whānau or volunteers to provide continuous observation for older adult patients with cognitive impairment has been shown to prevent falls (Carr, 2013; Tzeng \& Yin, 2007). Research by Ayton et al. (2017) and Feil and Wallace (2014) show older patients with cognitive impairment benefit from constant observers in regards to preventing falls. However, other research shows constant observers have no correlation with a decrease in rates of falls (Boswell, Ramsey, Smith, \& Wagers, 2001; Harding, 2010; Spiva et al., 2012). These research studies found the rates of falls increased or were inconclusive when constant observers were present. Further studies of research show there are different definitions of constant observers and different levels of engagement and this may be a reason constant observation was seen as ineffective in preventing falls (Dewing, 2013; Lang, 2014). 
Antipsychotic drugs are commonly overprescribed in the hospital setting for the management of aggression in older adults with cognitive impairment (Breining et al., 2017). Aggressive behaviour is challenging and disruptive to the ward environment as it exposes the patient, staff, other inpatients, and their family/whanau to violence. The contraindications of using antipsychotics for older adults are numerous and include increased mortality and risk of stroke, fall, pneumonia, walking difficulty, metabolic syndrome, daytime fatigue, tardive dyskinesia, and worsening cognitive function (Breining et al., 2017; Markota, Rummans, Bostwick, \& Lapid, 2016; Salzman et al., 2008; Vigen et al., 2011). Older adults with cognitive impairment receiving community-based care, and those newly exposed to antipsychotics, including healthy patients, were at significantly increased risk of death at one, three, and six months post-index (Maxwell et al., 2018). The risks of antipsychotic medications for older adults are currently not well understood, especially when used for this vulnerable patient group.

The management of older adults with cognitive impairment using constant observation and antipsychotic medications have been unsuccessful at times in terms of patient safety. Both interventions have advantages and disadvantages when used in the hospital setting.

Disadvantageous factors for these interventions are the lack of available resources and the high acuity of patients in the hospital setting. Given these disadvantages, environmental changes are a potential alternative to managing the care of older adults with cognitive impairment.

\subsection{Definitions of concepts pertinent to this research}

The definitions pertinent to this research are falls, aggressive behaviour and cognitive impairment. The concepts of dementia-friendly environment and patient safety are also important.

\subsubsection{Falls}

The falls definition used by the local DHB and the World Health Organisation (2018) states; a fall is an event resulting in a person coming to rest inadvertently on the ground or other lower level and includes assisted falls. This falls definition includes slips, trips, and near misses.

The older adult patients in the HOP service are at higher risk of severe injury or death due to a fall. According to the Accident Compensation Corporation (ACC), falling over is the most common injury in NZ and injuries from falls represent 39\% of all ACC claims and costed 
$\$ 1.1$ billion in 2018 (Analytics \& Reporting, 2018). The most popular place to fall is the home with 388,310 people getting injured by falling over at home and women are slightly more likely to be injured by falling than men (Analytics \& Reporting, 2018). Older adults have more severe falls and therefore worse injuries on average compared to younger adults (Analytics \& Reporting, 2018). Every year, one in three people over 65 injures themselves in a fall and this rises to one in two once people reach 80 (Analytics \& Reporting, 2018). In 2018, in the 65-plus age group, 93,954 older people had injuries from falling which came at a cost of $\$ 267,275,845$ (Analytics \& Reporting, 2018).

Falls occur due to several possible factors including physical, sensory, and cognitive changes associated with ageing. This occurs in combination with environments that are not adapted for an ageing population (World Health Organisation, 2018).

\subsubsection{Aggressive Behaviour}

Aggression may include verbal, physical or psychological abuse, threats, sexual harassment or assault, attacks, hold up and abduction (Health and Safety in Employment Act, 1992). These types of behaviour are used by the DHB to describe aggression, violence, or security emergencies. In a study undertaken in the United States of America (USA), aggression represented $60 \%$ of behavioural and psychological symptoms of cognitive impairment in hospitalised patients (Soto, 2012). Responses to a survey of healthcare staff showed verbal aggression was experienced by $93 \%$ of healthcare staff working throughout hospitals including older adult services in the previous year and physical aggression was experienced by $65 \%$ of respondents in NZ (Swain, Gale, \& Greenwood, 2014). Also, when the research was analysed by health worker role it was found that nurses and nursing support staff experienced the greatest number of aggressive incidents compared to doctors and allied health staff (Swain et al., 2014).

\subsubsection{Cognitive impairment}

Cognitive impairment refers to neuropsychiatric conditions including dementia, Alzheimer's, and delirium. These conditions are commonly unrecognised or mistaken for each other due to their fluctuating nature, a lack of formal cognitive assessment on admission, and diverse presentations (Vidal, Villas Boas, Valle, Cerqueira, \& Fukushima, 2013). The characteristics of cognitive impairment include disturbances in cognition, attention, consciousness, and/or perception; these occur due to several precipitating and predisposing factors (Vidal et al., 2013). Cognitive impairment is also associated with high levels of disability and dependence. 
It can be overwhelming not only for the people who experience it but also for their family/whānau.

The incidence of cognitive impairment in the USA ranges from one to six percent per year in the older adult population (Geda, 2012). An early NZ study suggested that for patients over 65 years the prevalence of dementia was $7.7 \%$ and for patients over 85 years the prevalence of dementia was 30\% (A. Campbell, Diep, Reinken, and McCosh (1985). In 2016, Alzheimer's NZ estimated $1.3 \%$ of the NZ population had dementia which is an increase of approximately $29 \%$ over the previous estimate (Alzhemier's New Zealand, 2017). It is projected that by 2050, 2.9\% of the NZ population will have dementia (Alzhemier's New Zealand, 2017). However, prevalence rates for cognitive impairment in NZ are not yet determined.

Most people with dementia are NZ European. In 2011 statistics showed that only 4\% (n = 1,970) of the estimated 48,182 New Zealanders with dementia were Māori (Alzhemiers New Zealand, 2017). It is predicted that by 2026 the number of Māori with dementia would have increased to 4,493 (5\% of the estimated 78,267 people with dementia) (Alzhemier's New Zealand, 2017). Number and rates in 2011 for Asian people with dementia were 1,838 (3.7\%) and for Pacific peoples 930 (1.9\%) (Alzhemier's New Zealand, 2017). By 2026, the proportion of European/other people with dementia is expected to drop and the proportion of all other ethnicities is expected to increase. Of the estimated 78,267 people with dementia in NZ, 6,568 (8.4\%) are expected to be Asian and 2,051 (2.6\%) are expected to be Pacific peoples (Alzhemier's New Zealand, 2017). The cost of care for older adults with dementia is estimated to have significantly increased from \$955 million in 2011 to \$1,676 million in 2016 and it is estimated that it could be more than $\$ 2.7$ billion by 2030 (Alzhemier's New Zealand, 2017).

With the increasing number of older patients with cognitive impairment, it is important to recognise this condition is not specific to older adults. Dementia affects a variety of people, including younger people, people with Down syndrome and people with alcohol and/or drug addictions (Ministry of Health, 2013). Therefore, appropriate information, education, sector knowledge and services need to be developed with these groups in mind.

The diagnosis of cognitive impairment increases stress on the patient and their family/ whānau because they may not have had access to the education and support services that can help them minimise or avoid symptoms of dementia. This can create challenges such as 
depression, anxiety, behavioural and psychological symptoms and carer stress which means it becomes challenging keeping the patient safe (Ministry of Health, 2013).

Patients are routinely assessed by health professionals on admission to the HOP service using the 4AT assessment tool, which is a validated screening instrument designed for rapid initial assessment of delirium and cognitive impairment. The 4AT tool was developed in the UK in 2011 and is supported by validation studies (Gagné et al., 2018; O’Sullivan et al., 2018). A score of three or higher indicates possible delirium and/or cognitive impairment although $4 \mathrm{AT}$ is not used as a diagnostic tool. A more detailed assessment of mental status using tools such as the Montreal cognitive assessment is required to reach the diagnosis of delirium or cognitive impairment (Yang et al., 2018). The Montreal Cognitive Assessment (MoCA) tool was commonly used in the clinical setting in NZ. Recently this has been replaced by the Mini-Addenbrooke's Cognitive Examination (Mini-ACE or M-ACE) as the recommended cognitive screening test in NZ.

Cognitive impairment impairs obstacle negotiation and can increase the risk of falling by impairing judgement, gait, perception, and hazard recognition (Peek et al., 2018; PierucciniFaria, Sarquis-Adamson, \& Montero-Odasso, 2019). Also agitation and wandering are risk factors for falls for older adults with cognitive impairment (Sato et al., 2018). Older adults have the added complication of complex medical conditions which only exacerbates the risk of falling (Peek et al., 2018). The result is older adults with cognitive impairment have twice as many falls as older adults without cognitive impairment and are commonly admitted to hospital with injuries from these falls (Harvey, Mitchell, Brodaty, Draper, \& Close, 2016). Hospitals have a responsibility to reduce the risk of falls and of aggressive behaviour.

\subsubsection{Dementia-friendly environment}

The principles of person-centred care take into consideration the individuals needs and preferences and is especially essential when caring for patients with a cognitive impairment. This includes several qualities including reassurance, effective communication, and reorientation (Young, Murthy, Westby, Akunne, \& O'Mahony, 2010). Person-centred care aims to maximise comfort and quality of life for patients with cognitive impairment which is beneficial for their family/whānau and healthcare professionals involved in their care as well (Thompson, 2015). It can be achieved by recognising the person, collaborating with them, validating their reality, and facilitating goals with them and their family (Raymond et al., 2014). 
The older adult requires person-centred care in the hospital especially when they have a cognitive impairment. Unfortunately, person-centred care is not always prioritised in the hospital due to multiple barriers (Edvardsson \& Nay, 2009). The obstacles include the busy nature of the acute setting, inadequate staffing levels and lack of staff education (Edvardsson \& Nay, 2009). Other obstacles from a clinical perspective, are the complexity of constantly changing patients and staff as well as external events. This was evident during data collection as the patients and staff involved were affected by three factors. The first factor was a junior doctors' strike which meant the DHBs services were limited, resulting in fewer admissions and less medical staff being available to provide care to patients. The second factor was the winter period, which meant more patients were admitted to the HOP Service and in response, more healthcare staff were employed to care for them. The third factor was that the healthcare staff have various educational backgrounds in their respective roles in the HOP service which meant they provided care for patients, but this care was delivered slightly differently from each other.

The ward environment can be improved by assessing if it is dementia-friendly. An environmental assessment tool for wards has been developed by the King's Fund (2014) based on research evidence, best practice, and survey responses from those who have used the tool in practice and is discussed in the next section.

\subsubsection{Patient safety}

Patient safety is recognised by the World Health Organisation as pivotal to healthcare. The World Health Organisation has World Patient Safety Day which calls for global solidarity and concerted action by all countries and international partners (World Health Organisation, 2020). The essence of patient safety is no one should be harmed in healthcare. Yet thousands of patients across the world suffer avoidable harm or are put at risk of injury while receiving healthcare every single day (World Health Organisation, 2020).

Falls accounted for two-thirds of all ACC claims in the 85+ age group in 2018 (Analytics \& Reporting, 2018). A serious fall, resulting in a fracture can cost up to $\$ 120,000$ to repair and for the person to be rehabilitated (Analytics \& Reporting, 2018). This is a significant cost for the healthcare service and has detrimental effects for the patients which highlight the importance of having alternative measures in place for older adult patient's safety in the hospital setting to prevent falls. 
The reportable event database (3DHB) records events for the DHB including for older adult patients with cognitive impairment. Common events for older patients are falls and aggression. A reportable event requires a healthcare worker to report events that have resulted in harm or loss of property to patients, visitors and employees in hospital (Ministry of Health, 2001). This also includes events that reflect on unsatisfactory situations in terms of the quality of clinical practice and may have caused harm if not intervened (Ministry of Health, 2001). Reportable events are not always preventable. Severity assessment codes are used to calculate the severity of a reportable event. Reportable events are reviewed initially by the ACNM then CNM and then the quality team. These individuals initiate appropriate action and make recommendations to prevent reoccurrence. All DHB staff are orientated to the process of reportable events. Older adults appear to be a group particularly at risk for reportable events. The occurrence of reportable events associated with older adults has been well documented in the literature (Justiniani, 1984; Liu \& Latham, 2010).

\subsubsection{The Enhancing the Healing Environment tool}

The Enhancing the Health Environment tool provides an excellent template to assess the ward environment for patients with dementia and is available on the King's Fund website (Appendix A). It is used in the UK to develop dementia-friendly environments in health facilities. The tool has been found to have a therapeutic impact on health care facilities where implemented and has led to an improvement in patient and healthcare staff satisfaction (Waller et al., 2017). The seven criteria of the tool describe the standard required for a healing environment; capturing meaningful interaction between patients, families, and staff; promoting well-being; encouraging eating and drinking; promoting mobility, continence, and personal hygiene; and orientating toward a calm, safe, and secure environment. The purpose of the evaluation was to focus on what the tool demonstrated in terms of the environment and its impact on patients in the wards.

Health facilities can use the tool to self-assess their environment against the seven areas and obtain their rating scores, which highlight areas for improvement and enable benchmarking against similar areas (Waller et al., 2017). This self-assessment allows facilities to implement changes to their healthcare setting in collaboration with patients and their families to improve the patient experience. The overarching design principles focus on promoting wellbeing and independence and consists of five sections containing a list of design elements that are known to support, encourage and enable people with dementia in care settings. The five sections are orientation, wayfinding, familiarity, meaningful activity, and legibility. All these are drawn 
from several sources and are research-based. These five sections lead to the outcomes: easing decision making; reducing agitation and distress; encouraging independence and social interaction; promoting safety and enabling activities of daily living.

When patients are admitted to hospital, the unfamiliar environment causes disorientation which exacerbates patients' cognitive impairment. This leads to patients becoming confused and exhibiting challenging behaviours. It can be reduced by creating a more dementiafriendly environment through a few minor changes. The Kings Fund Healing the Environment Assessment tool was completed in Ward A and revealed where change could be implemented. The environmental changes that had been implemented into other healthcare facilities and that were found to be feasible to adopt in Ward A were large face clocks, identification of bed spaces, a lavender oil diffusor, viewing gardens, and finger food stored in a snack basket constantly available in the high visible room (Figure 2). The photos of Ward A before environmental changes were implemented shown Figure 1 (page 2).

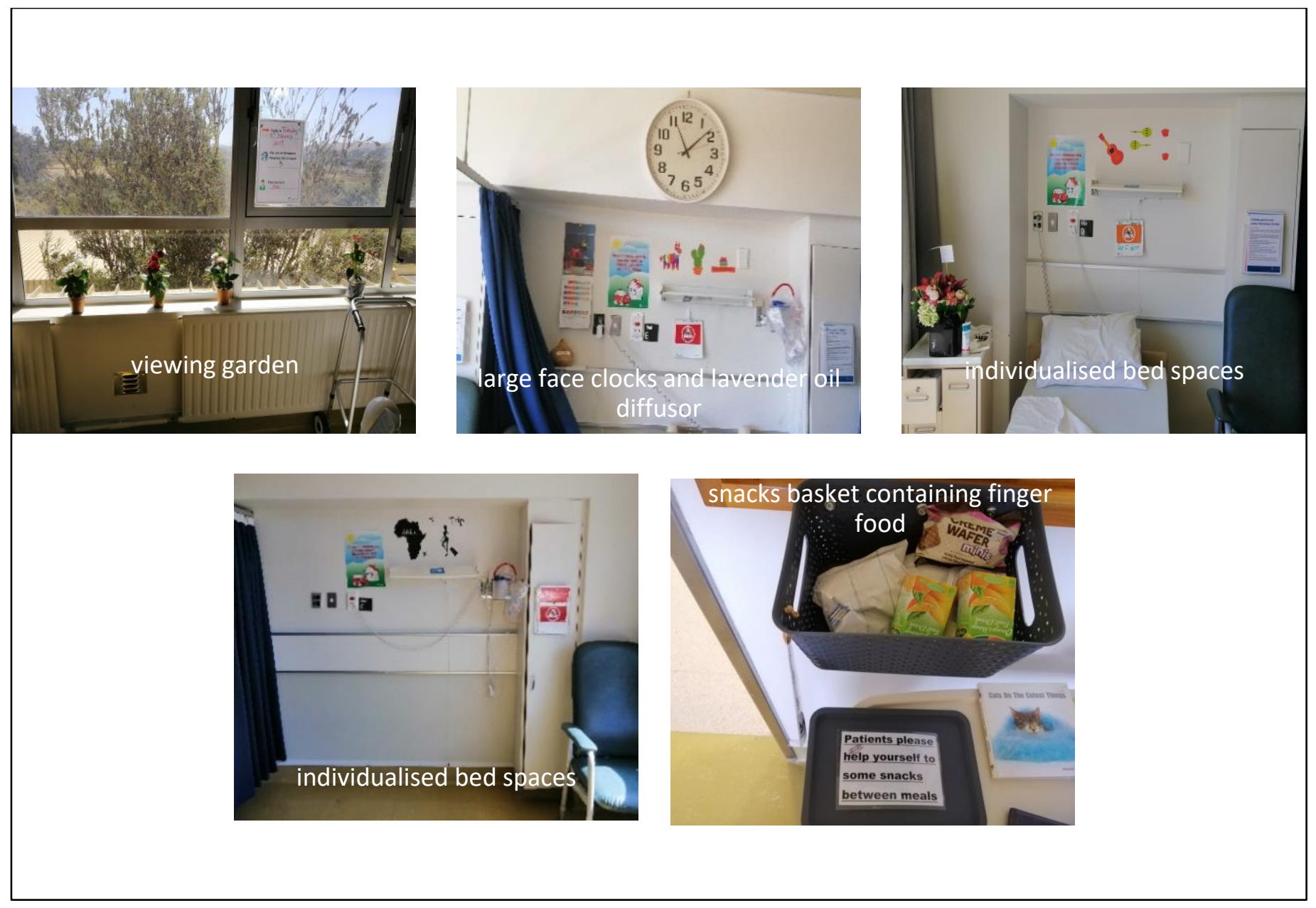

Figure 2: Photos showing the Ward A high visible room after the environmental changes were implemented 
Each of these environmental changes meets one of the sections related to the overarching principles of the Healing the Environment Assessment tool. The decision to use lavender oil rather than other essential oil scents was due to advice from a clinical aromatherapist. The advice was to use Lavandula Angustifolia with low levels of diffusion, discussed further in the literature review chapter. The environment has a significant impact on older adult patients with cognitive impairment. Research has shown that a change in environment, such as hospitalisation, leads to increased functional disability, lower quality of life, and increased frailty (Chodosh et al., 2004; Hanna, Efrat, Hagar, \& Anna, 2015). The negative impacts of hospitalisations are due to barriers such as space limitations (which can limit mobility), healthcare professionals' focus on the physical over holistic needs of patients, difficulty with providing time-consuming care in a stressful acutely changing environment, disruptions in the environment resulting from room changes, and lack of insufficient education of health professionals (Baillie, Merritt, \& Cox, 2012; Cowdell, 2010).

\subsubsection{Research with NZ population}

In NZ, an analysis of levels of government health research funding carried out in 2008 demonstrated that funding in NZ, after adjustment for population size, was less than one-third of that in Australia, less than one-fifth of that in the UK, and about $10 \%$ of that in the USA (Reid, Joyce, Fraser, \& Crampton, 2014). Current understanding of the existing literature on cognitive impairment in NZ is insufficient, therefore this research will provide insights into the older adult experience in the hospital. The research is unique as it adds to the understanding of how the environment can help older adults with cognitive impairments, specifically in NZ. It is vital to obtain this information as the NZ population is unique to the rest of the world. The unique population of NZ consists of multicultural healthcare users and a high number of patients with Māori and Pacific Island descent.

\subsection{Thesis overview}

This chapter has presented a background to the research about cognitive impairment concerning older adults in hospital and how this is managed in the hospital setting. It reviewed how environmental changes can influence the patient experience in the hospital and the concept of a dementia-friendly ward. The King's Fund Enhancing the Healing Environment tool and the changes that have been implemented though the service initiative after this assessment was completed in Ward A.

The literature review in Chapter 2 presents the search strategy and the Critical Appraisal Skills Programme (CASP) tool, which was used for the literature review. This chapter also 
includes an assessment of the environment's impact on older adults with cognitive impairment, methods for creating a dementia-friendly ward and critiques of each environmental change implemented Ward A.

The methodology and method present in Chapter 3 details the impact evaluation and the mixed methods used. The design used in this evaluation was impact evaluation. The method is discussed including sample size, demographic variables, and data analysis. This chapter discusses issues of evaluation design, ethical approval, confidentiality, and rigour.

The findings in Chapter 4 consists of quantitative data about the number of falls and aggressive incident. The qualitative data includes findings from the staff survey about their thoughts on the service initiative.

Lastly, the discussion in Chapter 5 discusses the further interpretation of data, implications for hospital settings, limitations, recommendations, and the concluding statement. 


\section{Chapter 2: Literature review}

The literature review chapter commences with the search strategy used to identify the research about environmental change in ward environments. Then the literature available for each environmental intervention implemented in the service initiatives is reviewed. The environmental interventions used were large face clocks, identification of bed spaces, lavender oil diffusor, viewing gardens, and finger food.

Search strategy

The databases used in this search were through the Victoria University portal and includes CINAHL, PubMed, Springer Link, Web of Science and Google Scholar. The search terms used were 'older adult', 'elderly', 'environment', 'cognitive impairment', 'dementia', 'hospital setting', 'orientation aides', 'timepiece', 'wayfinding ability', 'gardens', 'biophilia', 'indoor plants', 'lavender', 'agitation', and 'finger food'.

The inclusion criteria of the search were adults over 65 years as the HOP service is restricted to patients over the age of 65 . Also, the inclusion criteria involved research from a variety of settings such as all wards in the hospital setting and residential care facilities. This is because the search identified a low number of articles when limited only to the hospital setting. The exclusion criteria were review journal articles, as the articles from the initial search yielded many which were opinion-based rather than evidence-based.

\subsection{Critical appraisal approach}

The critical appraisal approach used to review literature was the CASP. The programme's website is a virtual platform and the website leads on to the CASP approach of Find, Appraise, and Act (CASP UK, 2018). Once the evidence is found using CASP, it is further clarified and focused on searching various types of sources that include secondary sources, bibliographic resources, and grey literature.

The CASP tools can be used to critically appraise different types of evidence and consist of seven specifically designed checklists. The checklists comprise of 10-12 questions each and are available for the appraisal of Randomized Controlled Trials, Systematic Reviews, Cohort Studies, Case-Control Studies, Qualitative Studies, Economic Evaluations, Diagnostic Studies, and Clinical Prediction Rule. These lists are wide-ranging and lend direction to any researcher who embarks on a study or has questions regarding its outcomes (Singh, 2013). The checklists, provide researchers and clinicians with a structured approach to finding 
evidence that has the potential to improve the quality of an individual's study plan and could be used to exclude research findings that are of low quality (Singh, 2013).

\subsection{Environmental interventions implemented}

The following environmental changes were implemented in Ward A; large face clocks, identification of bed spaces, a lavender essential oil diffusor, viewing gardens, and finger food in a snack basket.

\subsubsection{Large face clocks}

Large face clocks allow patients to see the time clearly, which improves orientation to time of the day and reduces confusion. This relates to the King's Fund overarching design principle of supporting orientation. According to the literature search, there is a gap in the literature about the use of large face clocks with older adults with cognitive impairment in the hospital setting.

Recognition of time is an important cognitive function in our daily lives. Recent studies have suggested that subjective time perception is strongly linked to what occupies time and whether one perceives it as, pleasant or stressful (Chaston \& Kingstone, 2004; Larson \& von Eye, 2010). Accurate time estimation abilities are assumed to play an important role in the efficient performance of many daily activities. Research has found that there is a disruption of time perception in patients with a cognitive impairment which is seen as greater error and variability in their time estimates (Requena-Komuro et al., 2020; Rueda \& SchmitterEdgecombe, 2009). While other research shows patients with cognitive impairment show no changes in the perception of interval length but are associated with alterations in the subjective passage of time (Coelho et al., 2016). In identifying the time of the day, people are given extrinsic and intrinsic cues, such as daily activities with various information, sunlight and dawn, physical fatigue, and hunger feelings. If orientation regarding the time of day is related to the number of environmental cues during a day, the capacity for time orientation might show a characteristic change. However, there are few studies which have investigated time orientation in association with daily cues in older adult patients with cognitive impairment. One such study showed impaired time orientation was more evident in the morning than in the afternoon which suggests the interventions facilitating time orientation might be arranged preferentially in the morning for patients with cognitive impairment (Iwamoto \& Hoshiyama, 2012). 
Products exist to support people with cognitive impairment, typically showing the time and date. However people with cognitive impairment seem to need a simpler display which shows only the day of the week and part of the day (Boyd, Evans, \& Harris, 2016). A product called the Day Clock was developed in consultation with people with cognitive impairment, carers, and professionals, and was made available on the market. The effect of time disorientation on people with cognitive impairment was well understood before this evaluation, but the impact of time disorientation on the carers of people with cognitive impairment was greater than anticipated and can be a significant source of anxiety and conflict (Boyd et al., 2016). The simplicity and standalone nature of the Day Clock design, while queried by some critics, is shown to be a valid approach which fits a specific market demographic (those with time disorientation who can still read but cannot make sense of the exact time or date) (Boyd et al., 2016). The negative impact of time disorientation on people with cognitive impairment and their family/whānau has been highlighted by the goals identified during the evaluations, and this impact can be reduced by using the right product. There is stronge evidence available in this field about the efficacy of assistive technology products for people with cognitive impairment and in particular the Day Clock, demonstrating that designing specifically for users' needs can lead to usable, effective products (Boyd et al., 2016).

A research article by McCusker et al. (2001) reports a variety of environmental factors can cause an increase in cognitive impairment symptoms. One of the environmental factors reviewed in their cohort study is the absence of a clock. The study completed in one acute care hospital in Montreal excluded those who could not speak English or French or were admitted to the older adult service. These exclusions meant many potential recruits were not included in this study. The study used validated objective measurements, which included the CAM method conducted by one study nurse, which decreases the risk of error. The authors identified that a variety of environmental factors increase cognitive impairment symptoms these include multiple room changes, care on the intensive care or long-term care unit, use of medical or physical restraints, absence of a clock, watch, or reading glasses, and presence of a family member. McCusker et al. (2001) states that there may not be a causal relationship between these factors. Additionally, the results cannot be applied to the community population as this type of community based was excluded from this study. The implications of this study for practice indicate that there may be an association between clocks and reducing cognitive impairments, but it is difficult to determine a relationship as many other factors were assessed during this study. 
The articles by Boyd et al. (2016); McCusker et al. (2001) indicate that there is a small amount of research available about the benefits of large face clocks for older adults. The research discussed does show support for the use of large face clocks for older adults with cognitive impairment to improve orientation, which is aligned with the King's Fund design principle of supporting orientation.

\subsubsection{Identification of bed spaces}

The identification of bed spaces such as contrasting colour schemes in each bed space using wall stickers mean patients can be more independent in regards to mobility and activities of daily living (Eastham \& Cox, 2017). This is because patients can manoeuvre around the ward using familiar landmarks. It also makes it easier for patients and staff to remember, locate and recognise their unique bed spaces. This relates to the King's Fund overarching design principles of supporting orientation and wayfinding. There has been little research conducted about the use of contrasting colour schemes in older adult patients with cognitive impairments.

Research conducted with sign comprehension showed older adults with cognitive impairment had poorer sign comprehension overall and difficulty with wayfinding icons or icons with text (Scialfa et al., 2008). The research was conducted in Canada and aimed to determine whether iconic sign comprehension declines in healthy aging and in the presence of cognitive impairment. Sign comprehension has an impact on effective driving, responses to warnings, and wayfinding which means signs that are poorly comprehended by older people increase accident risk and may compromise their independence. Therefore, the development of comprehensive signs for older adults with a cognitive impairment needs to take into consideration older adults' range of perceptual and cognitive abilities represented in the population (Scialfa et al., 2008).

The research by Eastham and Cox (2017) states the aims of research which was to explore the implications of a dementia-friendly ward as per the King's Fund assessment tool for activities of daily living for patients with dementia. The dementia-friendly ward consisted of several contrasting ward colours clear ward signage, positive staff interaction, memorabilia, and activity rooms and items (Eastham \& Cox, 2017). The qualitative methodology was appropriate to explore the staff's perceptions of concerning the dementia-friendly design and addressed the aims of the research. The recruitment strategy was snowball sampling and the researcher explained how and why participants were selected, and the potential bias of this 
type of sampling. The data were collected using an open-ended questionnaire, and the researcher justified the methods chosen. The data form is clear and analysed using thematic analysis. The researcher made it clear that they did not reveal their view or the anticipated outcome. The ethical issues were also taken into consideration by granting permission to access data from the NHS and briefing participants before the completion of questionnaires. However, it is unclear whether approval was sought from the ethics committee. The data analysis was thematic analysis, but it is unclear how the themes were derived from the data. The findings are explicit in this research on how staff can provide quality care to dementia patients in acute settings, however, the credibility of the findings is not discussed. The researcher discussed that the research is small scale and that the findings cannot be generalised to all dementia-friendly hospital settings.

The impairment of autonomous way-finding due to cognitive impairment obstructs the independence of older adults and their activities of daily living. An alternative is the use of augmented reality to aid autonomous wayfinding in a community setting. In the research article from the USA focuses on a spatial map and directional information which were shown via a head-up display to guide patients from the start zone on the hospital campus to a bakery in the nearby community (Sejunaite, Lanza, Ganders, Iljaitsch, \& Riepe, 2017). The research showed older adults' patients with cognitive impairment were able to follow the correct path in 113 out of 120 intersections with intermittent reassurance (Sejunaite et al., 2017). Also, older adults affirmed willingness to use such an augmented reality device in everyday life if needed or even pay for it. This shows augmented reality guided navigation is a promising means to sustain autonomous wayfinding as a prerequisite for the autonomy of older adults with cognitive impairment in their activities of daily living.

Other research using a GPS route navigation support on a mobile device yielded similar results. The small-scale exploratory research in the USA used older adults with cognitive impairment as the target group. The effects studied were two different types of audio instructions and assessed pedestrian safety while operating the device. The results showed when navigation instructions were spoken by a familiar voice it seemed to have a positive impact on the effectiveness of the navigation system compared to when an unfamiliar voice was used, while the use of warning sounds seemed to have a negative effect of wayfinding (Hettinga, De Boer, Goldberg, \& Moelaert, 2009). The research was limited by its small sample size however results show unsafe behaviour was not found when using the GPS route navigation. 
Further research in the form of a randomized controlled study about wayfinding examined the effects of a way-finding intervention (use of behavioural training and location maps) over a month on older adults with cognitive impairment ability to find their way in a new environment (McGilton, Rivera, \& Dawson, 2003). The research was conducted on four aged care facilities in Canada and the final sample consisted of 32 residents with Alzheimer's disease (17 in the treatment group and 15 in the control group) (McGilton et al., 2003). The results indicated that the older adults in the treatment group who had access to behavioural training and locations maps demonstrated an increased ability to find their way to the dining room one week after the intervention. However, the intervention effect was not sustained three months later which is not relevant to the older adults in the HOP service as they are discharged from hospital before this period.

An study by Marquardt (2011) is an overall literature review of architectural wayfinding design for people with dementia in nursing homes conducted in Germany. Wayfinding refers to navigation in an unfamiliar environment, which is increasingly complicated for older adults when they have a cognitive impairment. The results were summarised and substantiated through an interdisciplinary interpretation, considering changes in the orientation process of people with dementia. The literature considers that spatial disorientation and declining wayfinding abilities are among the early symptoms of dementia, limiting a person's ability to perform activities of daily living independently, and ultimately, perhaps leading to placement into a care facility. A prerequisite to maintaining residents' quality of life in a nursing home is their ability to orient themselves within their new environment. The available literature on wayfinding design for people with dementia in nursing homes was reviewed. Two aspects of interventions for residents' wayfinding abilities were identified: the design of the floor plan typology, and environmental cues. The design of the physical environment plays a significant role in supporting the wayfinding abilities of people with dementia. The floor plan design of a nursing home has a significant influence on residents' spatial orientation and wayfinding. Additional interventions such as signage, furnishing, lighting, and colours are extra supporting features, but they cannot compensate for an adverse architectural design. The creation of a supportive, dementia-friendly environment in terms of architectural design is important to consider. This is supported by design guidelines to encourage the wayfinding abilities of people with dementia.

The concept of wayfinding is additionally supported by a research review which specifically reported on the impact of problem behaviours, including impacts on resident activities of 
daily living cognitive function, and social function especially problem behaviours such as caregiver burden (Day, Carreon, \& Stump, 2000). This is one of the few research articles available to support reasoning and justifying this masters research which indicates little research is currently available. The emphasis on problem behaviours may also indicate, however, that many researchers do not fully appreciate the potential of environmental design to improve quality of life, beyond simply minimising undesirable conduct. The research highlighted that for the environmental design to have the greatest impact, design professionals and researchers must continue to educate administrators and families on the potential role of environmental design for thoroughly improving quality of life.

While there has been little research conducted about contrasting colour schemes, the literature search shows the floor design has a positive impact on older adults with cognitive impairment through encouraging independence. It also supports the King's Fund principle of orientation and wayfinding. This is further supported by a literature review which provides an overview of the intervention strategies aimed at reducing spatial orientation disorders in older adults' people with cognitive impairment (Caffò et al., 2014). This consisted of eight experimental studies using spatial cues, assistive technology programs, reality orientation training, errorless learning technique, and backward chaining programs are described (Caffò et al., 2014). These interventions are classified into two main approaches: restorative and compensatory, depending on whether they rely or not on ability to learn. The review of the intervention strategies suggests that both compensatory and restorative approaches may be valuable in improving wayfinding behaviour, with various degrees of effectiveness.

\subsubsection{Lavender oil diffusor}

Essential oils, such as lavender oil, are a non-pharmacological treatment that is simple to use and has minimal side effects. Lavender has been used for centuries to soothe, aide sleep, and improve emotional wellbeing. Lavender has become an increasingly popular alternative due to increased knowledge of its pharmacological effects and significant clinical potential on its own or as adjuvant therapy in different disorders (Koulivand, Khaleghi Ghadiri, \& Gorji, 2013). However, due to issues, such as methodological inadequacies, small sample sizes, short duration of lavender application, lack of information regarding dose rationale, variation between efficacy and effectiveness trials, the variability of administration methods, the absence of a placebo comparator, and lack of control groups, more standard experiments and research are needed to confirm the beneficial effect of lavender with neurological disorders (Kang, Nam, Lee, \& Kim, 2019; Koulivand et al., 2013). Some research did not define the 
contents of lavender and several factors, such as temperature, skin type and quality, and the size of area being treated, which may affect the level and rate of lavender absorption after massage or aromatherapy, were not considered (Kang et al., 2019; Koulivand et al., 2013).

Lavender oil administered in an aroma stream shows modest efficacy in the treatment of agitated and anxiety behaviour in patients with cognitive impairment when assessed by these systematic reviews, placebo controlled study and randomised controlled trial (Donelli, Antonelli, Bellinazzi, Gensini, \& Firenzuoli, 2019; Holmes et al., 2002; Wang, Albayrak, \& van der Cammen, 2019; Watson, Hatcher, \& Good, 2019). This relates to the King's Fund overarching design principle of legibility. Various modes of delivering lavender, including oral administration and lavender patches are shown to be effective with reducing agitation in older adult patients with cognitive impairment (Fißler \& Quante, 2014; Sakamoto et al., 2012).

The evidence for oral lavender is promising; however, the use of more widely used forms of lavender administrations (aromatherapy, inhalation, massage, etc.) is not currently supported by good evidence of efficacy (Koulivand et al., 2013). The use of oral lavender was not considered for the service initiative studied in this evaluation as it involves the vulnerable older patient consuming a medication which may interact with other medicines prescribed for their hospital admission. Besides, the use of lavender patches has the risk of not meeting infection control requirements. The mode of delivering lavender orally or via patches also means patient consent is required, which will be challenging with older adult patients with cognitive impairment. Other research shows lavender scent patches reduce the incidences of falls with older adults in residential facilities (Sakamoto et al., 2012). Furthermore, research support this notion as it shows when oral lavender is taken by rats with cognitive impairment it acts as an anxiolytic and anti-depressive agent and improves spatial memory deficits (Hritcu, Cioanca, \& Hancianu, 2012).

The literature search shows lavender can be administered in a variety of ways and at times can be effective and other times ineffective in reducing agitation. When lavender oil is diffused via a vaporiser, it is shown to reduce agitation and is in line with the King's Fund principle of legibility. Holmes et al. (2002) focused on long term stay patients with behavioural problems in a dementia unit. The study identified outcomes which were plotted as points on an aggression scale in a placebo-controlled study. The cohort was representative of a defined population as it included Alzheimer's and different types of dementia. The 
cohort included patients who had met the criteria for severe dementia which means all patients were included that should be included. However, the results of the study could be a random occurrence and it is difficult to determine due to the unpredictable behaviour of dementia patients. The results may not apply to NZ as the study was based in the UK which has a very different patient population. However, the results were measured objectively by an experienced independent blind reviewer. It appears the researchers identified all-important confounding factors including that aroma diffusers were used because hot rings or naked flames cannot be used for patients with dementia. The results of this study do align with other evidence available, and the researchers clearly state the study is small and only concentrated on patients with severe dementia. The study implies that a lavender diffusor shows a moderate efficacy in the treatment of agitated patients with dementia which is favourable for the HOP patients with cognitive impairment.

\subsubsection{Viewing gardens}

A literature review showed preliminary studies have reported the benefits of horticultural therapy and garden settings in the reduction of pain, improvement in attention, lessening of stress, modulation of agitation, lowering of Pro re nata which is a term commonly used in healthcare to administer medications as required and antipsychotics, and reduction of falls (Detweiler et al., 2012). These benefits are important factors in improving the quality of life and possibly reducing costs for long-term, assisted living and dementia unit residents. The research conducted by Kellert (1995) about biophilia also supports this with his theory that explores the biological need for humans to interact with nature. Most of the existing studies of garden settings have utilized views of nature or indoor plants with sparse studies employing therapeutic gardens and rehabilitation greenhouses (Detweiler et al., 2012). Ulrich (1984) published seminal research from the USA in which he studied the outcomes of having a specific view from their hospital room window for a group of patients' postcholecystectomy. One view was of a brick wall, while the other was of deciduous trees. Patients with the natural view had improved outcomes that were statistically significant, including shorter hospital stays, less analgesia use, and fewer emotional problems during recovery. This finding is further supported by more recent research by Goto et al. (2017) that specifically examined how viewing a Japanese garden affects patients with dementia. Goto et al. (2017) showed that viewing an indoor garden significantly reduced the heart rate, evoked short-term and long-term memories, and improved behavioural symptoms. 
Views of nature support orientation and provide meaningful activity. This relates to the King's Fund overarching principles of supporting orientation. The Goto et al. (2017) study focussed on patients with middle to late-stage dementia in a hospital in Japan. The intervention given was access to a variation of a Japanese garden. The outcomes considered were mood and behavioural assessment, which was tested using a behavioural assessment checklist, heart rate test which was tested using a fingertip heart rate monitor, and olfactory test which was tested using a small vaporizer to create a chrysanthemum-like aroma in the room. The cohort was recruited through consent and if their dementia was advanced it was gained from their legal guardian. The cohort was not representative of a defined population as patients with advanced dementia were not able to participate in the study due to the equipment for eye movement tests causing distress to patients with advanced dementia, so it only included patients with milder impairment. The exposure to the gardens was accurately measured through validated objective measurements, which included mood and behavioural assessment, heart rate tests, eye movement tests and olfactory tests. The researchers noted that confounding factors such as viewing the garden were delayed due to the heat of summer. The effects of the garden was measured as the experiments were conducted and data was collected by the researcher. The experiment identifies the participants involved in all variations of the garden and the reasons why they were included or excluded. The results of the experiment show the positive physiological and psychological effects of viewing a Japanese garden.

The results may not apply to the local population as this experiment was conducted in Japan with only Japanese participants who would have a relationship with Japanese gardens, while patients in New Zealand may not have any connection to Japanese gardens. The results of the study are unique as I was unable to locate other research about patients with cognitive impairment viewing gardens. The implications of this study for practice are a framework for understanding the spatial characteristic of Japanese gardens. This article offers a fresh perspective on the impact of garden design using physiological and psychological instruments. Its findings provide information about the impact of viewing gardens on elderly population with dementia. Also, this article highlights how different senses cooperate in creating the total impact of a landscape.

The literature search shows the practice of gardening and viewing gardens leading to reduced falls and aggression in older adults with cognitive impairment and is in line with the King's 
Fund principle of supporting orientation. However, it is essential to note that the practice of gardening is impractical in the hospital setting for older adults with cognitive impairment.

\subsubsection{Finger food}

Eating and drinking difficulties are recognised sources of negative health outcomes in people with cognitive impairment. The systematic review in EDWINA (Eating and Drinking Well IN dementiA) was aimed to assess the effectiveness of interventions to directly improve, maintain or facilitate oral food and drink intake, nutrition, and hydration status, in people with cognitive impairment or dementia (across all settings, levels of care and support, types and degrees of dementia) (Abdelhamid et al., 2016). Interventions included oral nutrition supplementation, food modification, dysphagia management, eating assistance and supporting the social element of eating and drinking. It involved comprehensively searching databases for relevant intervention studies.

The review was conducted with service user input under Cochrane Collaboration's guidelines. This included forty-three controlled interventions, and none were judged at low risk of bias (Abdelhamid et al., 2016). Oral nutritional supplementation studies indicated small positive short term but unclear long-term effects on nutritional status. Food modification or dysphagia management studies were smaller and of low quality, providing little evidence of improved nutritional status. Eating assistance studies provided inconsistent evidence, but studies with a strong social element around eating/drinking, although small and of low quality, provided the consistent suggestion of improvements in aspects of quality of life. The search found no definitive evidence on effectiveness, or lack of effectiveness, of specific interventions but studies were small and short term. People with cognitive impairment and their carers must tackle eating problems despite this lack of evidence (Abdelhamid et al., 2016). The need remains for high-quality trials tailored for people with cognitive impairment assessing robust outcomes.

Finger food is useful for anyone who has difficulty performing a movement or series of movements as it is food that can be eaten with fingers. Apraxia makes cutting up food and taking it to the mouth a complex, sometimes impossible, the task to accomplish. Finger food does away with cutlery and simplifies eating while enabling the patient to remain autonomous so is a good way of encouraging patients to increases their food intake. This relates to the King's Fund overarching principle of familiarity. 
Research by Pouyet, Giboreau, Benattar, and Cuvelier (2014) found that Alzheimer's patients make choices in regards to food preferences when given alternatives. The study addressed a focused issue as the aim was to investigate the attractiveness of finger food for people with Alzheimer's by studying choices and consumption of different types of finger food. The cohort was recruited from eight nursing homes in Paris. Staff were recruited in each home with the collaboration of medical staff and the experiments formed part of the introduction of the finger food diet into these facilities. The patients' family members provided consent and no clinical data were recorded. The reason these eight facilities were used in the research is unclear. The data collected was objective as it came from questionnaires about patients' behaviour completed by healthcare staff. The outcome was inaccurately measured as questionnaires were not validated. The researchers considered all confounding factors as they completed interviews with healthcare staff before and after research.

The results of the study show Alzheimer patients tended to choose first, and then consume finger foods with sauce and in two layers rather than those without sauce and in one layer, where all the ingredients were mixed. By contrast, their shape did not influence their choice of food consumption. It is difficult to determine the accuracy of results as there is no confidence intervals provided. The results cannot be applied to the local population is this was conducted in Paris, France which is very different demography from the New Zealand population. The results of the study do fit with other evidence available as cited by several other authors. The implications for practice are that the attractiveness of finger food needs to be considered for patients with Alzheimer's and this requires further research.

Research conducted in the UK by Barrat and Gatt (2001) specifically with females with dementia found a finger food menu compared to a normal menu had positive outcomes on wellbeing, independence, lower costs and patient weight gain. Additionally, research done in an Alzheimer's facility in the USA showed an increased number of finger foods offered to Alzheimer's' residents resulted in increased food consumption and improved body weights (Soltesz \& Dayton, 1993). This is further supported by a pilot study also completed in the USA in a nursing and rehabilitation home where some patients had Alzheimer's disease showed patients had more independent feeding skills, food intake and increased weight following the introduction of a finger food menu (Jean, 1997). The improved body weight was achieved through the addition of more finger foods on the menu. The advantages of these menu changes were they generally cost no more money, required no more staff, took no retraining of the kitchen staff, and required no special food purchases. Quality of life was 
maintained by helping the residents keep a sense of feeding independence and dignity which in turn improved morale enough for these residents to eat.

The literature search shows there has not been a significant amount of research conducted on older adults with cognitive impairment and consumption of finger food. The studies show the concept of food choices improves the quality of life as it provides choice. This is line with the King's Fund principle of familiarity as finger foods allows patients to make their own choices of food consumption rather than waiting for scheduled food service times as per the facility.

\subsection{Research gaps in the literature}

The positives of this literature search were that it showed reviewed articles' validity, results, and relevance. The search revealed articles that were peer-reviewed which indicates the articles critiqued exemplify the best research practices of the field. Another strength of the literature search was the discovery of an article that supported lavender oil administered in an aroma stream showing modest efficacy in the treatment of agitated behaviour in patients with severe dementia. The downside of the literature search was that it was unable to yield results specific to each environmental change implemented. The literature search did not locate articles specific to large face clocks, but the one article mentioned a variety of environmental factors pointed out that the absence of a clock showed an increase in cognitive impairment symptoms in patients. In addition, there were no articles specific to wayfinding abilities, but one article mentioned a variety of changes including contrasting ward colours, clear ward signage, positive staff interaction, memorabilia, and activity rooms and items. There was only one article that examined the impact on dementia patients when viewing a garden. The literature search was unable to locate an article on finger food but located an article which showed Alzheimer's patients can make choices regarding food preferences when given alternatives.

The literature search highlights that each article reviewed studies different types and severities of cognitive impairment including various stages of Dementia and Alzheimer's. Also, none of these articles was published in NZ and were instead published in the USA, UK, Korea, France, and Japan. The unique population of NZ compared to other parts of the world means data needs to be collected on the effect of the implemented environmental changes on older adults with cognitive impairment in NZ specifically. 


\subsection{Summary}

This chapter critiqued literature that investigates the impact of the service initiative environmental changes recommended by the King's Fund Healing the Environment Assessment tool in creating a dementia-friendly ward. It is anticipated that these environmental changes may reduce the rate of aggression and falls in Ward A where the changes have been implemented which creates patient safety. The next chapter is the methodology chapter which will discuss how rates of aggression and falls were tracked throughout this evaluation. 


\section{Chapter 3: Methodology and Methods}

In this chapter the methodology and methods are reported which include the methodological platform, and methods, data analysis. Furthermore, issues are highlighted around data collection including confidentiality, rigour, validity, reliability, and validity of the evaluation.

\subsection{Methodology}

Through this evaluation the methodology draws upon impact evaluation and mixed methods research. Both research processes are pivotal to understanding the results from this service initiative.

\subsubsection{Impact evaluation}

One of the pioneers of evaluation research is Michael Quinn Patton, who described evaluation as a trans-disciplinary, global profession (Patton, 2019). He describes evaluation as an examination of effectiveness. Patton in his book Blue Marble Evaluation outlines the importance of navigating the risks and opportunities that arise with completing an evaluation, (Patton, 2019). Experiments are different from evaluations, but it was realised that evaluations could not involve randomisation or controlled experimental environments (Miller \& Salkind, 2002). Impact evaluation was introduced to overcome the constraints of ethical, legal and time frame limitations of finding out whether an intervention was effective (Miller \& Salkind, 2002). To start an impact evaluation there needs to be a specific focus.

Impact evaluations begin with a clear question (see section 1.1), which guides the systematic and empirical data required to evaluate the impact of an intervention - positive and negative, intended and unintended, direct and indirect (Clarke, Conti, Wolters, \& Steventon, 2019; Gertler, Martinez, Premand, Rawlings, \& Vermeersch, 2016; White, 2010). An evaluation may include small projects, an extensive programme, or a collection of activities or policies (Brophy, Snooks, \& Griffiths, 2008).

Impact evaluation has several important design issues that should be addressed before starting the research. Like any research it needs to be well-designed with the data collection points identified. Also taking into consideration the timeframe, as the desired outcome cannot be achieved if the timeframe is limited. The intervention must be sufficiently implemented into a service before the evaluation commences. It is important that impact evaluation is part of an integrated monitoring system and makes available a range of evidence to inform decisions for service providers such as HOP. This will also ensure that data from other activities, such as 
performance monitoring and process evaluation can be used, as needed. Evaluating the implementation of innovative designs and initiatives is important to identify the negative impacts of initiatives as well as positive impacts (Brophy et al., 2008). This is achieved through the collection of multiple data sets about such service initiatives which are the aim of this evaluation. One aspect of impact evaluation is considering how causal attribution is recognised.

Causal attribution describes observed changes that have occurred by seeking to understand the role of an intervention or multiple interventions, to produce these changes which is key to impact evaluation (Rogers, 2014; White, 2010). Impact evaluation involves the collection of data after implementation of the service initiative, which has a cause-and-effect (Gertler et al., 2016). An evaluation such as this aims to clarify causal attribution (Brophy et al., 2008). In this research, the impact evaluation reports on the service initiative to determine whether patient safety is achieved by collecting data about rates of falls and aggression in the HOP service. The causal attribution in this impact evaluation will be a matter of reflecting upon whether the environmental changes make a difference to the data collected about falls and aggression in HOP. Translation of this research into the clinical setting involves the application of the results from this impact evaluation to other clinical areas that have similar patient groups so that patient safety will be improved.

Impact evaluation can be undertaken to improve an intervention or to inform decisions about whether to continue, alter, or replicate a response (Braun \& Clarke, 2012). This helps provide information to guide policy development and inform decisions made to replicate the initiatives more widely throughout the DHB. Also, evaluations are carried out to make services more effective and justify decisions for funding transparently in the DHB. The HOP service has limited resources as it is restricted by a budget. However, to effectively ensure patient safety, a rigorous and systematic evaluation is necessary to inform good decision making for limited available resources. This impact evaluation serves as a platform for the two data sets collected. Mixed methods research guided the approach to data collection and how findings are interpreted (Creswell, 2018b).

\subsubsection{Mixed Methods Research}

Mixed methods research is defined as the rigorous, collection of both quantitative and qualitative data in response to research questions (Creswell, 2018b). Quantitative and qualitative data separately provide important results. In mixed methods research, the data is 
then integrated to develop a more comprehensive understanding of results. For example, this evaluation results from the qualitative data provide important explanations on quantitative data. Integration is a planned activity to merge qualitative and quantitative data to generate inferences beyond the two separate data sets (Creswell, 2018a). Mixed methods research is considered appropriate when there is a need to provide greater exploration and evaluation of a research problem (Creswell, 2018b).

Mixed methods research originated in the late 1980s and has gone through periods of development and growth. It continues to grow and evolve with the publication of government policies and theses' in the social, science and health fields (Creswell, 2018b). Mixed methods research is considered the third type of research paradigm along with qualitative and quantitative research. The validity of mixed methods research is enhanced by taking into consideration the important elements of the qualitative and quantitative research paradigms (Creswell, 2018b; Polit, 2008). A mixed-method approach also provides a sophisticated, complex design that appeals to those at the forefront of analysing complex situations.

Mixed method research is described by three central designs. The designs are convergent mixed methods, explanatory sequential mixed methods and exploratory sequential mixed methods research (Creswell, 2018a, 2018b). The convergent design occurs when the researcher uses concurrent timing to implement the quantitative and qualitative strands during the same phase of the research process, prioritizes the methods equally, and keeps the strands independent during analysis and then mixes the quantitative and qualitative strands during the overall interpretation (Creswell, 2018a, 2018b). The explanatory sequential design starts with the collection and analysis of quantitative data, which is then followed by the subsequent collection and analysis of qualitative data (Creswell, 2018a, 2018b). The researcher interprets how the qualitative results help to explain the initial quantitative results. The exploratory sequential design uses sequential timing which begins with and prioritizes the collection and analysis of qualitative data then quantitative date builds from the exploratory results to generalize the initial findings (Creswell, 2018a, 2018b). The researcher then interprets how the quantitative results build on the initial qualitative results.

The qualitative data in this evaluation was integrated with the quantitative data to develop the overall results for the mixed methods design. The qualitative data provides context and explanations for the quantitative results, to explore outlier cases of success and failure and to develop systematic explanations of the program's performance as it was found in the 
quantitative results (Gertler et al., 2016). This combination allows the best representation of both approaches which may have been hidden if only one method was used (Fusch, Fusch, \& Ness, 2018). Both these types of data give an overall picture of what the environmental changes implemented into Ward A meant for older adults with cognitive impairment.

This evaluation had a convergent design meaning the quantitative data was collected and analysed separately to the collection and analysis of qualitative data (discussed further in the next section).

\subsubsection{Convergent mixed methods research}

The convergent mixed methods design is well described by Creswell (2018b) as a design that ensures different data sets are reunited to answering the research question in a parallel manner. The researcher aims to combine the results of the quantitative and qualitative data analysis so they can be compared as discussed in the discussion chapter. The convergent design evolved from the multimethod research design by D. Campbell and Fiske (1959) and has been extended by more contemporary mixed method researchers (Creswell, 2018b; Morse \& Niehaus, 2009). The convergent deigns intends to obtain different but complementary data on the same topic to understand the research question. The convergent design brings together strengths and weaknesses of quantitative and qualitative methods and allows for corroboration and validation of both data sets. Consequently, two separate data sets were collected. The data needs to be integrated rather than merged as statistical numbers cannot be merged with words.

In this evaluation, the dominant approach is a collection of quantitative data (Bamberger, 2012). Quantitative data is important as it shows the effect of the service initiative on the rate of falls in Ward A. Also, the qualitative data complements and strengthens the quantitative data because it provides a deeper understanding of the success of the service initiative. Had the evaluation timeframe been extended, more data could have been collected to strengthen the statistical analysis. Figure 3 illustrates the mixed method design used. The process of mixed methods research combines both quantitative and qualitative which gives an overall view of the environmental changes implemented into Ward A. Both the quantitative data collected about falls and aggression, and together with qualitative data about the healthcare staff's perspectives of the environmental changes provides an integrated view of the effectiveness of the service initiative. 

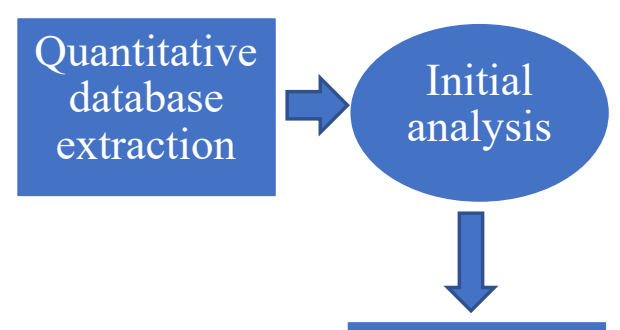

Statistical

analysis

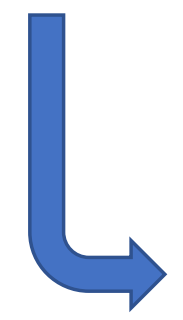

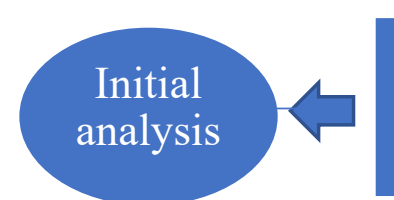

Qualitative

data

collection

\section{Findings (integrating \\ quantitative and qualitative data)}

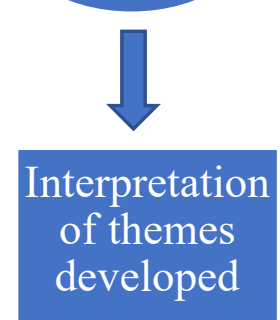

developed

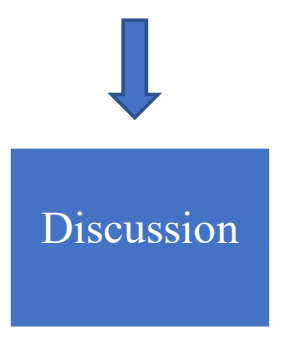

Figure 3: Convergent mixed method research design used in the research

Informed by Creswell, J.W. (2018).

\subsubsection{Mixed methods research in impact evaluation}

Impact evaluation and mixed methods research were central to the research design. The combination of impact evaluation and mixed methods provide information about the environmental changes in the HOP service. Mixed methods is the use of diverse methods for deliberate research to understand the impact of the interventions put in place (Bamberger, 2012). For this research, the environmental changes implemented into Ward A were reviewed in terms of rates of falls and aggression for older adults with cognitive impairment and staff perspectives of the implemented initiatives were analysed.

Healthcare is a complex system, and is aimed at humans, but this creates complications and unpredictability. Therefore, an impact evaluation using mixed methods is important to explore and make clear to establish patient safety. The Ministry of Health has made more efforts to guide and create design processes and embed interactions to DHBs around NZ to 
allow for safety for staff and patients and their family/whānau. Therefore, mixed methods are a way of collecting information about and further exploring unpredictable human behaviour.

In this impact evaluation, a mixed-methods design was used to present qualitative and quantitative findings and gain deeper insights into the impact of environmental changes for older adult patients with cognitive impairment. The evaluation viewed the problems from multiple perspectives, contextualized information, and developed a more complete understanding of the identified issue for patient safety.

\subsection{Methods}

A practice-based approach for the impact evaluation included; a retrospective study (quantitative data) of reported falls and aggressive behaviour, and a survey of healthcare staff about their experience of the change in the environment (qualitative data) across the HOP service which is discussed in this section. Another design that was considered was a retrospective study (quantitative data) of reported falls and aggressive behaviour and interviews of patients (qualitative data) in the high visible room where the environmental changes were implemented. The advantages of conducting interviews of patients' views of the environmental changes in the high visible room are that it would have obtained the patients' views which could not be collected in quantitative data. The disadvantages of conducting interviews of patients' views of the environmental changes are the complexity of obtaining informed consent due to patients' cognitive impairment. This would require obtaining consent from the patients' next of kin which would be inconvenient and unachievable in the masters timeline.

\subsubsection{Study site}

This evaluation is in the HOP service. The changes were made in January 2019 in Ward A, following completion of the King's Fund Enhancing the Healing Environmental Assessment tool. It consists of a service initiative in Ward A and the outcomes compared to Ward B, which has a similar patient group. The cost of the products for the initial changes was approximately $\$ 400$. This funded the purchase of two large face clocks, a diffusor, lavender essential oils, indoor garden, wall stickers for individualised rooms, snacks basket and finger food. 


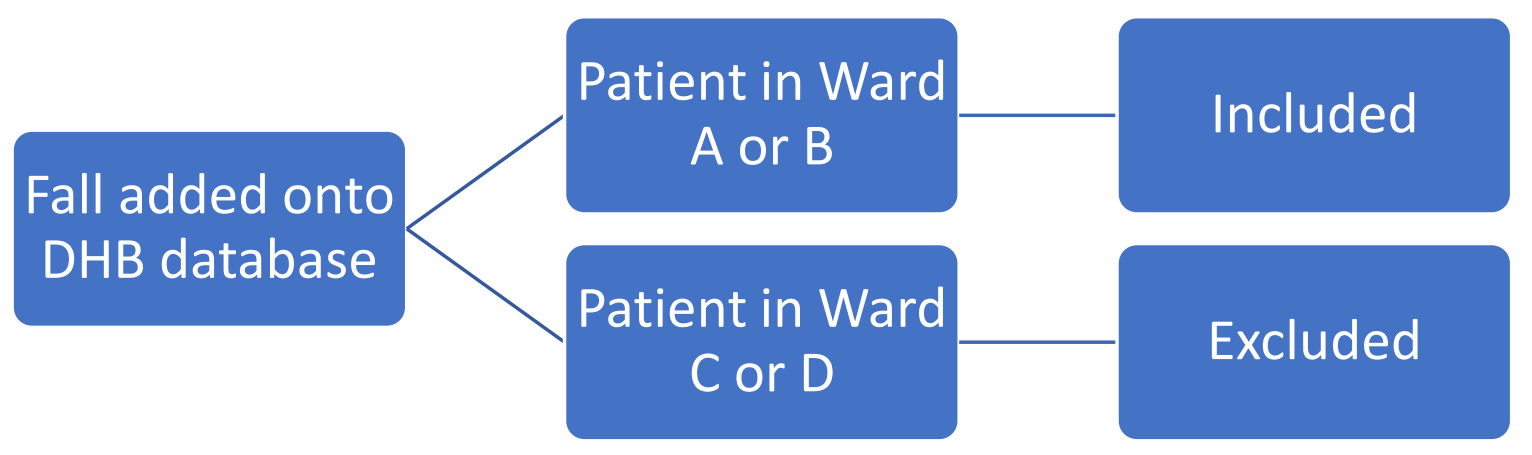

\section{Figure 4: Process of identification of sample included in the evaluation}

\subsubsection{Sample Size}

As per power calculations calculated by the University statistician, 10-20\% of total falls among this patient group occur in the HOP service high visible room. To detect a difference in the percentage of falls between Ward A and Ward B, data was required to be collected (commencing in February 2019) over 5 months, after the environmental changes had been implemented. For data to be sufficiently powered a minimum of 300 admissions were needed per ward. The one month between intervention and collection of data was required due to time constraints from the masters timeline.

\subsubsection{Sampling method - Quantitative data}

The sampling method for the quantitative data consists of all patient records $(n=385)$ of patients who were admitted to the HOP service between February 2019 to June 2019. As the focus of this evaluation was on the effectiveness of service initiatives, the patients who had multiple presentations in this service were counted as separate patients. An acute readmission is usually an unexpected emergency or an acute return of a patient to hospital (Ministry of Health, 2020). There were 64 repeat admissions: of these 56 people were admitted twice, six people were admitted three times, and two people four times. The data was collected retrospectively.

The data was retrieved with assistance from the quality advisor and Trendcare coordinator. Once collected the quality advisor assisted by identifying the incidents related to falls and aggression through the incident report database (3DHB). These incidents were grouped under 
"patient falls" for falls in 3DHB and "staff and other health and safety" for aggression in 3DHB. The data collected included National Health Index (NHI) number, sex, age, ethnicity, ward number area, reportable event number, type of incident, shift of incident, day of the week of occurrence and location of the incident. The Trendcare coordinator assisted by identifying the room number the patient was placed in when the incident occurred and whether they were in the high visible room.

Other data collected were obtained from an online medical records system managed by Concerto software. The variables relating to the patient include the length of stay, primary diagnosis, secondary diagnosis, typology of cognitive impairment, living arrangements before and after admission, and who they lived with before admission. Also, data was collected about all admissions over the study period, including, admission and discharge dates to determine the length of stay through a quality advisor.

\subsubsection{Sampling method -Qualitative data}

The qualitative data was collected in September 2019 by sending an information sheet and Qualtrics link for the survey to staff via a third party (the ward administrator). Qualtrics software was used to develop and distribute the survey due to ease of access. The software allows respondents to complete the survey at a time convenient to them, pause, and return to the survey later. It also allows respondents to discontinue the survey at any time.

Consideration was given to maximizing the survey response rate. The length of the survey was kept to a minimum to avoid substantial drop off in completion rates. Potential respondents were advised the survey would take between 10-15 minutes to complete. The survey questions were developed by the researcher and supervisors. Consent was evidenced through the first question in the anonymous survey. The survey (Appendix B) of healthcare staff $(n=60)$ asked four open-ended questions about the environmental changes implemented in Ward A. There were no demographic questions asked to maintain anonymity. For both the quantitative and qualitative data, the data extraction tool used was R studio coding base.

\subsubsection{Patient demographic variables}

For the quantitative data, the demographics of patients in Wards A and B in the HOP service. In particular, age, gender, ethnicity, and length of stay was gathered. The HOP service is restricted to patients over the age of 65 from diverse backgrounds in the DHB boundary. For qualitative data, the demographics include the healthcare staff of HOP service. This consists of approximately 60 healthcare professionals including medical teams, allied health 
teams, and nursing teams. The medical team consists of a house officer, registrars, and consultants. The allied health team consists of physiotherapists, occupational therapists, social workers, dieticians, transitional service assistants, ward clerks and speech language therapists. The nursing team consists of a charge nurse manager, associate charge nurse managers, a nurse educator, a discharge coordinator, a clinical nurse specialist, an associate director of nursing, registered nurses, enrolled nurses, and healthcare assistants.

\subsection{Data Analysis}

\subsubsection{Analysis of quantitative data}

The data about falls were analysed in R studio software with assistance from the statistician (see section 4.1). The R software is a free open-shareware software that can run on Unix, Windows, or Mac OS X computer operating systems. The R software can be downloaded from the Comprehensive R Archive Network (RStudio Team, 2015). The R software is an integrated suite of software facilities for data manipulation, calculation, and graphical display. It has an effective data handling and storage facility, a suite of operators for calculations on arrays such as matrices, a large, coherent, integrated collection of intermediate tools for data analysis, graphical facilities for data analysis and display either directly at the computer or on hardcopy, and a well-developed, simple and effective programming language (called 'S') (RStudio Team, 2015).

Mean, medians and standard deviations were used to analyse continuous (age, length of stay) variables and proportions was used to analyse categorical data (sex, ethnicity). Pearson's Chisquared test was used to establish whether there were any differences in patient characteristics. Pearson's Chi-squared test was the statistical test applied to categorical variables to see whether any statistical difference between the Wards characteristics. The Welch's $t$-test, or unequal variances t-test, was used to test the difference in continuous variables such as rates of falls per 100 people. Rate ratios were calculated to compare the rates of falls per 100 bed days. Analyses included confidence intervals and statistical difference was set at $\mathrm{p}=0.05$.

\subsubsection{Analysis of qualitative data}

The qualitative data were initially analysed using content analysis. There are several definitions and descriptions of content analysis as a qualitative method that have been presented over the years. In 1952, Berelson (1952) defined content analysis as "a research technique for the objective, systematic and quantitative description of the manifest content of 
communication" (p. 18). Krippendorff (2018) defined content analysis as "a research technique for making replicable and valid inferences from texts (or other meaningful matter) to the contexts of their use" (p. 18). Downe-Wamboldt (1992) underlines that content analysis is more than a counting process, as the goal is to link the results to their context or to the environment in which they were produced, "Content analysis is a research method that provides a systematic and objective means to make valid inferences from verbal, visual, or written data in order to describe and quantify specific phenomena" (p. 314). The content analysis of the qualitative data is discussed in 4.2.

Following the content analysis, the staff survey data was analysed using thematic analysis. Thematic analysis is a method of qualitative data analysis which allows the systematic identification of data into themes (Braun \& Clarke, 2012). It allows the researcher to view and identify shared meanings and experiences (Braun \& Clarke, 2012). The recognition of commonalities found in the data is pivotal to thematic analysis. The thematic analysis produces the answer to the question and can identify numerous patterns across the data set (Braun \& Clarke, 2012). The strengths of thematic analysis are the accessibility and flexibility of the approach (Braun \& Clarke, 2012). The approach offers a way of separating qualitative research from these broader debates, where appropriate, and making qualitative research results available to a wider audience (Braun \& Clarke, 2012). Its accessibility as a method also suits multimethod research being conducted by research teams, where not everyone is a qualitative expert. A thematic analysis approach is reported to be useful when little is known about the research topic, with themes emerging from the data.

Braun and Clarke (2012) six-phase approach was followed for the analysis of qualitative responses. The first step in the analysis was to become familiar with the data through repeated reading, marking notes of initial ideas or repeated patterns that emerged according to the data. Codes were then identified that may be related to the research questions. The codes and data were then examined to identify preliminary themes. This included data related to the research questions and data that was not directly related. The next step was to review themes by checking them against the data to ensure they were answering the research questions. Themes were then discussed with my supervisor and further refined. A more detailed analysis of these was then conducted to generate robust definitions and names. This phase involved developing a comprehensive analysis of each theme and their contribution to the understanding of the data. Finally, the findings from the analysis were discussed in the final 
report in the discussion chapter. Themes were described and supported by direct verbatim quotes from participants.

\subsection{Issues with the data collection}

There were several issues identified during the collection of quantitative and qualitative data. One issue identified with the quantitative data was that due to the structure of the reporting system, staff had discussed a patient's injuries and not disclosed which patient had been aggressive and caused harm. This means data about aggression did not have the richness compared to the data about falls. A decision was made with input from my supervisors and statistician to still use data available on aggression despite it being incomplete. The data was 'cleaned up' and saved on Citrix as the data on aggression will provide good qualitative data. The data were stored and reviewed but were unable to be uploaded onto R studio software due to this reason. Because limited data were collected concerning aggression, this variable was not able to be put into the evaluation findings which could not be presented to the DHB. A second issue was that, when the data were collected initially, data was only collected for each ward about falls and aggression. This meant that overall data about patients admitted to HOP was not collected so wards could not be compared within the study period. Therefore, a decision was made to collect data about overall admissions in the HOP service over the study time. This involved collecting information about all admissions in the HOP service and admission and discharge dates to determine the length of stay.

A third issue was that R software was blocked from being downloaded onto Citrix (the DHB computer system). So, an amendment had to made to the ethics committee to download the hospital data onto a USB on hospital grounds to a personal laptop where R software was available through the Victoria University website. This was approved but required the data to be managed in the specific way which involved removing all the patients' names but keeping the NHI number to identify readmissions. Also, it involved not collecting information about patients' addresses. Also, all work on this smaller data set from Citrix (the DHB dataset) would take place under the supervision of the statistician and supervisor. This data analysis of data would occur at a DHB computer in DHB grounds putting the smaller dataset onto a USB drive, then transferring it onto a laptop as the software was not available on the DHB Citrix software. After the completion of data analysis, the file was deleted from the USB before leaving the hospital grounds. 
A fourth issue was the management of patient readmissions. This was because, while there were a few readmissions, for each admission most of them were within one month of each other. The complete de-identification of data was difficult as readmissions had to be identified to provide a true sense of the rate of admissions to the two wards in question. Also, readmissions can be significant in the older adult population, and we believe this is an important point to discuss in these research findings if this occurs while we are analysing the data for our original question. Advice from a biostatistician, and from a senior quality advisor in the DHB was that that the definition of readmission is any admission after 28 days after discharge (Robinson \& Kerse, 2012). One of the reasons behind the readmissions was non-acute rehabilitation funding (NAR). When a patient was identified as commencing NAR, interrupted, extended, and discharged from NAR, this required the ward administrator to admit and discharge them from the ward. This creates the illusion that the patient was readmitted; however, the patient did not leave the ward and was not technically readmitted but according to data this is a readmission.

A fifth issue was when to conduct the staff survey on Qualtrics, as it is important to consider that the allied health and nursing staff group have different levels of staff for the winter period. Also, the medical doctors work in rotations so it was important to take into consideration when the staff had adequate exposure to the environmental changes so accurate information could be collected for the survey.

A sixth issue identified was that the data reflects all falls across both wards and does not take into consideration whether the patient is in the high visible room (where the changes were implemented). To analyse this, extra data was collected about the location of all patients admitted to HOP.

A seventh issue identified by my supervisor was that initially data was not collected about the exact site of falls. This is important because if falls are occurring away from the changes, it may indicate that environmental changes need to be put into another area depending on the site of the falls. The data about the location of the falls was collected from the reportable event database 3DHB.

An eighth issue was that data collected from Qualtrics initially had a poor response. After discussion with the supervisors, it was decided that field notes collected could be used but, this requires an ethics amendment. However, the response rate improved after two weekly 
reminders were sent and the ethics amendment was not approved by the ethics committee. Therefore, field notes were not included.

The final issue was influenced throughout the period of data collection including several doctors' strikes and inadequate nurse staffing levels. Both these events lead to inadequate staffing levels in the HOP service. This is despite research showing that improved staffing characteristics will improve the quality of care patients receive.

\subsection{Ethical approval}

Ethical approval was requested from the Human Ethics Committee at Victoria University of Wellington (approval number, 0000027096). Their guidelines state under section 5.1.2, that ethical consent must be sought if the researchers are accessing information that is not readily available in the public arena. Permission had been granted by the local DHB to access patients' records through a locality agreement (approval number CCDHB05/06/19).

\subsubsection{Confidentiality}

Patient records are confidential, so an 'Out of scope review' was requested by HDEC to determine whether an application should be reviewed by HDEC. Their reply stated that ethics need to be sought through the university ethics committee. In reference to confidentiality, patients' data is protected by the Health Information Privacy Code 1994. This ensures health information that is collected for purposes different from the original purpose such as research data, is only used for research purposes (Health Information Privacy Code, 1994, 2008). Health care systems around the world generate vast amounts of data as part of their routine operations (Clarke et al., 2019). These datasets are often designed to support direct care, and for administrative purposes, rather than for research (Clarke et al., 2019). In the case of this research, routine data provided a rich source of information on a large group of patients with different conditions across the health service. On admission to the DHB patients or family/whānau must sign a patient information form, which includes the patient's personal information and demographic information. The patient information form also states that a patient's health information may be used for research and all research projects are approved by an ethics committee. It also states that many research projects involve a review of past information and are not clinical trials.

The NHI numbers and patient names are kept separate from the main data spreadsheet and password protected. This is because this information includes patient identifiers. However, there is a requirement to develop and need to keep data including patients' identifiers so 
readmissions can be identified. This is especially important as readmissions increase with age and affect the older adult population, which is the primary focus of this evaluation (Robinson \& Kerse, 2012).

The data accessed is sensitive, in that it relies on a reportable event database (which is policydriven) which includes the reporting of falls and aggressive behaviour. The database will be accessed for research without the explicit consent of the people who provided the data. Therefore, it is important to maintain the confidentiality of these vulnerable patients, especially when accessing their private information.

\subsection{Rigour}

The evaluation was designed to produce unbiased results as the outcome data analysed is routinely collected and not subject to researcher influence. The survey tool was pretested and able to be completed anonymously which means staff were free to state their opinions without fear of consequence. Validity in quantitative research refers to the extent to which an instrument measures what it intends to measure (Creswell, 2011). Strategies utilised in the evaluation to ensure validity was the choice of mixed methods, which was considered an appropriate design for this study.

The evaluation's utility is demonstrated by obtaining evidence of the impact of the environmental changes for the local DHB before these changes are introduced to other wards. This is because data collected in this evaluation is representative of the local population and such unique data has not previously been collected. The propriety of this evaluation is respectfully collecting data and being receptive to healthcare staff's views of environmental changes in Ward A regardless of their opinions. The evaluation is feasible as it is achievable to have data collected over approximately five months. The data collection will be constantly updated and discussed with supervisors throughout this period.

The design of this evaluation assumes all episodes of falls and aggressive incidents were reported in the incident report database. In clinical practice, this may not have occurred due to staff time restrictions, lack of interest in reporting incidents, or lack of understanding of the importance of reporting these incidents. Therefore, there may be some incomplete data as in reality the rates could have been much higher in both wards.

This evaluation required peer reviewers, such as supervisors, to verify the coding of qualitative data and theme development. The advantage of using peer reviewers is that they 
can identify gaps in the evaluation that need to be addressed and they can provide reassurance that conclusions are sound and reasonable after reviewing the evaluation.

\subsection{Reflexivity}

Reflexivity is the process by which researchers gain self-awareness of their perspectives in the research (Whitaker \& Atkinson, 2019). Recognising how one's values may influence the findings of a study is important for the credibility and rigour of a study (Whitaker \& Atkinson, 2019). Throughout this study, I had an insider's perspective into the management of Ward A and the healthcare staff working in the HOP service. This research was conducted in the ward I work in; it involved asking survey questions to my colleagues and interpreting the data myself. At all stages of the study, I endeavoured to put my knowledge and experience "aside" and rely on the data presented. As a novice researcher, I acknowledge that despite my best efforts, I was probably not able to do this one hundred percent of the time and this influence may have been presented unconsciously throughout the evaluation. There are advantages and disadvantages to being an insider. Advantages include access to and trust of the group and shared understanding of the terminology (Bishop, 2005). The healthcare staff would routinely discuss the environmental changes in the ward I was employed in and understood my questions, and why I was asking those questions, and I understood what they were talking about. The disadvantages included the potential for bias and participants not always giving full answers because they thought I knew what they meant. To overcome this, the staff survey was sent by the ward administrator who is a third party, and I did not encourage staff to complete the staff surveys. This study aimed to obtain different stakeholders' views, even if they differed from each other's and my own through quantitative and qualitative data.

The next chapter reviews the findings and interprets these to form some conclusions on data collected. 


\section{Chapter 4: Findings}

This chapter outlines the results of this evaluation which has been divided into quantitative and qualitative results. Initially, the quantitative data are presented then the qualitative findings which included data about the healthcare staff survey.

\subsection{Quantitative data}

\subsubsection{Profile of patients}

Table 1 shows a profile of patients admitted to Ward A and Ward B over the five-month study period.

Table 1: Demographic characteristics and length of stay of patients admitted to Ward A and Ward B

\begin{tabular}{|l|r|r|}
\hline & Ward A & \multicolumn{1}{|c|}{ Ward B } \\
& $\mathrm{N}=159$ & $\mathrm{~N}=170$ \\
Sex & $66(41.5 \%)$ & $72(42.4 \%)$ \\
Female & $93(58.5 \%)$ & $98(57.6 \%)$ \\
\hline Ethnicity & & $8(3.8 \%)$ \\
Maori & $147(92.5 \%)$ & $8(4.7 \%)$ \\
Other (NZ European, European, Asian) & $6(3.8 \%)$ & $154(90.6 \%)$ \\
Pacific People & $85(13)$ & $84.7 \%)$ \\
\hline Age in years & $8.86 \pm 7.71$ & $83.24 \pm 7.88$ \\
Median (Interquartile range) & $61-102$ & $57-100$ \\
Mean \pm Standard deviation & $19(12.25)$ & $16(12)$ \\
Range & $21.99 \pm 17.47$ & $20.20 \pm 14.24$ \\
\hline Length of stay in days & $1-140$ & $1-89$ \\
Median (Interquartile Range) & & \\
Mean \pm Standard deviation & & \\
Range & & \\
\hline
\end{tabular}

Table 1 shows there were more women admitted to the wards, but the proportion of women was similar in Wards A and B. The patients' average age and ethnicity were also similar in the two wards. While the mean length of stay was similar in each ward, the median was three 
days less in Ward B. The range demonstrates that at least one patient in Ward A spent 51 more days than the people who had the longest length of stay in Ward B.

The Pearson's chi-squared test with the Yates' continuity correction for gender was used to compare Ward A and Ward B in terms of gender. The results showed there was an equal spread of females and males $\left(\mathrm{X}^{2}=0.0018, \mathrm{df}=1, \mathrm{p}=0.9656\right)$ and there was no reason to believe there is any difference between the wards. The Pearson's Chi-squared test for ethnicity also showed no difference between the wards $\left(X^{2}=0.3668, \mathrm{df}=2, \mathrm{p}=0.8324\right)$. The clinical significance of these statistical values is that the two wards looked similar statistically. The findings from Welch's Two Sample $t$-test for the length of stay for the patient journey $(\mathrm{t}=-1.0164, \mathrm{df}=305.24, \mathrm{p}=0.3103)$ show no difference between the wards. In summary, Table 1 shows there is little difference between the profiles of patients in Ward A and Ward B when considering sex, length of stay, ethnicity, and age. This suggests that both wards had comparable patient groups and could be used to make comparisons regarding the environmental changes implemented.

\subsubsection{Quantitative findings}

The quantitative data includes falls and aggressive incidents from the two wards in the HOP service between February and June 2019. The data was collected from the reportable incident database used in the DHB, 3DHB. The data considers patients discharged and admitted the same day to be part of the same admission, as discussed in 3.4. Otherwise, admissions are considered as separate incidents. The data does not include patients in Ward C and D as both the wards have different ward setup to the HOP service. The data excludes patients who moved between Wards A and B during the study period. Ward A is where the environmental changes were implemented into the high visibility area and Ward B was used as a control.

\subsubsection{Falls data}

Table 2 shows that overall, Ward A, where the environmental changes were implemented, had more falls compared to falls in Ward B. Figure 5 shows in both wards the most common site of falls was the bed space and there was a lower number of falls in Ward A in these bed spaces. This is important as the changes were only made in the high visible bed space area. The Pearson's Chi-squared test with Yates' continuity correction for the site of falls showed the difference was not statistically significant $\left(X^{2}=0.42913, \mathrm{df}=1, \mathrm{p}=0.5124\right)$. This means that the location of the falls did not significantly differ between Ward A and Ward B. 
Table 2: Summary of reported falls in Ward A and Ward B by fall location

\begin{tabular}{|l|r|r|}
\hline & Ward A & \multicolumn{1}{|c|}{ Ward B } \\
\hline Number of falls & 35 & 29 \\
\hline Site of falls & $19(54.3 \%)$ & $19(65.5 \%)$ \\
Bed space* & $16(45.7 \%)$ & $10(34.7 \%)$ \\
Not bed space** & & \\
\hline
\end{tabular}

* Includes when site not stated

** Includes toilet, bathroom, corridor, dayroom

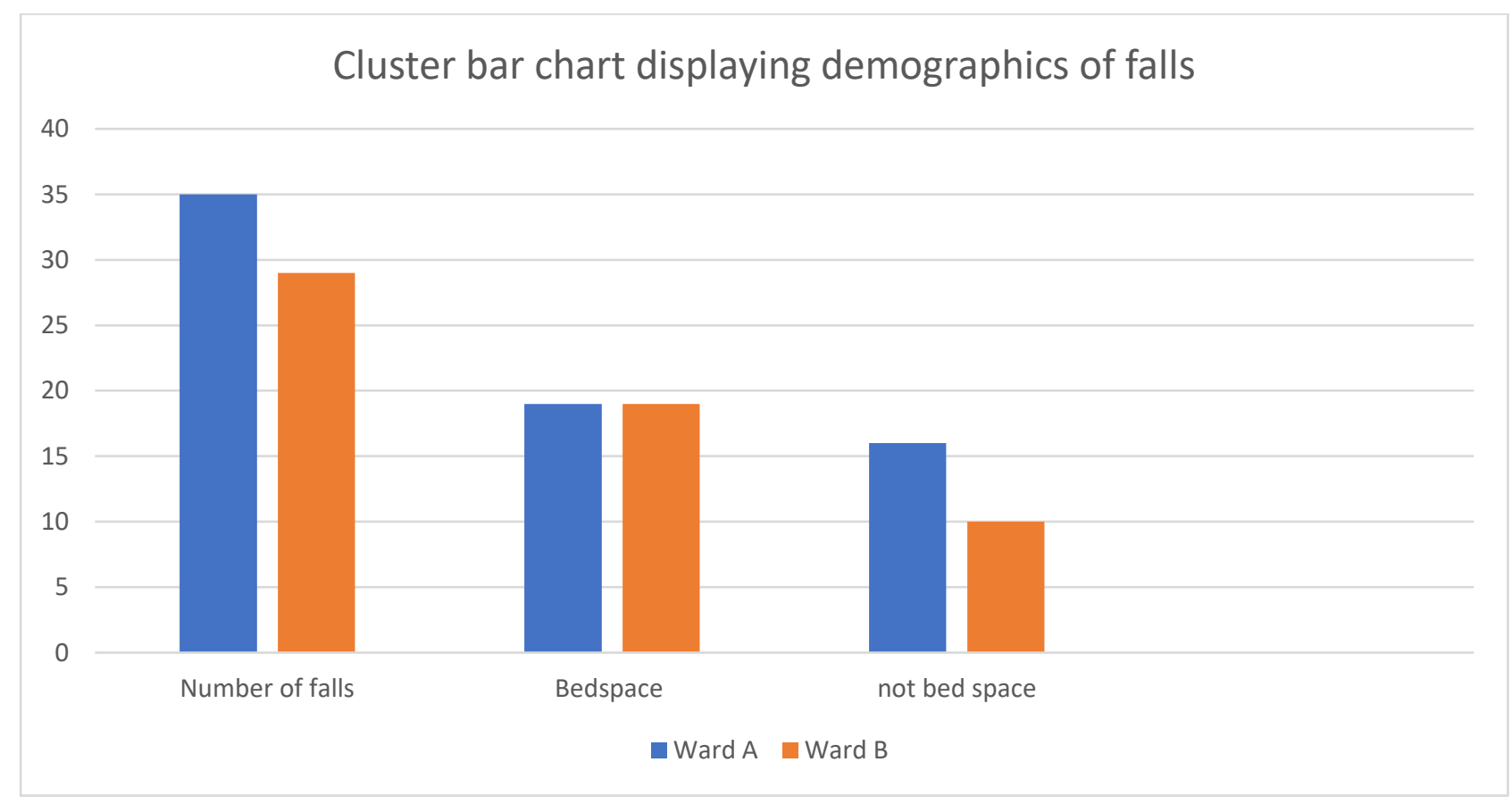

Figure 5: Displays demographics of falls

Table 3 shows the total number of falls in the high visible room in the bed space in Ward B $(n=13)$ where no environmental changes were implemented compared to Ward A $(n=11)$ where the environmental changes were implemented. 
Table 3: Falls rates and length of stay

\begin{tabular}{|c|c|c|c|c|}
\hline & \multicolumn{2}{|c|}{ Ward A } & \multicolumn{2}{|c|}{ Ward B } \\
\hline Site of fall & $\begin{array}{l}\text { Standard } \\
\text { Room (no } \\
\text { environmental } \\
\text { changes } \\
\text { implemented) }\end{array}$ & $\begin{array}{l}\text { High Visible } \\
\text { Room } \\
\text { (environmental } \\
\text { changes } \\
\text { implemented) }\end{array}$ & $\begin{array}{l}\text { Standard } \\
\text { Room }\end{array}$ & $\begin{array}{l}\text { High Visible } \\
\text { Room }\end{array}$ \\
\hline Bathroom or toilet & 7 & 2 & 3 & 0 \\
\hline Bed space & 9 & 8 & 8 & 11 \\
\hline Not stated & 1 & 1 & 0 & 0 \\
\hline $\begin{array}{l}\text { Other (corridor or } \\
\text { dayroom) }\end{array}$ & 7 & 0 & 5 & 2 \\
\hline Total falls & 24 & 11 & 16 & 13 \\
\hline No. of bed nights & 2,943 & 554 & 2,743 & 691 \\
\hline $\begin{array}{l}\text { No. of falls per } 100 \\
\text { nights }(95 \% \mathrm{CI})\end{array}$ & $0.82(0.53,1.20)$ & $1.99(1.04,3.45)$ & $0.58(0.35,0.93)$ & $1.88(1.05,3.14)$ \\
\hline Rate ratio & $\begin{array}{l}1.99 / 0.82=2.43 \\
4.97) \\
\text { The rate of falls } \mathrm{p} \\
\text { Ward A high visil } \\
\text { times higher than } \\
\text { for a standard roo }\end{array}$ & $\begin{array}{l}5 \% \text { CI }(1.19 \text {, } \\
100 \text { nights in } \\
\text { le rooms are } 2.43 \\
\text { he rate of falls } \\
\text { n. }\end{array}$ & $\begin{array}{l}1.88 / 0.58=3.23 \\
6.71) \\
\text { The rate of falls } \mathrm{p} \\
\text { Ward B high visil } \\
\text { times higher than } \\
\text { for a standard roo }\end{array}$ & $\begin{array}{l}5 \% \text { CI }(1.55, \\
\text { r } 100 \text { nights in } \\
\text { le rooms are } 3.23 \\
\text { he rate of falls } \\
\text {. }\end{array}$ \\
\hline
\end{tabular}

Table 3 assumes a length of stay of one equals one night. The number of falls per 100 days was calculated from the website (Open Source Statistics for Public Health, n.d.). The confidence interval was calculated in R studio using the epitools package (Aragon, 2020; RStudio Team, 2015). As the confidence intervals do not include one, I am confident that the rate of falls (per 100 days) was higher in the high visible rooms in both wards. This finding is expected as the high visible rooms in HOP service is where the patients at most risk of falling are placed. The ratio of the rate of falls in the high visible rooms to standard rooms per 100 nights is higher in Ward B, $3.2395 \%$ CI $(1.55,6.71)$ compared to Ward A, $2.4395 \%$ CI $(1.19,4.97)$. However, as the confidence intervals overlap it is unlikely that there is a 
difference in the ratio of the rate of falls in the high visible rooms to standard rooms between the two wards. The rate ratios and corresponding $95 \%$ confidence intervals are also displayed pictorially in a plot graph in Figure 6.

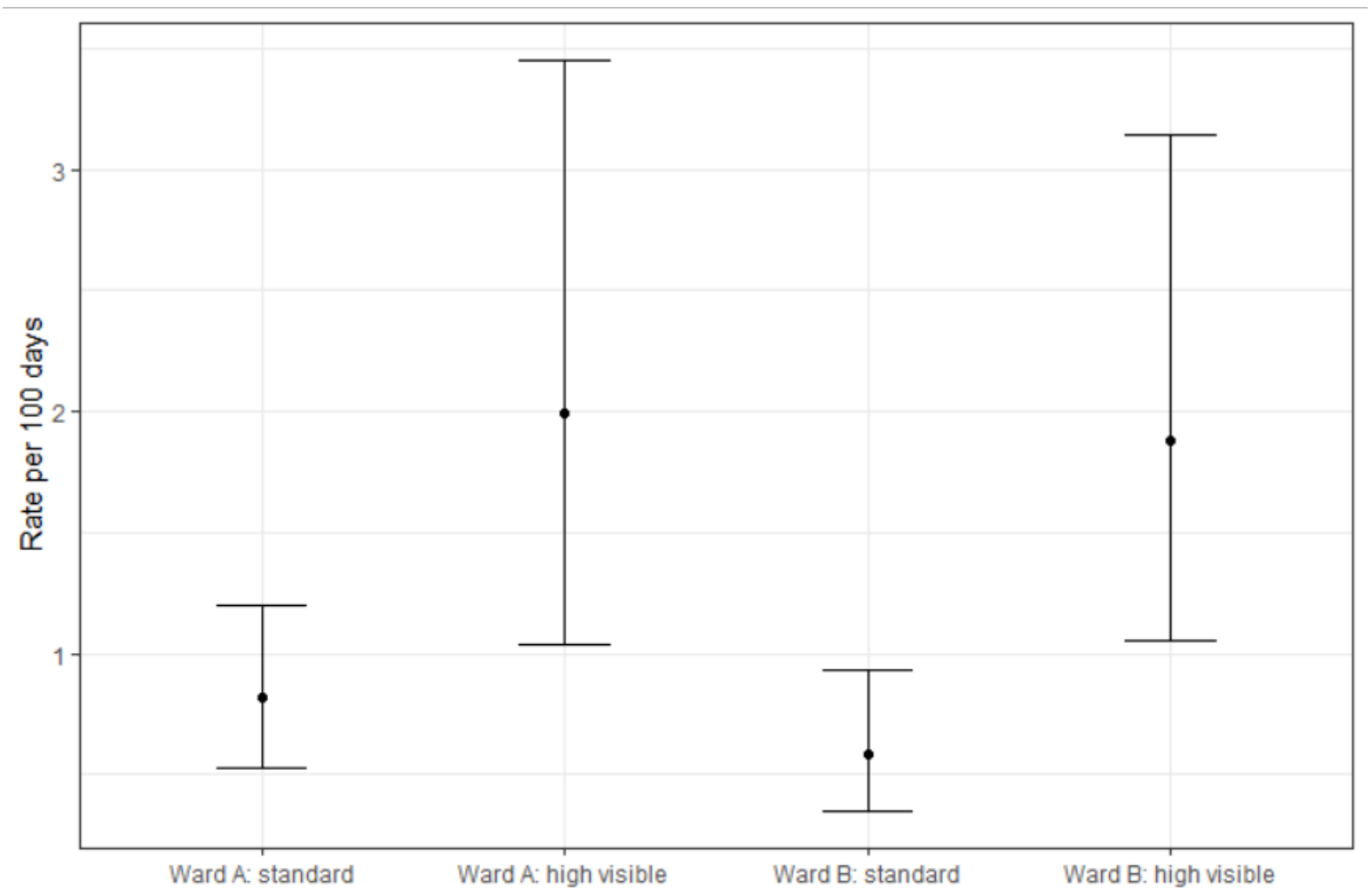

\section{Figure 6: Plots fall rates and length of stay as a plot (with 95\%)}

Figure 6 shows fewer patients were in the high visible rooms. So, there is more error associated with data, resulting in larger confidence intervals. The difference between confidence intervals can be seen in the plot graph. The differences in the plot show the high visible rooms have higher rates of falls, as illustrated by no or minimal overlap of the $95 \%$ CI. This is despite there being little difference between Ward A and Ward B.

\subsubsection{Aggression data}

The types of aggression included inappropriate behaviour, verbal abuse, physical assault, the threat of assault, threatening behaviour, and potential for harm. The quantitative findings of aggressive incidents include 19 reported incidents in Ward A and Ward B from February to June 2019. 
The reporting system allowed staff to submit incomplete reports about injuries that were inflicted upon them by patients. Due to the nature of the reporting system, staff may not have fully disclosed their own injuries and the patients' injuries. This means data on aggression is unlikely to be complete. The low number of aggressive incidents $(n=19)$ was likely to be due to underreporting. Table 4 shows that there was one more incident of aggression in Ward A compared to Ward B. Overall, reported incidents of aggression took place in the afternoon shifts. The data presented shows the raw counts for this data only, this is due to the small sample size which meant no statistical analyses were performed.

Table 4: Reported incidents of aggression

\begin{tabular}{|l|r|r|}
\hline & $\begin{array}{c}\text { Ward A } \\
\text { (environmental changes } \\
\text { made) }\end{array}$ & Ward B \\
\hline Total number of incidents & 10 & 9 \\
\hline Shift of incident & 3 & \\
Morning shift & 4 & 2 \\
Afternoon shift & 3 & 5 \\
Night shift & 3 & 2 \\
\hline Day of week of the incident & 1 & 2 \\
Monday & 0 & 1 \\
Tuesday & 2 & 1 \\
Wednesday & 1 & 3 \\
Thursday & 2 & 1 \\
Friday & 1 & 1 \\
Saturday & & 0 \\
Sunday & & 2 \\
\hline
\end{tabular}

Due to the time limitation of completing a master's thesis, there was only a short period of time over which data could be collected. As such, it is acknowledged that the sample size is small, and this may result in low statistical power to detect a difference between wards. 


\subsection{Qualitative findings}

All the data discussed in the qualitative findings section are from the healthcare staff survey through Qualtrics. The survey was conducted in October 2019 and was sent to the staff via the ward administrator. There were two reminder emails one and two weeks after the initial email to encourage participation.

\subsubsection{Profile of healthcare staff}

The staff who completed the staff survey included healthcare staff who work in the HOP in Wards A and Ward B. This included doctors, nurses, healthcare assistants, ward administrators, ACNMs, CNM, ADON, dieticians, speech language therapists, allied health assistants, physiotherapists, occupational therapists, and social workers. The survey was sent out to a total of approximately 60 healthcare staff. The responses of the healthcare staff are divided into six questions that the staff were asked in the survey in a table. The survey yielded 22 responses of which 20 consented to complete the survey.

\subsubsection{Qualitative findings}

The first question asked the healthcare staff members for consent to complete the survey (Appendix B). Table 5 shows the findings from the content analysis of the number of times particular words were used by healthcare staff when answering questions in the survey. The responses of the healthcare staff are coded in horizontal hierarchy diagram below using content analysis. The count of each comment is written in brackets to indicate the repetitive codes used for this diagram using content analysis.

Figure 7 shows the responses of healthcare staff in a diagram after coding. The above horizontal labelled hierarchy shows the actively generated codes and themes actively generated from the healthcare staff survey in the qualitative data. The counts of the comments show there were more positive comments $(n=25)$ compared to negative comments $(n=6)$ from healthcare staff. This is four times greater positivity which is reflected in the healthcare staff request to continue with the environmental changes (further discussed in 5.2.2). 
Table 5: Showing healthcare staff survey responses using content analysis

\begin{tabular}{|c|c|}
\hline Question & $\begin{array}{c}\text { Answers ( } \mathrm{n}=\text { number of times particular words were used } \\
\text { by healthcare staff when answering survey) }\end{array}$ \\
\hline $\begin{array}{l}\text { Two } \\
\text { What did you like about the changes to the } \\
\text { environment (clocks, lavender diffuser, indoor } \\
\text { garden, individualized rooms, finger food) } \\
\text { implemented in January } 2019 \text { to Ward A? }\end{array}$ & $\begin{array}{l}\text { Clocks }(n=8) \\
\text { Lavender diffusor }(n=6) \\
\text { Individualized rooms }(n=1) \\
\text { Finger food }(n=7) \\
\text { Orientation }(n=3) \\
\text { Calmer environment }(n=4) \\
\text { Improved environment }(n=2)\end{array}$ \\
\hline $\begin{array}{l}\text { Three } \\
\text { What did you not like about the changes to the } \\
\text { environment (clocks, lavender diffuser, indoor } \\
\text { garden, individualized rooms, } \\
\text { finger food) implemented in January } 2019 \text { to } \\
\text { Ward A? }\end{array}$ & $\begin{array}{l}\text { No concerns }(n=6) \\
\text { Not identify Indoor garden }(n=3) \\
\text { Lavender diffusor not suitable }(n=1) \\
\text { Finger food not suitable }(n=1)\end{array}$ \\
\hline $\begin{array}{l}\text { Four } \\
\text { Do you have any comments or suggestions on } \\
\text { the environmental changes implemented in } \\
\text { January 2019? }\end{array}$ & $\begin{array}{l}\text { Have music }(n=1) \\
\text { Daily calendar }(n=1) \\
\text { More diffusor }(n=1) \\
\text { More clocks }(n=1) \\
\text { Engaging with patients }(n=1) \\
\text { Helped with patients in room }(n=3)\end{array}$ \\
\hline $\begin{array}{l}\text { Five } \\
\text { Do you think the environmental changes } \\
\text { implemented have affected the behaviors of } \\
\text { older adult patients with cognitive impairment? }\end{array}$ & $\begin{array}{l}\text { Yes }(n=13) \\
\text { No }(n=6)\end{array}$ \\
\hline $\begin{array}{l}\text { Six } \\
\text { Please explain how the changes have affected } \\
\text { the behaviors of older adult patients with } \\
\text { cognitive impairment }\end{array}$ & $\begin{array}{l}\text { Improved environment }(n=4) \\
\text { Clocks work well }(n=5) \\
\text { Finger food helpful }(n=2) \\
\text { Patients are calmer }(n=5)\end{array}$ \\
\hline
\end{tabular}




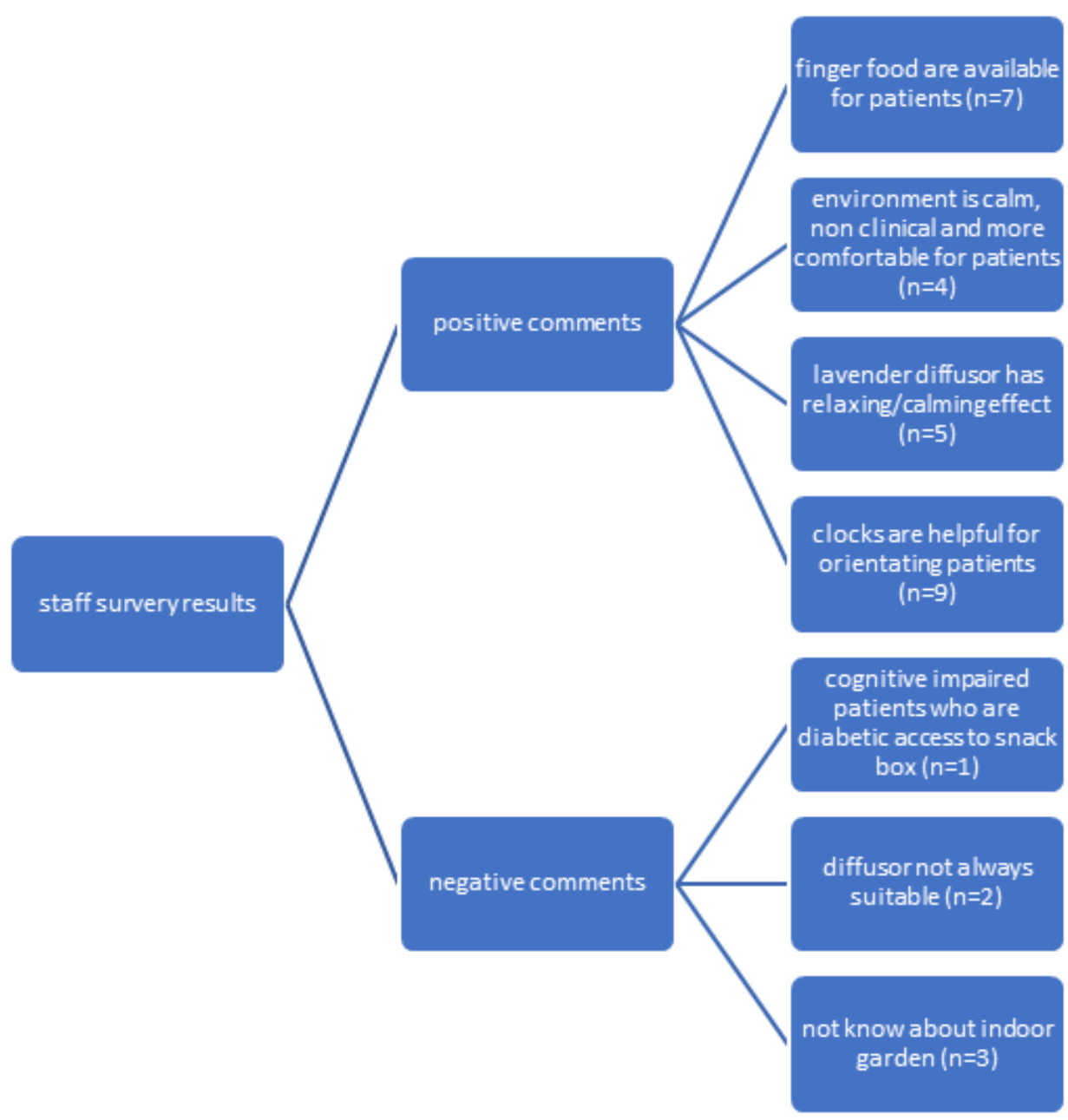

\section{Figure 7: Visual representation of healthcare staff survey responses}

The two main sub-themes that emerged from the qualitative data (Figure 8) were expressed about the service initiative were its "innovative concept" and "change to environment to improve cognitive function." 


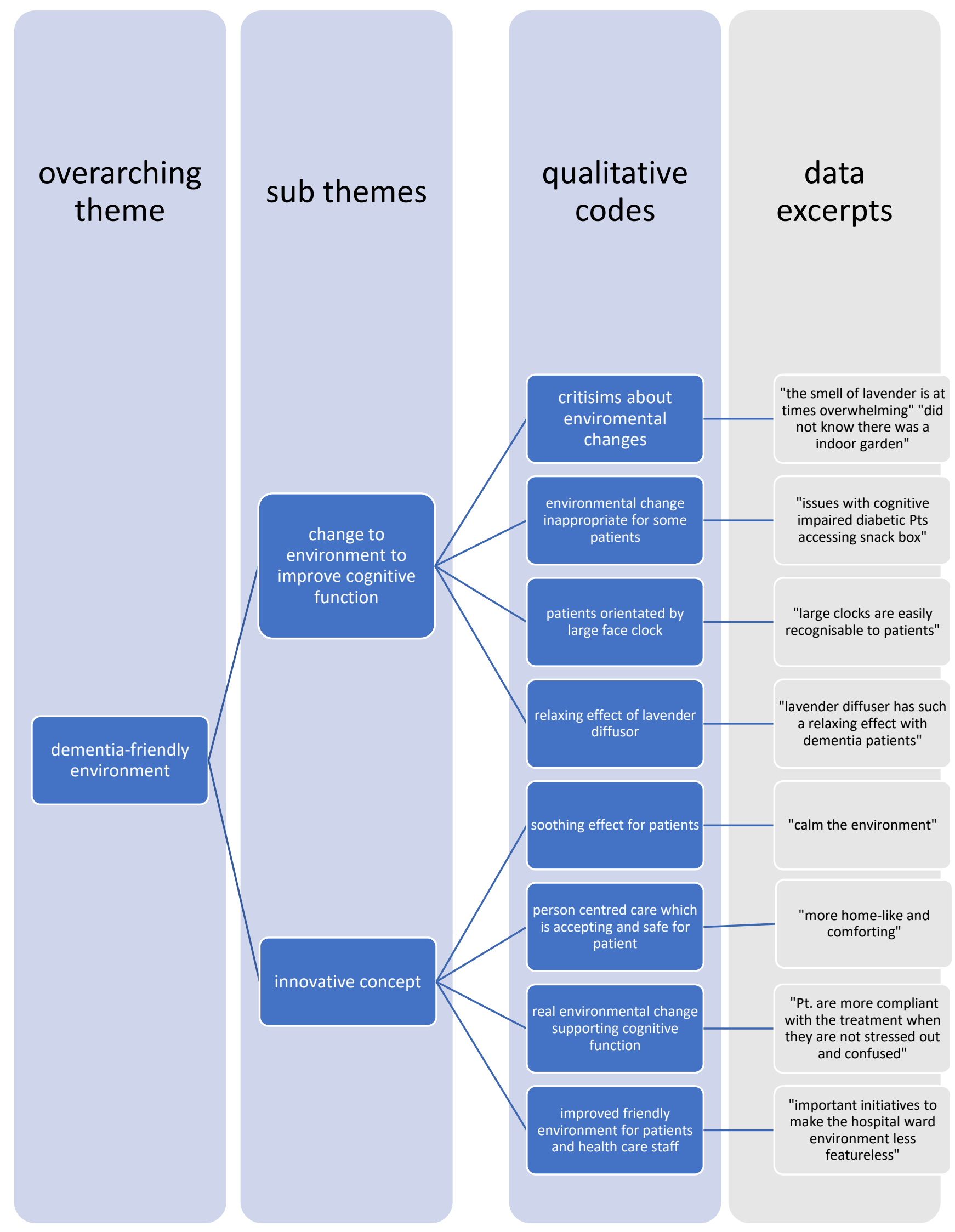

Figure 8: Overarching theme and sub-themes 
The "innovative concepts" sub-theme referred to respondent's comments about the effect of the environmental changes for patients and staff. The healthcare staff commented on the high visible room in various ways. One stated about the soothing effect for patients "it calms and orientates the p[atien]t. [t]o the [e]nvironment and time [sic]." Some staff made similar comments indicating these environmental changes were the most prominent in the high visible room. A healthcare staff member commented that "some patients are hungry at night and finger food is there for them" and "finger food [is] helpful for redirection [sic]."

Healthcare staff members commented the high visible room was now "more visually welcoming environment" and a different respondent commented it was "more home-like and comforting." Staff also mentioned the effect of the environment for the patients by stating, "P[atien]t[s] are more compliant with the treatment when they are not stressed out and confused [sic]." and "in total the changes can make patients more comfortable, and lower confusion and distress, and allow for rest and recuperation."

The comments mentioned earlier are similar to the other subtheme of "change to environment to improve cognitive function." The staff reported overall the environment changes "made the environment feel calm and non-clinical, gave alternative measure and methods to support patients during observation and engagement" and a "more visually welcoming environment." This meant the "P[atien]t are more compliant with the[ir] treatment when they are not stressed out and confused [sic]." In addition, the environmental changes were "important [environmental] initiatives to make the hospital ward environment less featureless, and allow patients to be oriented, and feel more comfortable and cared for" and the "changes to the environment help make patient stay in the hospital at ease." Some respondents mentioned the environmental changes were "important to both staff and patient satisfaction" as they assisted with reducing patients' delirium and cognitive issues.

Some respondents referred to specific environmental changes. In particular, the large face clocks meant the patients were "calm when they see there's a clock and orient them with time." Further information about the large face clock was "the large clocks are easily recognisable to patients who sometimes find it difficult to read as they can lose track of time or get confused, depending on their condit[i]on [sic]" and that "clocks are important for orientation."

Some respondents commented that the lavender oil diffusor "has such a relaxing effect with dementia patients" and "lavender diffuser has calm [e]ffect on patients and make[s] them 
sleep better at night [sic]". The respondents commented that the finger food was ideal as "some patients are hungry at night and finger foods is there for them."

There were criticisms about some of the environmental changes. For example, some respondents reported the lavender oil diffusor was "not suitable for all" and the "smell of lavender is at times overpowering." In addition, there was criticism about the snack box where the same respondent mentioned there were "some issues with cognitive impaired diabetic p[atient]ts accessing snack box [sic]." One respondent stated they "did not notice the indoor garden" and another "did not know there was an indoor garden." A third respondent commented that the individualised rooms "were not relatable to the individual". These criticisms are useful for future planning with the ward environment.

Overall, the feedback from the staff survey was positive about the environmental changes implemented and contributed to the overarching theme of dementia-friendly.

\subsection{Observation of methodology}

On reflection of the methodology, it is important to highlight that if only quantitative data were used it would mean the essential and valuable information found in the qualitative data would be missed. The use of mixed methods research yielded a stronger result than if either quantitative or qualitative research method were used independently. This is because the qualitative data was rich, and this mitigated some of the limitations of statistically significant quantitative findings

\subsection{Summary}

The results of the quantitative and qualitative data show there is some indication of a correlation between the environmental changes implemented in Ward A of falls and aggression. However, this data is not statistically significant as the sample size is too small, and the study period is limited by the short master's research timeline. 


\section{Chapter 5: Discussion}

This evaluation aimed to gain a better understanding of the impacts on patients when environmental changes were implemented into the high visible room in Ward A. This was obtained through the collection of quantitative and qualitative data. This discussion has a similar order to the results chapter and merges the quantitative and qualitative data. The chapter begins with further interpretation of the management of data sets, followed by the effect of the environment for older adults with cognitive impairment. Then the impact of cognitive impairment for falls and aggression in HOP. The specific changes made to the environment, the staff's perspectives of these environmental changes and the use of a dementia-friendly environment for older adults' patient safety.

Study implications are then considered along with limitations, along with recommendations for future research about the environmental changes implemented for older adults with cognitive impairment. The chapter closes with a concluding statement.

\subsection{Further Interpretation}

\subsubsection{Merging of data sets}

The quantitative data collected showed the patients in the HOP service had similar profiles, which made both groups comparable. The quantitative data about HOP patients is aligned with national statistics of cognitive impairment about the ethnicity of older adults with cognitive impairment, which is outlined in 1.2.3.3. This is important when taking into consideration whether the findings will apply to other healthcare facilities around NZ.

The lower rate of falls in Ward A in terms of the data sets cannot be related to the survey results from the healthcare staffs' experiences. This is because the patients were not asked about their views of the environmental changes as this was out of scope so could not be included into this research. However, the research shows the environmental changes implemented from the Kings Fund tool sets up a provision for research in the future.

The quantitative data and qualitative data suggest that the environment influences the behaviour of older adult patients with cognitive impairment, in that it can reduce rates of falls and aggression. In their survey replies, the healthcare staff that highlighted the environmental changes created a calmer more relaxing environment which is pleasant for patients and especially crucial for patients with cognitive impairment. As one survey respondent noted "[the changes have] made the environment feel calm and non-clinical, gave alternative 
measure and methods to support patients during observation and engagement". The findings answer the research questions in a positive manner which helps support the need to rethink the environment that patients receive their care is both new, exciting, and promising for the future. This research shows how the environment can help patient care in hospital which is further supported by current quantitative and qualitative literature from around the world (Eastham \& Cox, 2017; Giovannetti et al., 2007; Waller et al., 2017; Woods, 2001).

\subsubsection{Lack of data to support aggressive behaviour}

As a clinician, I am aware that aggression is a part of the syndrome of cognitive impairment. Aggression is associated with frontotemporal dementia, greater dementia severity, cognitive impairment, and other behavioural and psychological disturbances (Brodaty \& Low, 2003; Hirono, Mega, Dinov, Mishkin, \& Cummings, 2000; Patel \& Hope, 1993). Due to the time limitation of completing a master's thesis, the quantitative data collected is underpowered due to a smaller sample size than required. In addition, it is likely that causal attribution is less evident because of the underpowered sample size. Owing to the incomplete nature of the data about aggression, the findings are inconclusive and do not form an extensive part in the discussion chapter.

\subsubsection{Effect of environment for older adults with cognitive impairment}

Older adults are encouraged and supported by the healthcare system to remain in their homes to maintain autonomy and independence. However, when older adults have cognitive impairment the environment poses a challenge in terms of creating appropriate, safe, and supportive living environments (van Hoof, Kort, van Waarde, \& Blom, 2010). This is achieved through dementia-friendly care which is important so older adults can perform optimally. Research that provides an understanding of patients' needs and experiences from the perspectives of patients with cognitive impairment is needed to inform meaningful changes in environments. The issues that patients with cognitive impairment consider as priorities should have practical implications for effective allocation of resources, thus making relevant and responsive changes. This is important as patients and their stories can be pivotal drivers for effective changes in the healthcare setting (Hawkins \& Lindsay, 2006).

The admission to hospital for older adults presents further complications when they have a cognitive impairment. Research shows that the relationships between environmental attributes and care experiences of older adult patients with cognitive impairment are complex, with both the physical and social environments having significant impacts on the care experience of the patient (Hung et al., 2017; Parke \& Chappell, 2010). In this evaluation, it 
was not possible to obtain the patients' perspectives of the environmental changes. The healthcare staff's perspectives of the environmental changes were optimistic and outlined in Figure 9. This is discussed further in 5.1.4 and particularly important as the environment can have an impact on falls and aggression for older adults with cognitive impairment.

5.1.4 The impact of cognitive impairment for falls

When older adults are admitted to hospital because of an acute health event, they are at high risk of adverse outcomes during and after hospitalisation. This includes impaired functional decline, falls, depression, admission to an aged care facility, and death (Dendukuri, McCusker, \& Belzile, 2004).

Falls can be reduced by making changes to the hospital environment which is outlined in this evaluation in the quantitative data which showed the number of falls in the high visible room in Ward A was 11 where the initiatives were implemented while the number of falls in the high visible bay in Ward B was 13 where the initiative was not implemented.

The impact of the environment on falls is further supported by research published by the government (Health Quality \& Safety Commission New Zealand, 2019). The Health Quality \& Safety Commission recognises the importance of preventing falls and reducing harm from falls and has 10 Topics of information and professional development exercises which are evidence-based. The Commission outlines how to create a safer environment for an older person in the hospital by initiatives such as clearing pathways, using lighting effectively, locking all wheels and reducing the risk of slipping (Health Quality \& Safety Commission New Zealand, 2019). Both this HOP service initiative and the initiatives by the Health Quality \& Safety Commission have the same aim to reduce falls the only difference is the process to which this occurs.

\subsubsection{Effect of environment on healthcare staff}

An unexpected finding which became evident in the qualitative data was that some staff who took the survey found the new environmental changes positive for themselves. This highlights how attention should be given to the effects of the hospital environment on the wellbeing and productivity of healthcare staff themselves. This is crucial because research has shown that levels of staff motivation and job satisfaction can have a direct impact on patient outcomes (Schmalenberg \& Kramer, 2008). The finding of a calmer working environment is further supported by other research which states healthcare staff jobs are extremely stressful and staff and addressing suboptimal working conditions may prevent 
burnout (McVicar, 2003). By strengthening the bond between the working environment and staff satisfaction to improve patient care, more attention should be given to the parts of the hospital design directly affecting healthcare staff. In particular the physical layouts and interior ambience related to communication, productivity and team work should be considered (Mroczek, Mikitarian, Vieira, \& Rotarius, 2005). This type of research has multiple implications for healthcare field and has the potential to influence how the healthcare is delivered.

5.1.6 The specific environmental changes implemented

As the evaluation was not able to ask patients about the environmental changes directly due to ethical implications, an important part of the evaluation was to ask the staff their perspectives about the environmental changes implemented into Ward A. The following paragraph explores the findings from the staff perspective with what is reported in published literature in the order it is discussed in the literature review.

The finding that the staff observed the changes had a direct impact on both patient behaviour and falls and staff perceptions indicate that increasing patients' orientation can be achieved with large face clocks. This finding confirms earlier research that clocks are may be an important way to orientate older adults with cognitive impairment (McCusker et al., 2001). Similarly the improvements in the room were considered to help patients be more independent by improving their wayfinding (Kelly, Innes, \& Dincarslan, 2011).

The staff perceptions show the calming effects of the lavender oil diffusor which is a finding that the staff alleged to have a direct impact on both patient behaviour and falls. Lavender oil administered in an aroma stream has been shown to have modest efficacy in the treatment of agitated and anxiety behaviour in patients with cognitive impairment (Holmes et al., 2002). The finding also showed that most staff, but not all liked the lavender aroma. This latter finding of staff perspectives has not been reported in earlier research.

The finding about the value of the indoor garden, while not noticed by all staff, was also important as it provided a link to the home environment. Other researchers have reported that access and exposure to the outdoors and nature is important for conservation of dignity (Schwarz \& Rodiek, 2007). Also, research conducted shows the ecosystem services delivered by indigenous biodiversity and natural ecosystems contribute in a wide variety of ways to the wellbeing of NZ and New Zealanders (Roberts et al., 2015). 
The finding that finger food was liked and made a difference adds to other research on this topic. Research shows for older adults, enjoying meals, having healthy food choices, and having a variety of menu choices were priorities (Jeong \& Seo, 2014). Thus, by considering food preferences and the health of older adults and offering a variety of options it allows them to enjoy their food and improve their satisfaction. Staff reports that some patients ate at night time indicates the importance of this as not all patients have family who can bring in treats. Pouyet et al. (2014) report that the patient's ability to choose food at their convenience is beneficial to their stay in hospital.

Allowing patients with cognitive impairment to become calm and orientated through service initiatives is important to prevent falls. This is recognised in research which shows the factors that lead to an elevated risk of falling include the presence of agitation and cognitive impairment (Kunik et al., 2010; Richardson \& Carter, 2017).

5.1.7 Dementia-friendly environment for older adults' safety

The environmental changes implemented were dementia-friendly and were chosen to improve the environment in the hope that the change would impact on patients falling or displaying aggressive behaviour. The environment in which a person with cognitive impairment resides can be a positive therapeutic intervention on its own, regardless of the type of healthcare that person receives (Day et al., 2000; Marquardt, 2011). Health professionals have recognised the importance of developing a relationship with cognitively impaired patients and taking into consideration their own resources and attitudes, so patients receive optimal care (McKenzie \& Brown, 2020). The upholding of basic human rights forms the foundation of dementia-friendly environments and is recognised in New Zealand government legislation (Health and Disability Commisioner, 1994). Dementia-friendly environments aim to preserve the dignity of people with cognitive impairment even though they have complex health needs. There is an inherent tension between ensuring a patient's safety and promoting their autonomy and quality of life. It is essential that personal dignity and patient-centred care form the basis of a dementia-friendly environment as it is shown to reduce aggression and falls for patients with cognitive impairment (Chenoweth et al., 2009; Galvin et al., 2010).

Dementia-friendly environments can also be achieved by educating staff about how to change their service arrangements to provide person-centred care. This education could be achieved through support from the Alzheimer's Foundation in NZ which supports organization's through their Dementia-friendly Recognition Programme (Alzhemiers New Zealand, 2020). 
The Dementia-friendly Recognition Programme is an accredited and recognition framework for any organisation to become dementia-friendly. It helps organisations understand about what living with dementia is like and improve services to better meet the needs of people living with the condition. To achieve a dementia-friendly environment, requires considerable support from the health organisation. Several NZ hospitals are providing the required training; examples include the Bay of Plenty DHB's Care Companion Programme workbook, the Whanganui DHB's Close Care with Dignity training programme and the Capital and Coast DHB's Care with Dignity programme. These programmes aim to promote addressing patients' individual needs in the hospital setting and providing targeted care and are also part of the Health Safety Quality \& Safety Commission's initiative Reducing Harm From Falls. Reducing falls was a national programme led by the Health Quality \& Safety Commission, working in partnership with a wide range of stakeholder organisations, from 2012-13 until 2017-18. Work began in mid-2012 to reduce harm that people can suffer if they fall and hurt themselves - especially older adults receiving care, whether in hospital, residential care, or in their own home. The effectiveness of these programmes throughout NZ is also seen in international literature which shows dementia-friendly programmes support patients and their family, so hospital environments allow the promotion of health, healing, and wellbeing. In addition, the programmes provide staff with tools to provide quality, costeffective care that can minimise avoidable adverse events for older adults (Handley, Bunn, \& Goodman, 2017; Palmer et al., 2014; Parke et al., 2017).

Another important factor for the NZ population is taking into consideration the needs of older adult Māori with cognitive impairment. Research conducted shows Māori older adults with cognitive impairment require a holistic approach which includes cultural values and understanding (Townsend, 2011). The consideration of a holistic approach encourages acceptance, affectionate care, and improve the individual's quality of life based upon their human rights (Martin, 2009; Perkins, 2006). The evaluation findings from my study provide further evidence about the impact of a change to improve the patient experience and increase patient safety. The service initiative based on the Kings Fund Healing the Environment Assessment tool is a gateway to what could potentially be a way to create a better low-cost environment for older adults with cognitive impairment in other settings.

\subsection{Implications for hospital settings}

The implications of the research are that in addition to standard medical care there is a place for low-cost interventions to minimize falls and aggressive incidents in patients with 
cognitive impairment and provide a more optimal work environment for healthcare staff that is also safer for patients. The evaluation also demonstrated the importance of a dementiafriendly environment for patients, family and staff and provided an important opportunity for nurses to discuss this type of environment.

\subsubsection{Medical model}

Since a major implication of this evaluation is the importance of expanding the understanding of patient care this will involve looking beyond the traditional medical care model (WhiteChu, Graves, Godfrey, Bonner, \& Sloane, 2009). In the past, people living with cognitive impairment have mainly been supported with a medical model of care, which does not maximise the person's wellbeing and independence (White-Chu et al., 2009). The traditional medical model focuses on efforts made to correct an underlying condition (Cowles, 2012).

Changing the physical environment provides an important complement to medical treatment, and was reported as useful for empowering patients, increasing their orientation, and helped them be calmer. Allowing patients to see the time, choose whether they wanted to eat snacks meant that patients could make some of their own decisions. Supporting patients to make their own decisions with their family/whānau empowers them and improves patient safety (Spence Laschinger, Gilbert, Smith, \& Leslie, 2010). The changes made are in line with those occurring overseas.

Overseas, models of care have moved towards a more integrated approach that includes both the health and social aspects of care (Korpela, Elfvengren, Kaarna, Tepponen, \& Tuominen, 2012; Visse, Widdershoven, \& Abma, 2012). In NZ, although we have started moving in this direction, we have a long way to go. Healthcare services need to consider the spiritual, familial, cultural, economic, social, and occupational needs as well as the health needs of the people with cognitive impairment to maximise their independence and wellbeing. Healthcare staff require additional education on how to manage patients with cognitive impairment and support patients to maximise their independence. This is discussed further in 5.1.6 about packages which have been successful in NZ.

\subsubsection{Low-cost interventions}

Another implication of the evaluation is that it was a low-cost intervention implemented to address falls and aggression in older adults with cognitive impairment. In my role as ACNM, it is critically important that I support patient safety. Also provide a cost-effective environment for staff and patients through a dementia-friendly environment. This highlights 
the importance of causal attribution as determining whether the environmental changes should be implemented into other clinical areas with older adults.

Once impact evaluation results are available, they can be combined with information on program costs to determine cost-benefit analysis and cost-effectiveness (Gertler et al., 2016). The decision to use scarce resources based on the views of those delivering services means that those who can shout loudest - or those who have the most influential contacts - may be the most successful in attracting funding for their services (Brophy et al., 2008). This is not the most rational way of spending money for the benefit of the DHB, and the decisionmaking processes are unlikely to be understandable or justifiable to people not directly involved.

This impact evaluation considered the hospital budget before the implementation of environmental changes. The availability of resources was discussed with the CNM before commencing planning for this research. The involvement and support of the CNM meant resources and time were spent on this project which would be beneficial to patients in the ward within the specified budget. This involved a rigorous and systematic evaluation being conducted form the best possible decision based on gathered evidence. The evaluation conducted was using the Kings Fund Healing the Health Environment Assessment tool. The budget for health is scarce, so resources are required to be used in a way that achieves benefits across the DHB. The cost of the products for the initial changes was approximately $\$ 400$. This funded the purchase of two large face clocks, a diffusor, lavender essential oils, indoor garden, wall stickers for individualised rooms, snacks basket and finger food. When this is compared to the high costs of older adults' injuries from falls reducing one fall would more than pay for it. The average cost to ACC from a falls claim in 2010/11 was $\$ 561$, but claims exceeded an average of $\$ 1000$ for people aged $\geq 85$ years (de Raad J.P, 2012). Falls that occur in hospital incur these costs plus often lead to increased length of stay and one extra day in hospital in the HOP service costs approximately $\$ 1000$ per patient. Multiple efforts are therefore needed to tackle falls, including implementing such low-cost measures that were evaluated in this study.

\subsubsection{Reflection post completion of the thesis}

The results of this evaluation are particularly useful as the conclusions can be applied to a broader population of interest (Gertler et al., 2016). Several changes were implemented in the 
HOP service after the collection of data for this evaluation and after permission was obtained from the CNM.

The first change in the HOP service after consultation with the CNM was the Ward B ACNM requested the same environmental changes to be implemented into Ward $\mathrm{B}$. The second change was healthcare staff in Ward A suggested the lights were too bright at night in the nurses' station for patients in the high visible room. Staff indicated the bright lights made the older adult patients with cognitive impairment more confused and wakeful at night leading to day-night reversal. As the lighting is necessary so staff can see patients in the high visible room and so nurses can complete documentation changing lighting posted an issue. The solution arranged was for a dimmer to be placed creating a lower stimulus environment.

The third change made beyond this thesis is the use of essential oils in the diffusor. A staff member mentioned they liked the diffusor however were tired of the smell of lavender. After consultation with a clinical aromatherapist, it was established that pure floral and citrus scents worked best for older adults with cognitive impairment. So, a larger variety of essential oils were obtained with positive feedback from healthcare staff and even involved other ACNMs in other wards using these essential oils in their respective wards.

These examples indicate the nursing staff recognising the widespread consensus that a hospital's physical environment can influence patient outcomes and how the environment creates a healing environment for patients.

\subsection{Limitations}

To appreciate the findings of this study, some limitations need to be considered. The first limitation was the unknown and underreporting of falls and aggressive incidents. It is a real possibility that several falls or aggressive incidents occurred for patients which were not reported by the patient because of their cognitive impairment. Staff may have also underreported incidents due to a variety of reasons including, lack of understanding of reasons for reporting the incident, perceived lack of practical usefulness, lack of time to report events due to high acuity in the ward with competing priorities, and fear of being reprimanded (Kousgaard, Joensen, \& Thorsen, 2012). The research cannot make direct links between environmental changes such as diffusor use with falls and/or aggression as the data collection period was constricted due to the masters timeframe. 
Another limitation was owing to the incomplete nature of the data about aggression, the findings are inconclusive and do not form an extensive part in the discussion chapter.

My evaluation had a lack of statistical power due to the sample size not being large enough. A discussion with the statistician revealed that the sample size would require at least 1,400 admissions per ward, which is approximately two years of data collection, to be statistically significant. This exceeds the timeframe for this evaluation research but does indicate scope for further investigation.

The study took place on only two wards within one hospital and the sample of healthcare staff was small, therefore sample size is a limitation. Therefore, caution is indicated in generalizing the results of this study to other healthcare staff in different organizational settings. However, the demographic data for the patients in the study does reflect the NZ population. The implementation of the environmental changes was based on international literature (Eastham \& Cox, 2017; Goto et al., 2017; Holmes et al., 2002; McCusker et al., 2001; Pouyet et al., 2014). The mixed-method design provided rich data. The findings of the qualitative data were illustrative of the findings of the quantitative findings in the study to which they provided more depth.

During data collection, I received interesting comments about the environmental changes from healthcare staff, patients, and their family/whanau. It would have been valuable to include this information in the study, but this was outside the boundaries of the ethics approval. The ethics committee were approached to amend the data collection option to incorporate these comments, but the amendment was rejected. This highlights the importance of well-designed research. Such as if in the original ethics application, I had highlighted the use of anecdotes from journaling and comments from patients and their family/whānau this could have been avoided.

\subsection{Recommendations}

The recommendation for the practice setting is based on the finding that the environment has an impact on rates of falls and incidents of aggression for older adults with cognitive impairment. 
Recommendations are:

- The DHB introduce the dementia-friendly initiatives implemented for this evaluation into other areas of the hospital where people with cognitive impairment are cared for.

- The local DHB should continue to work on initiatives set out by the Health Quality \& Safety Commission such as the work on the impact of the environment on falls and the 10 topics of information and professional development exercises.

- The local DHB should review the completeness of reportable event documentation for falls and aggressive behaviour. For falls this should include where the fall took place. All aggressive incidents should be reported including the location and the instigator and events preceding the event.

- The local DHB should consider doing a further evaluation to ensure the study is adequately powered.

- Further research is warranted into the development and testing as well as implementation and translation of environmental changes for older adults with cognitive impairment.

- The Local DHB should continue to implement environmental changes and include an evaluation as part of the implementation. The changes that should be extended are large face clocks, lavender oil diffusor, and finger food.

\subsection{Conclusion}

This evaluation demonstrated how a dementia-friendly environment can improve patient safety within a hospital setting. It showed a small reduction in falls, however this reduction was not statistically significant. Aggressive behaviour by patients with cognitive impairment was poorly reported by staff so the evaluation could not analyze this outcome. Staff working with patients with cognitive impairment indicated in their completed survey that the environmental changes had a positive impact on patients. This supports the findings in the current literature, that the environment has a significant influence on cognitive function. Making an effort to improve the environment as was done in this research demonstrates a commitment to making life easier for patients and healthcare staff who work with patients with cognitive impairment.

Future research should be directed to a longitudinal study allowing for the collection of larger sample size to show any real change in the number of falls and/or aggression. As aggressive behaviour is linked to cognitive impairment and falls, research needs to focus on how to 
optimize dementia-friendly environments and how this is paired to develop services for older adults in the future. 


\section{References}

Abdelhamid, A., Bunn, D., Copley, M., Cowap, V., Dickinson, A., Gray, L., . . Hooper, L. (2016). Effectiveness of interventions to directly support food and drink intake in people with dementia: systematic review and meta-analysis. BioMed Central Geriatrics, 16(26), 26-26. doi:10.1186/s12877-016-0196-3

Alzhemier's New Zealand. (2017). Dementia economic impact report. Wellington: Deloitte Retrieved from http://natlibprimo.hosted.exlibrisgroup.com/NLNZ:NLNZ:NLNZ_ALMA21287314720002836

Alzhemiers New Zealand. (2017). Dementia economic impact report 2016. Retrieved from https://www.alzheimers.org.nz/getmedia/79f7fd09-93fe-43b0-a837771027bb23c0/Economic-Impacts-of-Dementia-2017.pdf/

Alzhemiers New Zealand. (2020). Dementia Friendly Recognition Programme, . Retrieved from https://www.alzheimers.org.nz/get-involved/a-dementia-friendly-nz/dementiafriendly-recognition-programme

Analytics \& Reporting, A. (2018). Dataset for publication - "Falls", . Retrieved from New Zealand: https://catalogue.data.govt.nz/dataset/fall-data/resource/c66f2bd6-acf5-4fec94e5-de1a9c40f8d6

Aragon, T. J. (2020). Epitools: Epidemiology Tools. R package version 0.5-10.1. Retrieved from https://CRAN.R-project.org/package=epitools

Ayton, D., O' Brien, P., Treml, J., Soh, S. E., Morello, R., \& Barker, A. (2017). Nurses' perceptions of preventing falls for patients with dementia in the acute hospital setting. Australasian Journal on Ageing, 36(4), E70-E72. doi:10.1111/ajag.12474

Bamberger, M. (2012). Introduction to mixed methods in impact evaluation. Impact Evaluation Notes, 3(3), 1-38.

Barrat, J., \& Gatt, J. (2001). Using finger foods to promote independence well-being and good nutrition in people with dementia. Psychology Special Interest Group for the Elderly Newsletter, 77, 26-30.

Berelson, B. (1952). Content analysis in communication research: Free Press.

Boswell, J. D., Ramsey, A. J., Smith, A. M., \& Wagers, A. B. (2001). The cost-effectiveness of a patient-sitter program in an acute care hospital: A test of the impact of sitters on the incidence of falls and patient satisfaction. Quality Management in Health Care, 10(1), 10-16. doi:10.1097/00019514-200110010-00003

Boyd, H., Evans, N., \& Harris, N. (2016). A clock that does not tell the time: How the day clock meets the needs of people living with dementia Designing Around People, 137145. doi:10.1007/978-3-319-29498-8_14

Braun, V., \& Clarke, V. (2012). Thematic analysis. In H. Cooper \& et al. (Eds.), APA handbook of research methods in psychology, Vol 2: Research designs: Quantitative, qualitative, neuropsychological, and biological (pp. 57-71, Chapter x, 701 Pages). Washington: American Psychological Association.

Breining, A., Bonnet-Zamponi, D., Zerah, L., Micheneau, C., Riolacci-Dhoyen, N., ChanChee, C., . . L Leperre-Desplanques, A. (2017). Exposure to psychotropics in the French older population living with dementia: A nationwide population-based study. International Journal of Geriatric Psychiatry, 32(7), 750-760. doi:10.1002/gps.4517

Brodaty, H., \& Low, L.-F. (2003). Aggression in the elderly. Journal of Clinical Psychiatry, 64(Suppl 4), 36-43.

Brophy, S., Snooks, H., \& Griffiths, L. (2008). Small-Scale Evaluation in Health. London: SAGE Publications. 
Caffò, A. O., Hoogeveen, F., Groenendaal, M., Perilli, A. V., Picucci, L., Lancioni, G. E., \& Bosco, A. (2014). Intervention strategies for spatial orientation disorders in dementia: A selective review. Developmental Neurorehabilitation, 17(3), 200-209. doi:10.3109/17518423.2012.749951

Campbell, A., Diep, C., Reinken, J., \& McCosh, L. (1985). Factors predicting mortality in a total population sample of the elderly. Journal of Epidemiology and Community Health, 39(4), 337. doi:10.1136/jech.39.4.337

Campbell, D., \& Fiske, D. (1959). Convergent and discriminant validation by the multitraitmultimethod matrix. Psychological Bulletin, 56(2), 81-105. doi:10.1037/h0046016

Carr, F. (2013). The role of sitters in delirium: An update. Canadian Geriatrics Journal, 16(1), 22-36. doi:10.5770/cgj.16.29

CASP UK. (2018). Critical Appraisal Skills Programme. Retrieved from https://casp-uk.net/

Chaston, A., \& Kingstone, A. (2004). Time estimation: The effect of cortically mediated attention. Brain and Cognition, 55(2), 286-289. doi:10.1016/j.bandc.2004.02.013

Chenoweth, L., King, M. T., Jeon, Y.-H., Brodaty, H., Stein-Parbury, J., Norman, R., . . . Luscombe, G. (2009). Caring for Aged Dementia Care Resident Study (CADRES) of person-centred care, dementia-care mapping, and usual care in dementia: a clusterrandomised trial. The Lancet Neurology, 8(4), 317-325. doi:10.1016/S14744422(09)70045-6

Chodosh, J., Seeman, T. E., Keeler, E., Sewall, A., Hirsch, S. H., Guralnik, J. M., \& Reuben, D. B. (2004). Cognitive decline in high-functioning older persons is associated with an increased risk of hospitalization. Journal of the American Geriatrics Society, 52(9), 1456-1462. doi:10.1111/j.1532-5415.2004.52407.x

Clarke, G. M., Conti, S., Wolters, A. T., \& Steventon, A. (2019). Evaluating the impact of healthcare interventions using routine data. $b m j, 365,12239$.

Coelho, S., Guerreiro, M., Chester, C., Silva, D., Maroco, J., Coelho, M., . . de Mendonça, A. (2016). Time perception in mild cognitive impairment: interval length and subjective passage of time. Journal of the International Neuropsychological Society, 22(7), 755-764. doi:10.1017/S1355617716000606

Cowles, L. A. (2012). Social work in the health field: A care perspective: Routledge.

Creswell, J. W. (2011). Designing and conducting mixed methods research (2nd ed.). Los Angeles: SAGE Publications.

Creswell, J. W. (2018a). Designing and conducting mixed methods research (3rd ed.). Thousand Oaks, California: SAGE.

Creswell, J. W. (2018b). Research design : qualitative, quantitative, and mixed methods approaches (5th ed.). Thousand Oaks, California: SAGE Publications, Inc.

Day, K., Carreon, D., \& Stump, C. (2000). The therapeutic design of environments for people with dementia: A review of the empirical research. The Gerontologist, 40(4), 397416. doi:10.1093/geront/40.4.397

de Raad J.P. (2012). Towards a value proposition: Scoping the cost of falls. Wellington New Zealand Institute of Economic Research.

Dendukuri, N., McCusker, J., \& Belzile, E. (2004). The identification of seniors at risk screening tool: Further evidence of concurrent and predictive validity. Journal of the American Geriatrics Society, 52(2), 290-296. doi:10.1111/j.1532-5415.2004.52073.x.

Detweiler, M. B., Sharma, T., Detweiler, J. G., Murphy, P. F., Lane, S., Carman, J., . . Kim, K. Y. (2012). What is the evidence to support the use of therapeutic gardens for the elderly? Psychiatry investigation, 9(2), 100-110. doi:10.4306/pi.2012.9.2.100

Dewing, J. (2013). Special observation and older persons with dementia/delirium: A disappointing literature review. International Journal of Older People Nursing, 8(1), 19-28. doi:10.1111/j.1748-3743.2011.00304.x 
Donelli, D., Antonelli, M., Bellinazzi, C., Gensini, G. F., \& Firenzuoli, F. (2019). Effects of lavender on anxiety: A systematic review and meta-analysis. Phytomedicine, 153099. doi:10.1016/j.phymed.2019.153099

Downe-Wamboldt, B. (1992). Content analysis: method, applications, and issues. Health care for women international, 13(3), 313-321. doi:10.1080/07399339209516006.

Eastham, A. J., \& Cox, D. (2017). Dementia-friendly wards. International Journal of Health Governance, 22(1), 25-36. doi:10.1108/IJHG-05-2016-0027

Edvardsson, D., \& Nay, R. (2009). Acute care and older people: Challenges and ways forward. Australian Journal of Advanced Nursing, 27(2), 63-69.

Feil, M., \& Wallace, S. (2014). The use of patient sitters to reduce falls: Best practices. Pennsylvania Patient Safety Advisor, 11(1), 8-14.

Fißler, M., \& Quante, A. (2014). A case series on the use of lavendula oil capsules in patients suffering from major depressive disorder and symptoms of psychomotor agitation, insomnia and anxiety. Complementary Therapies in Medicine, 22(1), 63-69. doi:10.1016/j.ctim.2013.11.008

Fusch, P., Fusch, G., \& Ness, L. (2018). Denzin's paradign shift: Revisiting triangulation in qualitative research. Journal of Social Change, 10(1), 19-32. doi:10.5590/JOSC.2018.10.1.02

Gagné, A.-J., Voyer, P., Boucher, V., Nadeau, A., Carmichael, P.-H., Pelletier, M., . . . Émond, M. (2018). Performance of the French version of the 4AT for screening the elderly for delirium in the emergency department. Canadian Journal of Emergency Medicine, 1. doi:10.1017/cem.2018.367

Galvin, J. E., Kuntemeier, B., Al-Hammadi, N., Germino, J., Murphy-White, M., \& McGillick, J. (2010). "Dementia- Friendly Hospitals: Care Not Crisis" An Educational Program Designed To Improve The Care Of The Hospitalized Patient With Dementia. Alzheimer disease and associated disorders, 24(4), 372. doi:10.1097/WAD.0b013e3181e9f829

Geda, Y. (2012). Mild cognitive impairment in older adults. Current Psychiatry Reports, 14(4), 320-327. doi:10.1007/s11920-012-0291-x

Gertler, P. J., Martinez, S., Premand, P., Rawlings, L. B., \& Vermeersch, C. M. J. (2016). Impact Evaluation in Practice (2 ed.): The World Bank.

Giovannetti, T., Bettcher, B. M., Libon, D. J., Brennan, L., Sestito, N., \& Kessler, R. K. (2007). Environmental adaptations improve everyday action performance in Alzheimer's disease: Empirical support from performance-based assessment. Neuropsychology, 21(4), 448-457. doi:10.1037/0894-4105.21.4.448

Goto, S., Gianfagia, T. J., Munafo, J. P., Fujii, E., Shen, X., Sun, M., . . Herrup, K. (2017). The power of traditional design techniques: The effects of viewing a Japanese garden on individuals with cognitive impairment. Health Environments Research \& Design Journal, 10, 74-86. doi:10.1177/1937586716680064

Handley, M., Bunn, F., \& Goodman, C. (2017). Dementia-friendly interventions to improve the care of people living with dementia admitted to hospitals: A realist review. British Medical Journal, 7(7). doi:10.1136/bmjopen-2016-015257

Hanna, A., Efrat, S., Hagar, B., \& Anna, Z. (2015). From research to reality: Minimizing the effects of hospitalization on older adults. Rambam Maimonides Medical Journal, 6(2), e0017. doi:10.5041/RMMJ.10201

Harding, A. D. (2010). Observation assistants: sitter effectiveness and industry measures. Nursing Economics, 28(5), 330.

Harvey, L., Mitchell, R., Brodaty, H., Draper, B., \& Close, J. (2016). The influence of dementia on injury-related hospitalisations and outcomes in older adults. Injury, 47(1), 226-234. doi:10.1016/j.injury.2015.09.021 
Hawkins, J., \& Lindsay, E. (2006). We listen but do we hear? The importance of patient stories. British journal of community nursing, 11(Sup4), S6-S14. doi:10.12968/bjen.2006.11.Sup4.21767

Health and Disability Commisioner. (1994). Health and Disability Commissioner Act. New Zealand Retrieved from http://www.legislation.govt.nz/act/public/1994/0088/latest/DLM333584.html

Health and Safety in Employment Act. (96). (1992). Retrieved from http://legislation.govt.nz/act/public/1992/0096/latest/DLM278829.html

Health Quality \& Safety Commission New Zealand. (2019). Interventions for reducing falls and harm from falls in older people with cogntive impairment. . Wellington Health Quality \& Safety Commission New Zealand,

Hettinga, M., De Boer, J., Goldberg, E., \& Moelaert, F. (2009). Navigation for people with mild dementia. Paper presented at the MIE.

Hirono, N., Mega, M. S., Dinov, I. D., Mishkin, F., \& Cummings, J. L. (2000). Left frontotemporal hypoperfusion is associated with aggression in patients with dementia. Archives of neurology, 57(6), 861-866. doi:10.1001/archneur.57.6.861

Holmes, C., Hopkins, V., Hensford, C., Maclaughlin, V., Wilkinson, D., \& Rosenvinge, H. (2002). Lavender oil as a treatment for agitated behaviour in severe dementia: a placebo controlled study. International Journal of Geriatric Psychiatry, 17(4), 305308. doi:10.1002/gps.593

Hritcu, L., Cioanca, O., \& Hancianu, M. (2012). Effects of lavender oil inhalation on improving scopolamine-induced spatial memory impairment in laboratory rats. Phytomedicine, 19(6), 529-534. doi:10.1016/j.phymed.2012.02.002

Hung, L., Phinney, A., Chaudhury, H., Rodney, P., Tabamo, J., \& Bohl, D. (2017). "Little things matter!" Exploring the perspectives of patients with dementia about the hospital environment. International Journal of Older People Nursing, 12(3), e12153. doi:10.1111/opn.12153

Iwamoto, Y., \& Hoshiyama, M. (2012). Time orientation during the day in the elderly with dementia. Physical \& Occupational Therapy in Geriatrics, 30(3), 202-213. doi:10.3109/02703181.2012.713453

Jean, L. (1997). " Finger food menu" restores independence in dining. Health care food \& nutrition focus, 14(1), 4-6.

Jeong, J., \& Seo, S. (2014). Importance of satisfaction with food for older adults' quality of life. British Food Journal.

Justiniani, F. (1984). Iatrogenic disease: an overview. The Mount Sinai journal of medicine, New York, 51(2), 210-214.

Kang, H.-J., Nam, E. S., Lee, Y., \& Kim, M. (2019). How strong is the evidence for the anxiolytic efficacy of lavender?: Systematic review and meta-analysis of randomized controlled trials. Asian nursing research. doi:10.1016/j.anr.2019.11.003

Kellert, S. R. (1995). The biophilia hypothesis. Washington DC: Island Press.

Kelly, F., Innes, A., \& Dincarslan, O. (2011). Improving care home design for people with dementia. Journal of Care Services Management, 5(3), 147-155. doi:10.1179/175016811X13020827976726

Korpela, J., Elfvengren, K., Kaarna, T., Tepponen, M., \& Tuominen, M. (2012). Collaboration process for integrated social and health care strategy implementation. International Journal of Integrated Care, 12. doi:10.5334/ijic.816

Koulivand, P. H., Khaleghi Ghadiri, M., \& Gorji, A. (2013). Lavender and the nervous system. Evidence-Based Complementary and Alternative Medicine, 2013. doi:10.1155/2013/681304 
Kousgaard, M. B., Joensen, A. S., \& Thorsen, T. (2012). Reasons for not reporting patient safety incidents in general practice: A qualitative study. Scandinavian Journal of Primary Health Care, 30(4), 199-205. doi:10.3109/02813432.2012.732469

Krippendorff, K. (2018). Content analysis: An introduction to its methodology. United States of America Sage publications.

Kunik, M. E., Snow, A. L., Davila, J. A., McNeese, T., Steele, A. B., Balasubramanyam, V., . .. Walder, A. (2010). Consequences of aggressive behavior in patients with dementia. The Journal of Neuropsychiatry and Clinical Neurosciences, 22(1), 40-47. doi:10.1176/jnp.2010.22.1.40

Lang, C. E. (2014). Do sitters prevent falls? A review of the literature.(Report). Journal of Gerontological Nursing, 40(5), 24. doi:10.3928/00989134-20140313-01

Larson, E., \& von Eye, A. (2010). Beyond flow: Temporality and participation in everyday activities. American Journal of Occupational Therapy, 64(1), 152-163. doi:10.5014/ajot.64.1.152

Liu, C.-j., \& Latham, N. (2010). Adverse events reported in progressive resistance strength training trials in older adults: 2 sides of a coin. Archives of physical medicine and rehabilitation, 91(9), 1471-1473. doi:10.1016/j.apmr.2010.06.001

Markota, M., Rummans, T. A., Bostwick, J. M., \& Lapid, M. I. (2016). Benzodiazepine use in older adults: Dangers, management, and alternative therapies. Mayo Clinic Proceedings, 91(11), 1632-1639. doi:10.1016/j.mayocp.2016.07.024

Marquardt, G. (2011). Wayfinding for People with Dementia: A Review of the Role of Architectural Design. Health Environments Research \& Design Journal, 4(2), 75-90. doi: $10.1177 / 193758671100400207$

Martin, B. (2009). Together we can respond to dementia: Future directions for services. Wellington: New Zealand

Maxwell, C., Campitelli, M., Hogan, D., Diong, C., Austin, P., Amuah, J., . . Bronskill, S. (2018). Relevance of frailty to mortality associated with the use of antipsychotics among community-residing older adults with impaired cognition. Pharmacoepidemiology and Drug Safety, 27(3), 289-298. doi:10.1002/pds.4385

McCusker, J., Cole, M., Abrahamowicz, M., Han, L., Podoba, J. E., \& Ramman-Haddad, L. (2001). Environmental Risk Factors for Delirium in Hospitalized Older People. Journal of the American Geriatrics Society, 49(10), 1327-1334. doi:10.1046/j.15325415.2001.49260.x

McGilton, K., Rivera, T., \& Dawson, P. (2003). Can we help persons with dementia find their way in a new environment? Aging \& Mental Health, 7(5), 363-371. doi:10.1080/1360786031000150676

McKenzie, E., \& Brown, P. (2020). The provision of person-centred dementia care in the context of mental health co-morbidities: 'It can be upsetting and distressing and it's incredibly sad'. Australasian Journal on Ageing. doi:10.1111/ajag.12860

McVicar, A. (2003). Workplace stress in nursing: A literature review. Journal of Advanced Nursing, 44(6), 633-642. doi:10.1046/j.0309-2402.2003.02853.x

Miller, D. C., \& Salkind, N. J. (2002). Handbook of research design and social measurement. Bloomington, USA: Sage.

Ministry of Health. (2001). Reportable events Guidelines. Retrieved from Wellington: https://www.health.govt.nz/system/files/documents/publications/reportableevents.pdf

Ministry of Health. (2013). New Zealand Framework for Dementia Care. Retrieved from https://www.health.govt.nz/system/files/documents/publications/new-zealandframework-for-dementia-care-nov13.pdf 
Ministry of Health. (2020). Reducing acute readmissions to hospital. Retrieved from https://nsfl.health.govt.nz/accountability/performance-and-monitoring/data-quarterlyreports-and-reporting/reducing-acute

Morse, J. M., \& Niehaus, L. (2009). Mixed method design : principles and procedures. Walnut Creek, Calififornia: Left Coast Press.

Mroczek, J., Mikitarian, G., Vieira, E. K., \& Rotarius, T. (2005). Hospital design and staff perceptions: An exploratory analysis. The Health Care Manager Journal, 24(3), 233244. doi:10.1097/00126450-200507000-00008

O’Sullivan, D., Brady, N., Manning, E., O’Shea, E., O’Grady, S., O 'Regan, N., \& Timmons, S. (2018). Validation of the 6-Item Cognitive Impairment Test and the 4AT test for combined delirium and dementia screening in older Emergency Department attendees. Age and Ageing, 47(1), 61-68. doi:10.1093/ageing/afx149

Open Source Statistics for Public Health. (n.d.). Single person-time rate. Retrieved from https://www.openepi.com/PersonTime1/PersonTime1.htm

Palmer, J. L., Lach, H. W., McGillick, J., Murphy-White, M., Carroll, M. B., \& Armstrong, J. L. (2014). The Dementia Friendly Hospital Initiative education program for acute care nurses and staff. The Journal of Continuing Education in Nursing, 45(9), 416-424. doi:10.3928/00220124-20140825-20

Parke, B., Boltz, M., Hunter, K. F., Chambers, T., Wolf-Ostermann, K., Adi, M. N., . . Gutman, G. (2017). A scoping literature review of dementia-friendly hospital design. The Gerontologist, 57(4), e62-e74. doi:10.1093/geront/gnw128

Parke, B., \& Chappell, N. L. (2010). Transactions between older people and the hospital environment: a social ecological analysis. Journal of Aging Studies, 24(2), 115-124. doi:10.1016/j.jaging.2008.09.003

Patel, V., \& Hope, T. (1993). Aggressive behaviour in elderly people with dementia: a review. International Journal of Geriatric Psychiatry, 8(6), 457-472.

Patton, M. Q. (2019). Blue Marble Evaluation: Premises and Principles. New York: Guilford Publications.

Peek, K., Bryant, J., Carey, M., Dodd, N., Freund, M., Lawson, S., \& Meyer, C. (2018). Reducing falls among people living with dementia: A systematic review. Dementia, 1471301218803201. doi:10.1177/1471301218803201

Perkins, C. (2006). Dementia: A New Zealand Guide. Auckland, New Zealand

Pieruccini-Faria, F., Sarquis-Adamson, Y., \& Montero-Odasso, M. (2019). Mild cognitive impairment affects obstacle negotiation in older adults: Results from "Gait and Brain Study". Gerontology, 65(2), 164-173. doi:10.1159/000492931

Polit, D. F. (2008). Nursing research : Generating and assessing evidence for nursing practice (8th ed.). Philadelphia: Wolters Kluwer Health/Lippincott Williams \& Wilkins.

Pouyet, V., Giboreau, A., Benattar, L., \& Cuvelier, G. (2014). Attractiveness and consumption of finger foods in elderly Alzheimer's disease patients. Food Quality and Preference, 34, 62-69. doi:10.1016/j.foodqual.2013.12.011

Raymond, M., Warner, A., Davies, N., Nicholas, N., Manthorpe, J., \& Iliffe, S. (2014). Palliative and end of life care for people with dementia: Lessons for Clinical Commissioners. 15(4), 406-417. doi:10.1017/S146342361300039X

Reid, I. R., Joyce, P., Fraser, J., \& Crampton, P. (2014). Government funding of health research in New Zealand. The New Zealand Medical Journal., 127(1389), 25-30.

Requena-Komuro, M.-C., Marshall, C. R., Bond, R. L., Russell, L. L., Greaves, C., Moore, K. M., ... Hardy, C. J. (2020). Altered Time Awareness in Dementia. Frontiers in neurology, 11, 291. doi:10.3389/fneur.2020.00291 
Richardson, A., \& Carter, R. (2017). Falls in critical care: A local review to identify incidence and risk. Nursing in Critical Care, 22(5), 270-275. doi:10.1111/nicc.12151

Roberts, L., Brower, A. L., Kerr, G. N., Lambert, S. J., McWilliam, W. J., Moore, K., . . . Townsend, M. (2015). The nature of wellbeing: How nature's ecosystem services contribute to the wellbeing of New Zealand and New Zealanders: Department of Conservation.

Robinson, T., \& Kerse, N. (2012). Medical readmissions amongst older New Zealanders: A descriptive analysis. The New Zealand medical journal, 125(1367), 24.

Rogers, P. J. (2014). Overview: Strategies for causal attribution: UNICEF Office of Research-Innocenti.

RStudio Team. (2015). RStudio: Integrated Development for R. RStudio, Inc. Boston, MA,. Retrieved from https://www.r-project.org/

Rueda, A. D., \& Schmitter-Edgecombe, M. (2009). Time estimation abilities in mild cognitive impairment and Alzheimer's disease. Neuropsychology, 23(2), 178-188. doi: $10.1037 / \mathrm{a} 0014289$

Sakamoto, Y., Ebihara, S., Ebihara, T., Tomita, N., Toba, K., Freeman, S., . . Kohzuki, M. (2012). Fall prevention using olfactory stimulation with lavender odor in elderly nursing home residents: A randomized controlled trial. Journal of the American Geriatrics Society, 60(6), 1005-1011. doi:10.1111/j.1532-5415.2012.03977.x

Salzman, C., Jeste, D., Meyer, R. E., Cohen-Mansfield, J., Cummings, J., Grossberg, G., . . . Maslow, K. (2008). Elderly patients with dementia-related symptoms of severe agitation and aggression: Consensus statement on treatment options, clinical trials methodology, and policy. The Journal of clinical psychiatry, 69(6), 889. doi:10.4088/jcp.v69n0602

Sato, S., Kakamu, T., Hayakawa, T., Kumagai, T., Hidaka, T., Masuishi, Y., . . Fukushima, T. (2018). Predicting falls from behavioral and psychological symptoms of dementia in older people residing in facilities. Geriatrics \& Gerontology International, 18(11), 1573-1577. doi:10.1111/ggi.13528

Schmalenberg, C., \& Kramer, M. (2008). Essentials of a Productive Nurse Work Environment. Nursing Research, 57(1), 2-13. doi:10.1097/01.NNR.0000280657.04008.2a

Schwarz, B., \& Rodiek, S. (2007). Introduction: Outdoor environments for people with dementia. Journal of Housing for the Elderly, 21(1-2), 1-11. doi:10.1300/J081v21n01_01

Scialfa, C., Spadafora, P., Klein, M., Lesnik, A., Dial, L., \& Heinrich, A. (2008). Iconic sign comprehension in older adults: The role of cognitive impairment and text enhancement. Canadian Journal on Aging/La Revue canadienne du vieillissement, 27(3), 253-265. doi:10.3138/cja.27.3.253

Sejunaite, K., Lanza, C., Ganders, S., Iljaitsch, A., \& Riepe, M. (2017). Augmented reality: Sustaining autonomous way-finding in the community for older persons with cognitive impairment. The Journal of frailty \& aging, 6(4), 206-211. doi:10.14283/jfa.2017.25 PMID: 29165538

Singh, J. (2013). Critical appraisal skills programme. . Journal of Pharmacology and Pharmacotherapeutics, 4(1), 76. doi:10.4103/0976-500X.107697

Soltesz, K. S., \& Dayton, J. H. (1993). The effects of menu modification to increase dietary intakes and weights of Alzheimer's residents. Journal of the American Dietetic Association, 93(9), A104-A104. doi:10.1016/0002-8223(93)91351-P

Soto, M. E. (2012). Improving care of older adults with dementia: Description of 6299 hospitalizations over 11 years in a special acute care unit. Journal of the American Medical Directors Association, 13, 486-e481. doi:10.1016/j.jamda.2011.12.058 
Spence Laschinger, H. K., Gilbert, S., Smith, L. M., \& Leslie, K. (2010). Towards a comprehensive theory of nurse/patient empowerment: Applying Kanter's empowerment theory to patient care. Journal of nursing management, 18(1), 4-13. doi:10.1111/j.1365-2834.2009.01046.x

Spiva, L., Feiner, T., Jones, D., Hunter, D., Petefish, J., \& Vanbrackle, L. (2012). An Evaluation of a Sitter Reduction Program Intervention. Journal of Nursing Care Quality, 27(4), 341-345. doi:10.1097/NCQ.0b013e31825f4a5f

Swain, N., Gale, C., \& Greenwood, R. (2014). Patient aggression experienced by staff in a New Zealand public hospital setting. The New Zealand Medical Journal (Online), 127(1394).

Thompson, R. (2015). Transforming dementia care in acute hospitals. Nursing Standard, 30(3), 43. doi:10.7748/ns.30.3.43.e9794

Townsend, M. (2011). Māori and Dementia: Māori health professionals' perceptions of dementia, support offered and suggested improvements. University of Waikato,

Tzeng, H.-M., \& Yin, C.-Y. (2007). Using family visitors, sitters, or volunteers to prevent inpatient falls. The Journal of Nursing Administration, 37(7/8), 329-334. doi:10.1097/01.NNA.0000285116.68313.c1

Ulrich, R. S. (1984). View through a window may influence recovery from surgery. Science (New York, N.Y.), 224(4647), 420-421. doi:10.1126/science.6143402

van Hoof, J., Kort, H. S., van Waarde, H., \& Blom, M. M. (2010). Environmental interventions and the design of homes for older adults with dementia: an overview. American Journal of Alzheimer's Disease \& Other Dementias®, 25(3), 202-232. doi: $10.1177 / 1533317509358885$

Vidal, E. I. O., Villas Boas, P. J. F., Valle, A. P., Cerqueira, A. T. A. R., \& Fukushima, F. B. (2013). Delirium in older adults. British Medical Journal, 346(7904). doi:10.1136/bmj.f2031

Vigen, C. L. P., Mack, W. J., Keefe, R. S. E., Sano, M., Sultzer, D. L., Stroup, T. S., . . Schneider, L. S. (2011). Cognitive effects of atypical antipsychotic medications in patients with Alzheimer's disease: Outcomes from CATIE-AD. The American journal of psychiatry, 168(8), 831-839. doi:10.1176/appi.ajp.2011.08121844

Visse, M., Widdershoven, G. A., \& Abma, T. A. (2012). Moral learning in an integrated social and healthcare service network. Health Care Analysis, 20(3), 281-296. doi:10.1007/s10728-011-0187-7

Waller, S., Masterson, A., \& Evans, S. C. (2017). The development of environmental assessment tools to support the creation of dementia friendly care environments: Innovative practice. Dementia, 16(2), 226-232. doi:10.1177/1471301216635829

Wang, G., Albayrak, A., \& van der Cammen, T. J. (2019). A systematic review of nonpharmacological interventions for BPSD in nursing home residents with dementia: from a perspective of ergonomics. International psychogeriatrics, 31(8), 1137-1149. doi:10.1017/S1041610218001679

Watson, K., Hatcher, D., \& Good, A. (2019). A randomised controlled trial of Lavender (Lavandula Angustifolia) and Lemon Balm (Melissa Officinalis) essential oils for the treatment of agitated behaviour in older people with and without dementia.

Complementary Therapies in Medicine, 42, 366-373. doi:10.1016/j.ctim.2018.12.016

Whitaker, E., \& Atkinson, P. (2019). Reflexivity.

White-Chu, E. F., Graves, W. J., Godfrey, S. M., Bonner, A., \& Sloane, P. (2009). Beyond the medical model: The culture change revolution in long-term care. Journal of the American Medical Directors Association, 10(6), 370-378. doi:10.1016/j.jamda.2009.04.004 
White, H. (2010). A contribution to current debates in impact evaluation. Evaluation, 16(2), 153-164. doi:10.1177/1356389010361562

Woods, R. T. (2001). Discovering the person with Alzheimer's disease: Cognitive, emotional and behavioural aspects. Aging \& Mental Health, 5, 7-16. doi:10.1080/713650008

World Health Organisation. (2018). WHO Falls fact sheet fact No 344. Retrieved from http://www.who.int/mediacentre/factsheets/fs344/en/

World Health Organisation. (2020). Patient Safety. Retrieved from https://www.who.int/patientsafety/en/

Yang, Z., Abdul Rashid, N. A., Quek, Y. F., Lam, M., See, Y. M., Maniam, Y., . . Lee, J. (2018). Montreal Cognitive Assessment as a screening instrument for cognitive impairments in schizophrenia. Schizophrenia Research, 199, 58-63. doi:10.1016/j.schres.2018.03.008

Young, J., Murthy, L., Westby, M., Akunne, A., \& O'Mahony, R. (2010). Diagnosis, prevention, and management of delirium: Summary of NICE guidance. British Medical Journal, 341(7766), 247. doi:10.1136/bmj.c3704 


\section{Appendices}

Appendix A 


\title{
Is your ward dementia friendly?
}

\author{
EHE Environmental \\ Assessment Tool
}

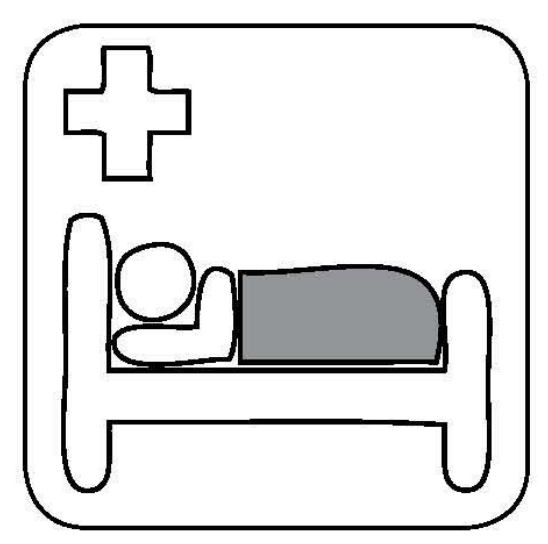




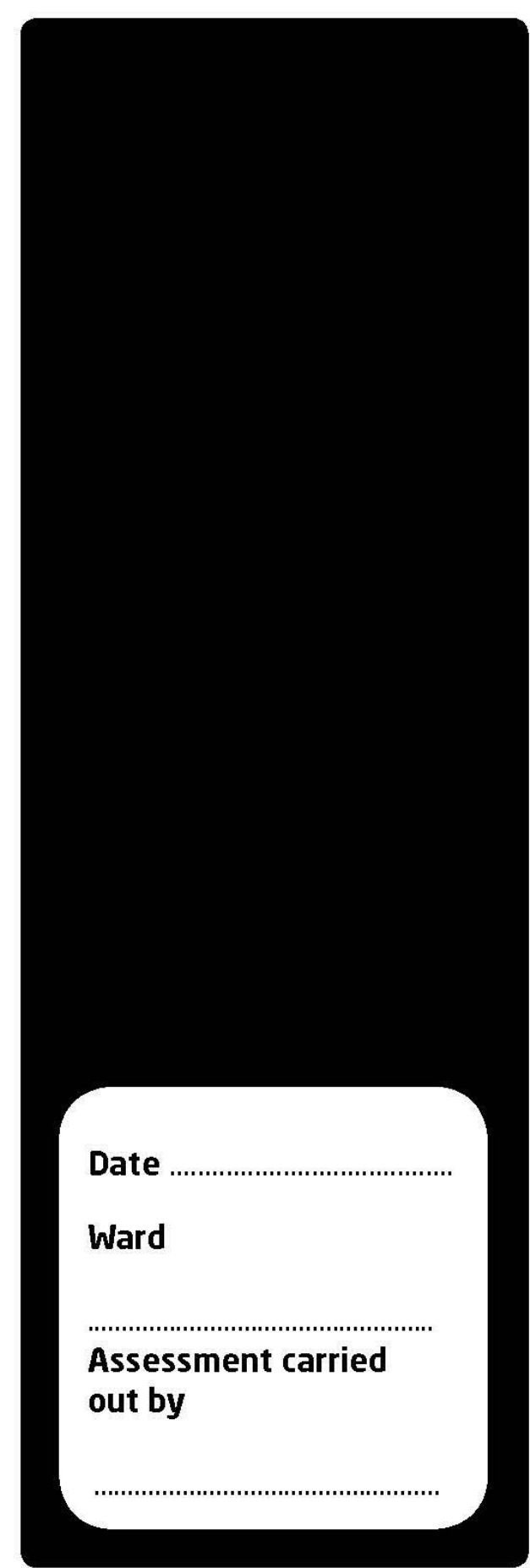

\section{The EHE assessment tools}

In order to help as many health and care organisations as possible to develop more supportive design for people with dementia, The King's Fund has developed a suite of dementia friendly assessment tools for use in care settings. Tools are available for wards; areas of hospitals where patients are ambulatory such as clinics; care homes; extra care housing and health centres.

\section{How to use the ward assessment tool}

The assessment tool can be used by a single individual but involving others who have a different perspective, for example; people with dementia or a family member; clinical, managerial or estates staff; or dementia specialists, can offer valuable opportunities for gaining different views on the care environment and how to improve it. Completing the tool together can also encourage constructive conversations about the philosophy and purpose of care.

The assessment tools contain seven sections and a set of questions to prompt discussions and should be completed in full. Walk around the area being assessed and consider each of the questions in turn. Give each question a score out of five, where five indicates that it is met completely and one indicates it is not met at all.

A summary sheet has been provided at the end of the assessment tool which should help pinpoint the areas that might be considered for initial improvement. Notes about how others have used the results, together with The Fund's overarching design principles for dementia friendly design, are reproduced at the end of the tool.

\section{How the tool was developed}

The first assessment tool for the ward environment was developed in collaboration with NHS trusts participating in The King's Fund's Enhancing the Healing Environment (EHE) programme. Since then over 70 care organisations have been involved in field testing the tools.

The tools have been informed by research evidence, best practice and over 300 survey responses from those that have used the tools in practice. Each of the sections draws on this evidence to develop a rationale for effecting change in care environments. These rationales also address the visuospatial problems often associated with dementia.

For further details go to www.kingsfund.org.uk I dementia

\section{Before using the tool}

Before carrying out the assessment please ensure that all relevant management backing has been secured to build support and commitment to the results.

It may also be useful to take photographs as these can be used to mark progress and act as a record of improvements. If photographs are taken all relevant permissions need to be obtained.

If you would like to provide any feedback on the tool or to contact us please email ehe@kingsfund.org.uk 


\section{The environment promotes meaningfu interaction between} patients, their families and staff

Rationale

Uncared for and unwelcoming spaces can cause anxiety and provoke concerns in patients and their relatives about the standards of care. The arrangement of furniture provides clues as to the purpose of the space. There should be a choice of seating, older people are Ifkely to need chairs with arms, and arranging chairs in clusters will encourage conversation.

Participation in age appropriate activities can help to relieve anxiety.

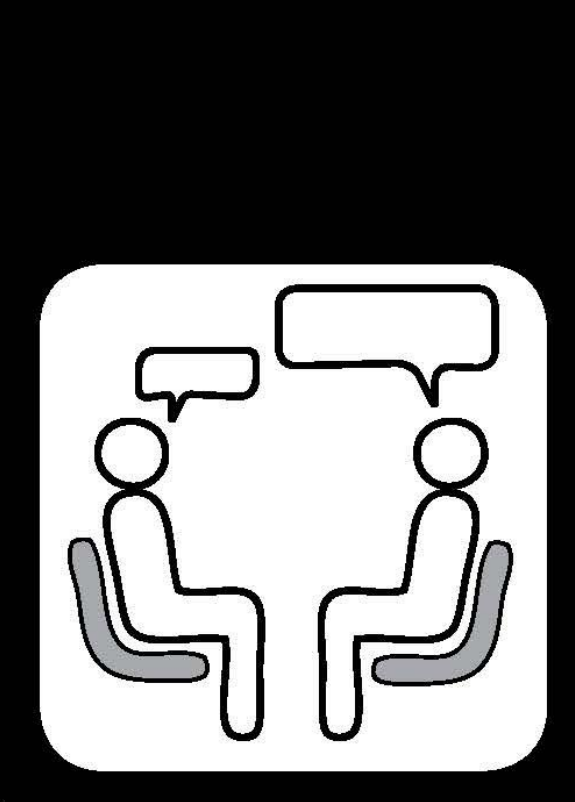

\section{Questions}

Please score each answer from 1 - 5 (1=barely met, 5 =totally met)

A Does the approach to the ward look and feel welcoming?

B Is there an obvious reception desk?

C Does the ward give a good first impression i.e. does it look clean, tidy and cared for?

D Are there obvious social areas such as day rooms?

E Is there a choice of seating provided including chairs with arms?

F Are the chairs in social areas arranged in small clusters to encourage conversation?

G Are other activities encouraged rather than just passively watching TV?

H Can staff observe and be seen in all areas of the ward?
Please give examples of good practice/ areas of concern 
The environment promotes

\section{well-being}

Rationale

Older people need higher light levels and people with dementia may interpret shadows or dark areas as holes in the floor and

try to step over them. Stripes on flooring could be confusing and disorientating. Appropriate light levels can help promote normal patterns of waking and sleeping. Personal objects are reassuring and help promote self-care. Views and access to the outside are essential for well-being.

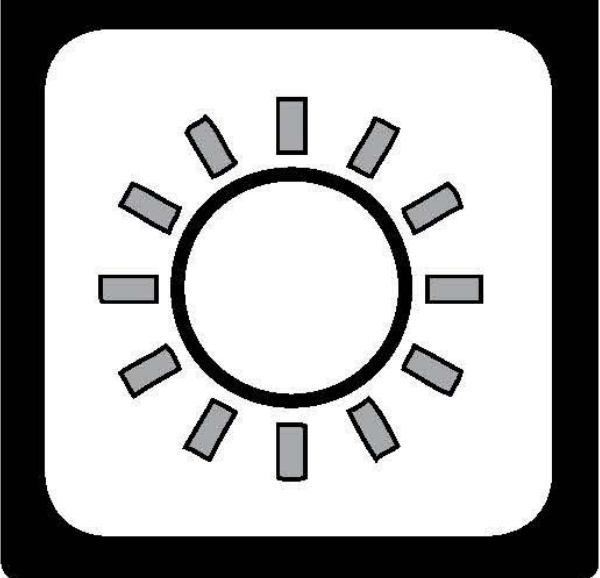

\section{Questions}

Please score each answer from 1 - 5

(1=barely met, 5 =totally met)

A Is there good natural light in bed areas and social spaces?

B Is the level of light comfortable and appropriate and can it be adjusted to suit sleep/wake patterns and care needs?

C Is the lighting and natural light from windows even e.g. without pools of light and/or dark areas, stripes or shadows?

D Are personal objects, including self-care items, situated where the patient can find them?

E Are links to and views of nature maximised e.g. by having low windows and using natural materials and colours?

F Is there independent access to a pleasant, safe outside space e.g. garden, courtyard or terrace?

G Have sheltered seating areas been provided in the outside space?

Has planting been chosen to be colourful and non-toxic?
Please give examples of good practice/ areas of concern 
Rationale

Having a choice of where to

eat, e.g. with others or by

themselves, may encourage

people to eat and drink as will

the provision of nutritious

drinks and snacks. For people

with dementia crockery, cutlery

and drinking glasses should

be chosen to look familiar

(hospital beakers and specially

shaped plates may not be

recognised). People many not be

able to distinguish white food

presented on a white plate so

crockery needs to offer a colour

contrast to food and drink.

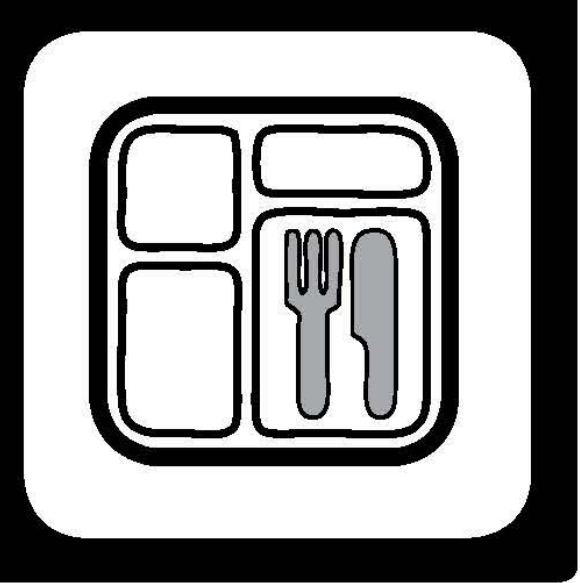

\section{Questions}

Please score each answer from 1 - 5

(1=barely met, $5=$ totally met)

A Do patients and/or their relatives have constant independent access to hot and cold drinks?

B Do patients have independent access to snacks and finger food?

C Is the crockery and glassware of familiar design and in a distinctive colour that contrasts with tables and trays?

D Is there somewhere for patients to eat other than by their beds?

E Is there a space where patients can eat together?

F Is there enough space and chairs for staff and carers to help with eating and drinking?
Please give examples of good practice/ areas of concern 
1 The environment promotes

mobility

Rationale

Being able to walk

independently is important.

Safety can be enhanced by

providing handrails and small

seating areas where people can

rest. People with dementia may

interpret shiny floors as being

wet or slippery and changes in

flooring colour as something to

step over. Speckles or pebble

effects in flooring could look

like pieces of litter. Interesting

artworks will encourage mobility

as well as helping people find

their way around.

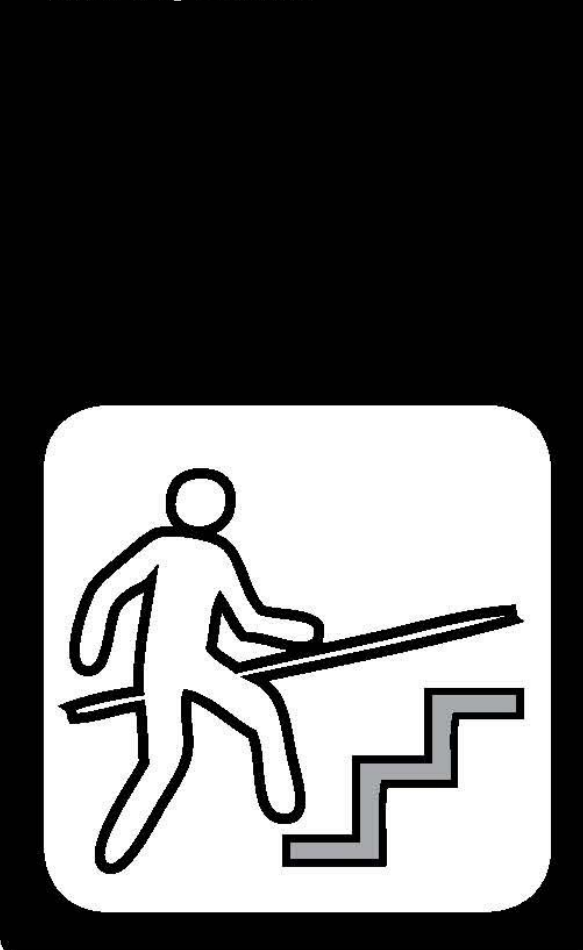

\section{Questions}

Please score each answer from 1 - 5

(1=barely met, 5 =totally met)

A Is there space for patients to walk around independently?

B Is the flooring matt rather than shiny and of a consistent colour i.e. does not have speckles, pebble effects or stripes?

C Is the flooring in a colour that contrasts with the walls and furniture?

D Are the handrails in the corridors in a colour that contrasts with the walls?

E Is it possible to grasp the handrails properly?

F Are there small seating areas for people to rest along corridors and/or by the reception desk?

G Are there points of interest e.g. photographs or tactile artworks?
Please give examples of good practice/ areas of concern 
The environment promotes

continence and personal hygiene

Rationale

Not being able to find the toilet provokes anxiety and using the

same signs and door colours

to denote all toilets will help

people find them more easily.

Ensuring good colour contrast

on sanitary fittings will make

toilets and basins easier to

see and use. Traditional and

familiar designs will help ease

anxiety and promote self-care.

Being plunged into darkness if

sensor lights go out can be very

frightening. People may not

recognise themselves in a mirror

and this can cause distress.

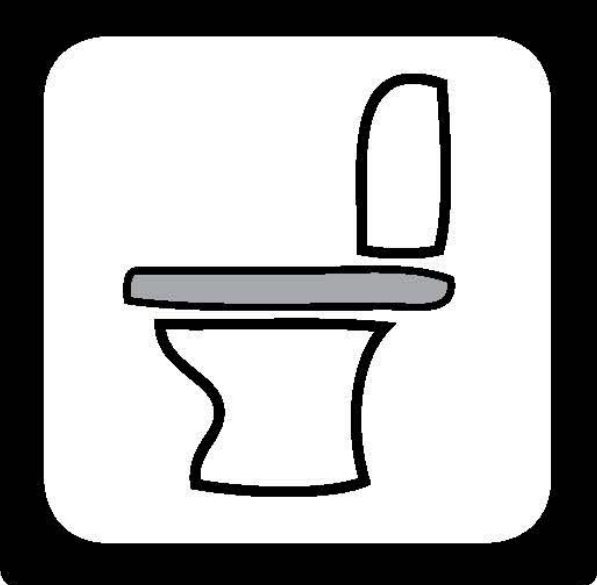

\section{Questions}

Please score each answer from 1 - 5

(1=barely met, 5 =totally met)

A Can the signs to the toilets be seen from all patient areas?

B Are all toilet doors painted in a single distinctive colour and do they have the same clear signage?

C Are the toilet seats, flush handles and rails in a colour that contrasts with the toilet/bathroom walls and floor?

D Are the taps and shower controls clearly marked as hot and cold and are they and the toilet flushes of traditional design?

E Are basins, baths and toilet roll holders of familiar design?

F Are all of the toilets and showers large enough for staff to assist patients when the door is closed?

G If sensor lights have been installed do they allow sufficient time for completion of toileting or washing?

H Is it possible to cover mirrors if required?
Please give examples of good practice/ areas of concern 
The environment promotes

\section{orientation}

Rationale

People with dementia are likely to become agitated in unfamiliar surroundings. Providing visual clues and prompts, including

accent colours and artworks, to

help them find their way around is

particularly important. Signs using

both pictures and text need to

be placed at a height where they

can easily be seen. Personalising

bed spaces and providing clocks

and calendars will help with

orientation. Strong patterns on

wall coverings or furnishings can

be misinterpreted.

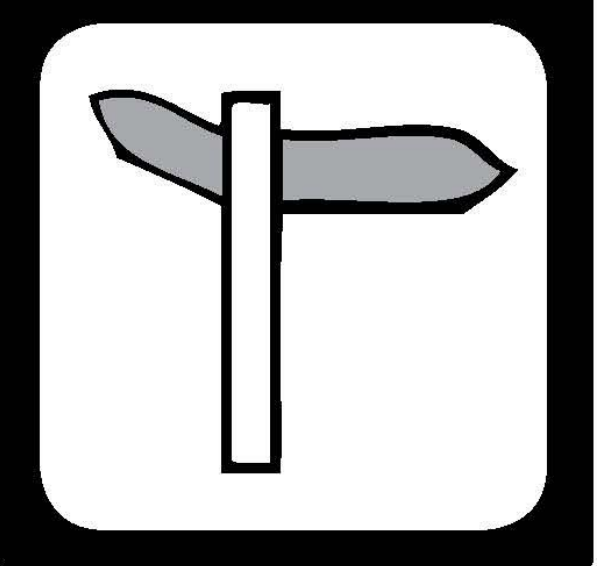

\section{Questions}

Please score each answer from 1 - 5

(1=barely met, 5 =totally met)

A Do doors have a clear or transparent vision panel to show where they lead to?

B Are signs of a good size and a contrasting colour to the door so as to be seen easily?

C Do signs on doors e.g. for toilets or day rooms use both pictures and words and are they hung at a height (approximately 4 foot/ $1.2 \mathrm{~m}$ ) that makes viewing them easy?

D. Are pictures/objects and/or colours used to help patients find their way around?

E Are bedrooms/bed spaces personalised e.g. through the use of numbers, accent colours, memory boxes, or personal photographs?

F Have strong patterns been avoided in wall coverings, curtains, furnishings and screens?

G Is there a large face clock easily visible from the bedside?

H Are patients able to see a calendar in the ward?

I Is there clear signage showing the name of the hospital and the ward?
Please give examples of good practice/ areas of concern 
Rationale

Clutter and distractions,

including notices, can cause

added confusion and should

be avoided. Noise can make

concentration difficult and can

increase anxiety. Locked doors

and window restrictors can lead

to frustration and anger when

they cannot be opened. All

staff should be familiar with

current statutory and regulatory

requirements for Deprivation of

Liberty Safeguards.

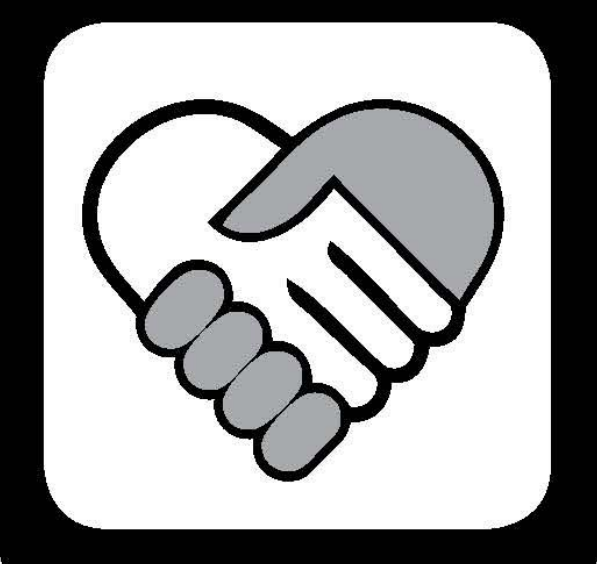

\section{Questions}

Please score each answer from 1 - 5

(1=barely met, 5 =totally met)

A Are notices kept to a minimum to avoid distraction and confusion?

B Are spaces clutter free?

C Have noise absorbent surfaces been used e.g. on floors and ceilings to aid noise reduction?

D Are the staff call system and machine/sensor alarms designed to alert staff but not to disturb patients?

E Do patients have any control over the sounds they hear e.g. can they listen to their own choice of music?

F Are doors to exits clearly marked but 'staff only' areas disguised e.g. by painting the doors and handles in the same colours as the walls/ continuing the handrail across the door?

G Are patients cared for in the least restrictive environment possible while maintaining the appropriate level of safety and security?

H Are safety and security measures e.g. baffle locks, window restrictors and alarms, as discreet as possible?

I Are all hazardous liquids and solids e.g cleaning materials, locked away?
Please give examples of good practice/ areas of concern 


\title{
Summary
}

Please add your scores for each criterion here

A B C D E $\mathrm{B}$ G $\mathrm{B}$

\begin{abstract}
1 The environment promotes meaningful
interaction between patients, their families and staff

$\square \square \square \square \square \square \square \square$
\end{abstract}

2 The environment promotes well-being $\quad \square \square \square \square \square \square \square \square$

3 The environment encourages eating

and drinking

4 The environment promotes mobility

$\square \square \square \square \square \square \square$

5 The environment promotes continence

and personal hygiene

6 The environment promotes orientation

7 The environment promotes calm, safety

and security

\section{How the results might be used}

Scores can be benchmarked against other similar areas in the organisation or more widely to look at comparisons and to

highlight particular priorities for improvement. Remember it is often the simple things that can make a big difference such as de-cluttering spaces or providing small seating areas. Similarly a local photographic competition can produce stunning artworks.

If there are low scores in a particular area, think what action can be taken immediately and what actions need to be addressed with others. If the scores are low overall this should help inform discussions on the need for environmental improvements with senior management in the organisation.

\section{How others have used their results}

Evaluations of the tools indicate that people have already used their results to:

- secure finance from their boards to improve the care environment

- influence their managers and estates colleagues to support change

- educate staff and help change attitudes

- improve signage, flooring and colour schemes as part of maintenance programmes

- redesign dining areas and change crockery. 


\section{Overarching design principles}

The design principles focus on promoting well-being and independence rather than providing detailed room by room guidance.

They have been developed as a result of the EHE programme and bring together best practice in creating more supportive care environments for people with cognitive problems and dementia. The principles are drawn from a number of sources, including research evidence and the learning gained from changes tested in a

range of care environments.

www.kingsfund.org.uk/sites/files/ kf/EHE-developing-supportivedesign-for-people-with-dementiabibliography1.pdf

Each of the five sections contains a list of design elements that are known to support, encourage and enable people with dementia in care settings. It is unlikely that all the elements can be addressed at the same time unless a new build or comprehensive refurbishment is being planned. However, many of the principles are simple, can be introduced with very little financial outlay and are known to be helpful in creating a more supportive physical environment for people with dementia and those that care for them.

\section{MEANINGFUL ACTIVITY}

Can be encouraged by providing

Books and games

Drinks and snacks

Gardens

Handrails

Interactive artworks

Memorabilia

Places to walk

Resting points

\section{FAMILIARITY}

\section{Can be enabled by}

Domestic scale seating

and dining areas

Personal and self care items

Photographs and memory boxes

Recognisable sanitary ware

Traditional crockery and cutlery

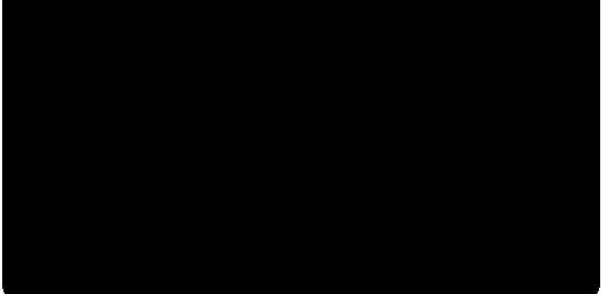

LEGIBILITY

Can be aided by ensuring

Clear sight lines

Discreet security measures

Even lighting

Matt, even coloured, flooring

Noise reduction

Uncluttered spaces 
Appendix B 


\section{Patient safety of older adults with cognitive impairment: Evaluation of an existing service improvement initiative}

\section{INFORMATION FOR PARTICIPANTS}

You are invited to take part in this research. Please read this information before deciding whether to take part. If you decide to participate, thank you. If you decide not to participate, thank you for considering this request.

\section{Who am I?}

My name is Radhika and I am a master's student in HLTH 594 at Victoria University of Wellington. This research project is work towards my thesis.

\section{What is the aim of the project?}

This project was conducted as older adult patients with cognitive impairment have increased incidents of falls and aggressive behaviour while in hospital. Efforts to prevent these incidents occurring are important because they lead to clinical and social complications and increased length of stay in hospital. A recent approach to addressing these incidents and to improve patient safety is to change aspects of the hospital environment, using The Kings Fund Enhancing the Healing Environment Assessment tool. I have completed this tool and used findings to inform environmental changes in the high visible room in ward $A$, therefore the focus of my research is to evaluate the effects of these changes.

This is an impact evaluation study. The health of the older person service consists of Wards $A$ and Ward B. The change is expected to have some impact on patient incidents such as falls and aggressive behaviour which I will monitor over the next few months.

I will be doing a retrospective study (quantitative data) of reported falls and aggressive behaviour, and a survey of health care staff about your experience of the changes in the environment (qualitative data). I will then be analysing this data and incorporating this into my thesis.

The findings from the evaluation of the impact of environmental changes that were introduced into ward A will provide the local DHB and health care staff with important evidence concerning the benefits or harm of these environmental changes.

The environmental changes made were informed by research and includes large face clocks, 
identification of bed spaces, viewing indoor gardens, lavender essential oil diffusor and snacks constantly available to patients.

This research has been approved by the Victoria University of Wellington Human Ethics Committee.

\section{How can you help?}

You have been invited to participate because you work in the health of the older person service and specifically with older adult patients. If you agree to take part, thank you for completing the survey when it is emailed out. The survey will ask you questions about your thoughts about the environmental changes in the high visible room in ward $A$. The survey will take you approximately 5 minutes to complete.

\section{What will happen to the information you give?}

This research is anonymous. This means that nobody, including myself will be aware of your identity. By answering it, you are giving consent to use your responses in this research. Your answers will remain completely anonymous and unidentifiable. Once you submit the survey, it will be impossible to retract your answer. Please do not include any personal identifiable information in your responses.

\section{What will the project produce?}

The information from my research will be used in my master's and a report produced to the local DHB.

\section{If you have any questions or problems, who can you contact?}

If you have any questions, either now or in the future, please feel free to contact me.

\section{Student:}

Name: Radhika Patel

University email address:

patelradh@myvuw.ac.nz

\section{Supervisor:}

Name: Kim van Wissen

School: Graduate School of Nursing, Midwifery and Health

Email: Kim.vanwissen@vuw.ac.nz

\section{Human Ethics Committee information}

If you have any concerns about the ethical conduct of the research, you may contact the Victoria University HEC Convenor: Dr Judith Loveridge. Email hec@vuw.ac.nz or telephone +64-4-463 6028 . 
Thanks for taking the time to complete this survey about environmental changes in ward A.

The completion of this survey will indicate consent and all answers will remain anonymous. Answer the following questions and please return to the ward administrator via email.

1. What did you like about the changes to the environment (clocks, lavender diffuser, indoor garden, individualized rooms, finger food) implemented in January 2019?

2. What did you not like about the changes to the environment (clocks, lavender diffuser, indoor garden, individualized rooms, finger food) implemented in January 2019?

3. Do you have any comments or suggestions on the environmental changes implemented in January 2019? 
4. Do you think the environmental changes implemented have affected the behaviors of older adult patients with cognitive impairment?

No $\square \quad$ Yes $\square$

If Yes, please explain how the changes have affected the behaviors of older adult patients with cognitive impairment

Thanks for your answers and time, it is greatly appreciated Radhika 